Camillo Spöri, Jason Tai Hong Kwan, Arman Bonakdarpour, David P. Wilkinson, Peter Strasser

\title{
The Stability Challenges of Oxygen Evolving Electrocatalysts: Towards a Common Fundamental Understanding and Mitigation of Catalyst Degradation
}

Journal article | Accepted manuscript (Postprint)

This version is available at https://doi.org/10.14279/depositonce-8719

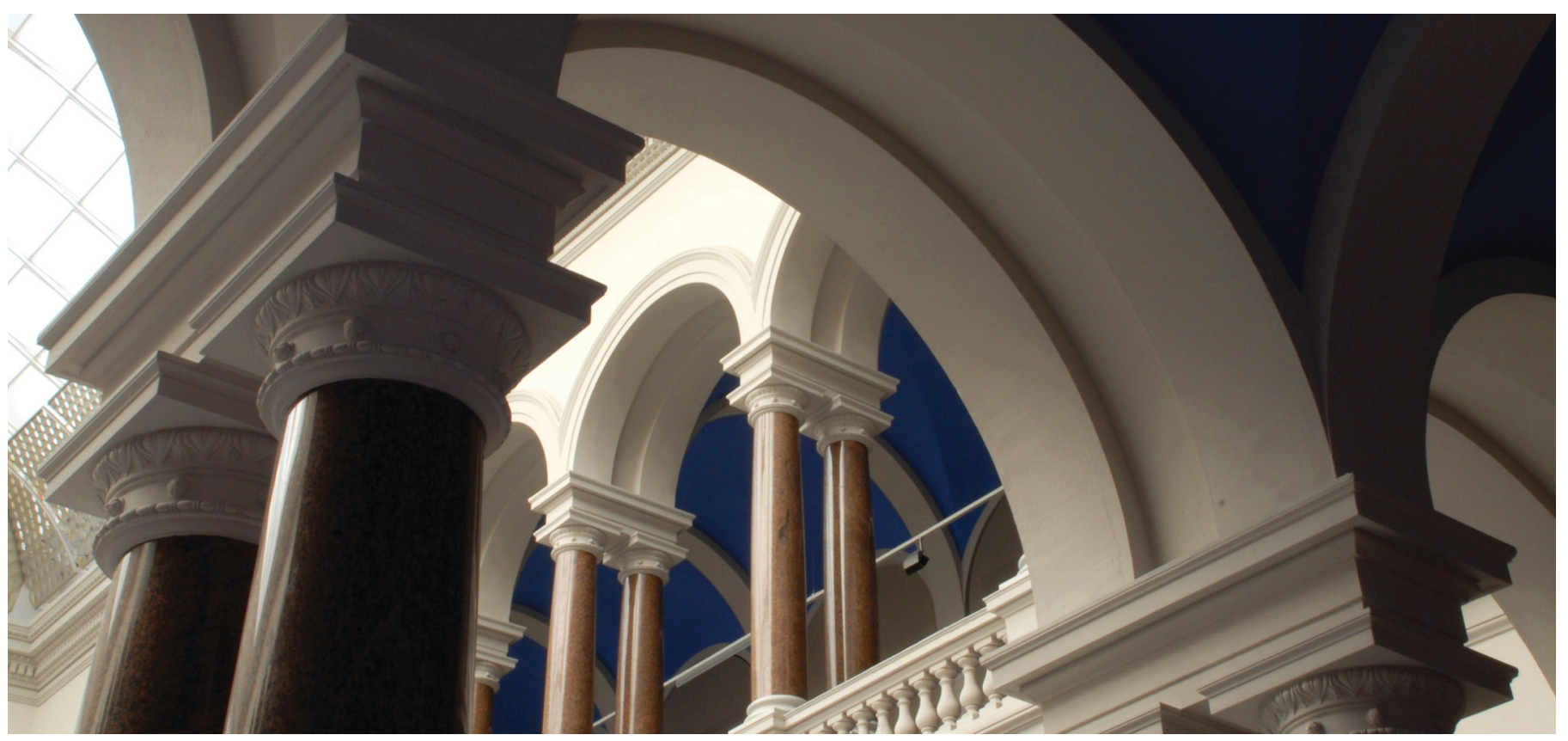

Manuscript submitted unter different title. This is the peer reviewed version of the following article:

Spöri, C., Kwan, J. T. H., Bonakdarpour, A., Wilkinson, D. P., \& Strasser, P. (2017). The Stability Challenges of Oxygen Evolving Catalysts: Towards a Common Fundamental Understanding and Mitigation of Catalyst Degradation. Angewandte Chemie International Edition, 56(22), 5994-6021.

https://doi.org/10.1002/anie.201608601

which has been published in final form at https://doi.org/10.1002/anie.201608601. This article may be used for non-commercial purposes in accordance with Wiley Terms and Conditions for Use of SelfArchived Versions. 


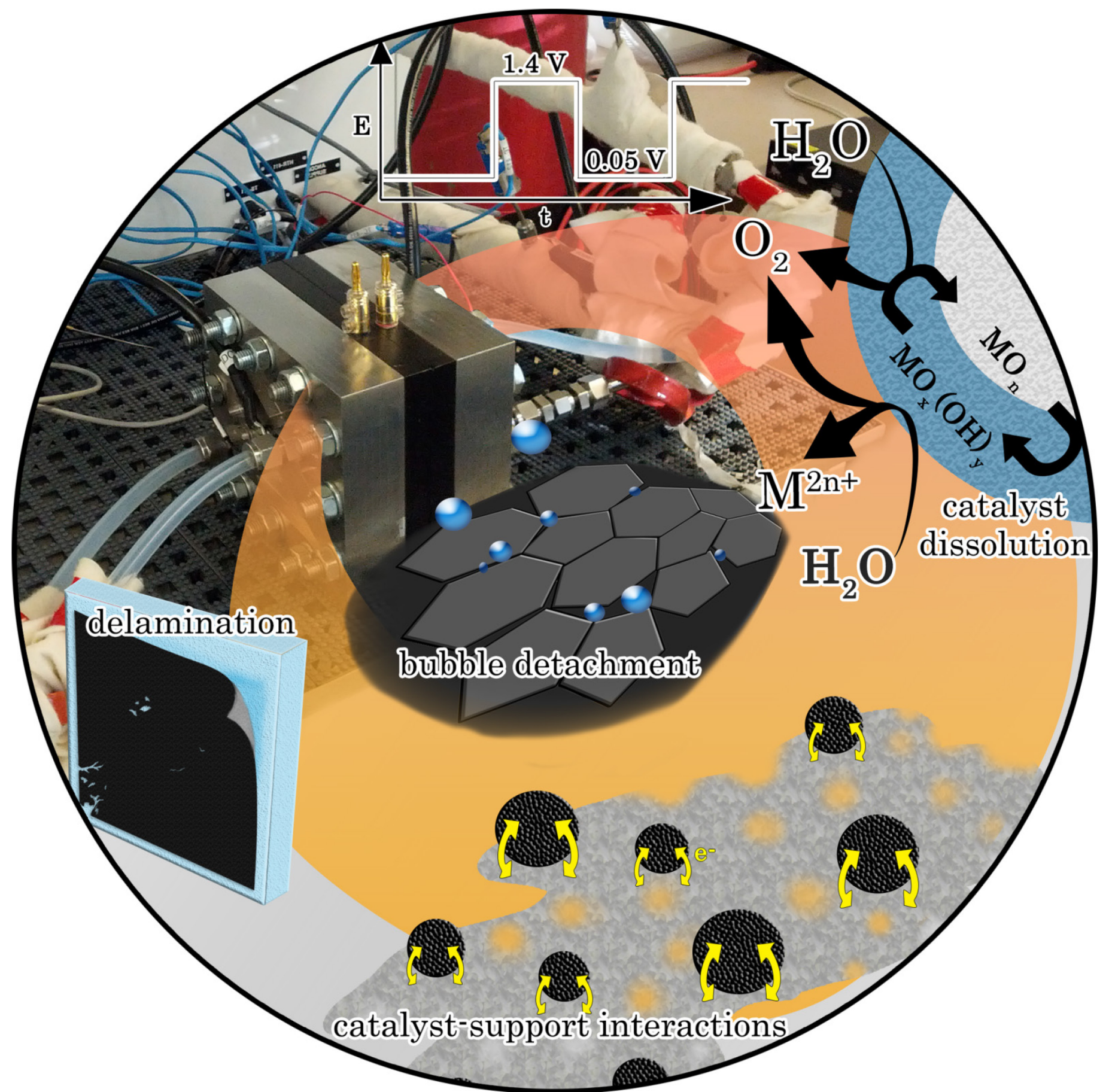

The Stability Challenges of Oxygen Evolving Electrocatalysts: Towards a Common Fundamental Understanding and Mitigation of Catalyst Degradation
Camillo Spöria, Jason Tai Hong Kwan ${ }^{\mathrm{b}}$, Arman Bonakdarpour $^{\mathrm{b}}$, David P. Wilkinson ${ }^{* b}$ and Peter Strasser ${ }^{* a, c}$ 


\section{Abstract:}

The electrochemical oxygen evolution reaction (OER) is an important half-cell reaction in the industrial production of numerous inorganic chemicals. However, over the last decade it has also received growing attention as scalable proton- and electron-providing process for use in the production of solar fuels, such as hydrogen, hydrocarbons, or alcohols carried out in water- and $\mathrm{CO}_{2}$-electrolyzers. To operate these emerging devices efficiently and economically in the future, active and stable electrocatalysts will be critical. While advances have been made in understanding and tuning OER efficiency and activity, the stability of OER catalysts and the reduction of their degradation continue to be major challenges. While most stability studies limit themselves to short-term testing in idealized three-electrode setups, a much stronger focus on advancing our understanding of degradation of OER catalysts in realistic Membrane Electrode Assemblies (MEAs), deployable in electrolyzer devices yielding industrial current densities, is critically needed.

This review addresses the technical challenges, their scientific basis, as well as recent progress and the road ahead with respect to the stability and degradation of OER catalysts operating at electrolyzer anodes in acidic environments with an emphasis on MEA based operation. First, we start clarifying the complexity associated with the term "catalyst stability", cover today's performance targets and outline major catalyst degradation mechanisms and their mitigation strategies. Then we evaluate suitable in-situ experimental methods to get insight into catalyst degradation and describe achievements in tuning OER catalyst stability. Finally, we highlight the importance of identifying universal figures of merit for stability and develop a comprehensive accelerated life test (ALT) that would yield comparable performance data across labs and catalyst types. As a whole, this review will help to disseminate and highlight the important relations between structure, composition and stability of OER catalysis under different operating conditions.
Peter Strasser is the chaired professor of "Electrochemistry and Electrocatalysis" in the Chemical Engineering Division of the Department of Chemistry at TU Berlin. He was assistant professor at the Department of Chemical and Biomolecular Engineering at the University of Houston, after he served as senior member of staff at Symyx Technologies, Inc. He earned his Ph.D. in Physical Chemistry and Electrochemistry from the Fritz-Haber-Institute of the MaxPlanck-Society in Berlin under the direction of Gerhard Ertl. He studied chemistry at Stanford University, USA, the University of Tuebingen, Germany, and the University of Pisa, Italy.

Professor David P. Wilkinson is a Canada Research Chair in the Department of Chemical and Biological Engineering at the University of British Columbia (UBC). He received his B.A.Sc. Degree in Chemical Engineering from UBC (1978) and his Ph.D. degree in Chemistry from the University of Ottawa in 1987 where his graduate work was done with Professor Brian Conway. Professor Wilkinson previously worked for over 20 years as an industrial leader in the

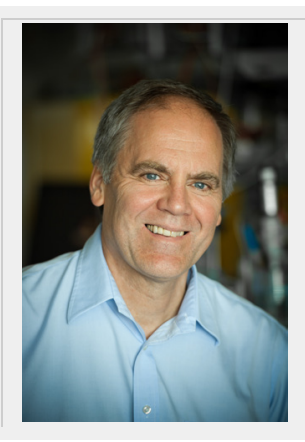
areas of fuel cells and advanced lithium batteries. His main research interests are in electrochemical and photochemical devices, and processes to create clean and sustainable energy and water. He has over 77 U.S. patents and more than 165 publications covering innovative research in these fields.

[a] C. Spöri and Prof. Dr. P. Strasser

The Electrochemical Energy, Catalysis and Materials Science

Laboratory, Department of Chemistry

Technische Universität Berlin

Straße des 17. Juni 124, 10623 Berlin, Germany

E-mail: pstrasser@tu-berlin.de

www.technischechemie.tu-berlin.de

[b] J.T.H. Kwan, Dr. A. Bonakdarpour and Prof. Dr. D.P. Wilkinson

Department of Chemical and Biological Engineering

University of British Columbia

2360 East Mall, Vancouver, B.C, Canada V6T 1 Z3

E-mail: david.wilkinson@ubc.ca

[c] Prof. Dr. P. Strasser

Ertl Center for Electrochemistry and Catalysis

Gwangju Institute of Science and Technology

Gwangju 500-712, South Korea

Supporting information for this article is given via a link at the end of the document. 


\section{Introduction}

A modified Klass model predicts fossil fuel depletion times for oil, coal and gas are about 35, 107 and 37 years, respectively from the year 2012. ${ }^{[1]}$ To reduce the fossil fuel dependency and the alarming emissions of greenhouse gases $(\mathrm{GHGs})^{[2]}$, global research on renewable energy such as solar, wind and hydro power has intensified. However, cost reduction, adequate energy storage and well-designed powergrid integration are required in order to completely replace fossil fuels. ${ }^{[3]}$ Among the potential energy storage solutions, hydrogen-based storage is emerging as a promising technology. ${ }^{[4]}$ A study conducted by the US DOE, using the GREET model, shows gaseous $\mathrm{H}_{2}$ at Standard Temperature and Pressure (STP) conditions has a lower heating value (LHV) and higher heating value (HHV) of 120.2 and $142.2 \mathrm{MJ} \mathrm{kg}^{-}$ ${ }^{1}$, respectively. ${ }^{[5]}$ This is the highest value out of all liquid and gas fuels considered in this DOE study.

The "hydrogen economy" was coined by John Bockris in a General Motors talk in 1970 and is defined as an energy-delivery system that utilizes hydrogen gas as the driving fuel. ${ }^{[6]}$ A hydrogen economy consists of: i) an energy conversion device (e.g., hydrogen fuel cell), ii) a storage system (e.g., pressurized tanks), and iii) a continuous $\mathrm{H}_{2}$ production system (e.g., water electrolyzers) at industrial scales with efficient distribution infrastructures. Electrolysis of water to hydrogen and oxygen gas requires electricity as the source of energy, cathode and anode electrodes with appropriate catalytic properties and a supporting electrolyte, which could be alkaline or acidic. Alkaline water electrolysis is a mature hydrogen producing technology with 100 MW capacity plants reported as early as 1920 , producing $\mathrm{H}_{2}$ gas for use in ammonia production and petroleum refining. ${ }^{[7]}$ Alkaline electrolyzers have proven lifetimes of up to 15 years and operate safely and reliably. ${ }^{[8]} \mathrm{A}$ typical alkaline electrolysis cell operates at a temperature of $80{ }^{\circ} \mathrm{C}$ using a 30-50 wt.- $\% \mathrm{KOH}$ electrolyte, and one of $\mathrm{Ni}, \mathrm{Co}$ or $\mathrm{Fe}$ as the anode catalyst and has maximum allowable current densities of about $0.4 \mathrm{~mA} \mathrm{~cm}^{-2} \cdot{ }^{[7,9]}$ The anodic and cathodic equations for alkaline electrolysis are shown in equation (1) and (2), respectively

$$
\begin{gathered}
2 \mathrm{OH}^{-}(\mathrm{aq}) \rightarrow \mathrm{H}_{2} \mathrm{O}+\frac{1}{2} \mathrm{O}_{2}(g)+2 e^{-}(1) \text { [anode, } \mathbf{E}_{\text {ox }}^{\circ}=0.40 \mathrm{~V} \text { vs. SHE] } \\
2 \mathrm{H}_{2} \mathrm{O}(\mathrm{l})+2 e^{-} \rightarrow \mathrm{H}_{2}(g)+2 \mathrm{OH}^{-}(a q)(2) \text { [cathode, } \mathrm{E}_{\text {red }}^{\circ}=-0.83 \mathrm{~V} \text { vs. SHE] }
\end{gathered}
$$

Fig. 1 shows an alkaline electrolyzer with the migration of hydroxide ions and release of gaseous products. ${ }^{[10]}$ Alkaline electrolysis, however, suffers from a number of significant limitations such as low maximum current densities due to large ohmic losses ${ }^{[9 a]}$ and the possibility of forming explosive gas mixtures. ${ }^{[10]}$ Ohmic losses have been partially addressed using smart design architectures such as a zerogap separator system. ${ }^{[9 b]}$ 


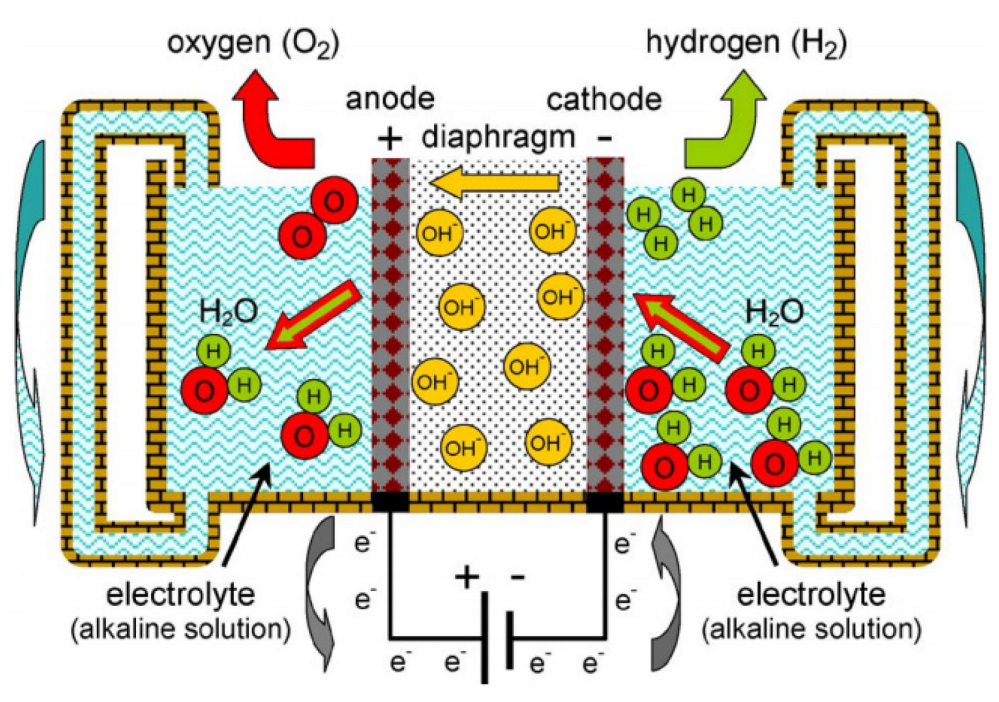

Fig. 1: Alkaline electrolyzer components and migration of chemical species within ${ }^{[10]}$; reprinted with permission from IEEE

Acidic electrolysis, using proton exchange membrane water electrolyzers (PEMWE), is a more recent technology that features a gas-tight $\left(\leq 0.2 \mathrm{~mm}\right.$ thickness) solid phase polymer membrane with $\mathrm{H}^{+}$as a charge carrier instead of $\mathrm{OH}^{-} \cdot{ }^{[10]}$ Commercial membrane electrode assemblies (MEAs) used for the PEMWE typically use noble metal catalysts with mass loadings in the order of $0.05-2 \mathrm{mg} \mathrm{cm}^{-2} \mathrm{such}$ as a Pt cathode and an Ir or $\mathrm{IrO}_{2}$-based anode. ${ }^{[11]}$ A schematic of the PEMWE is shown in Fig. 2 with the anodic and cathodic reactions shown in (3) and (4), respectively.

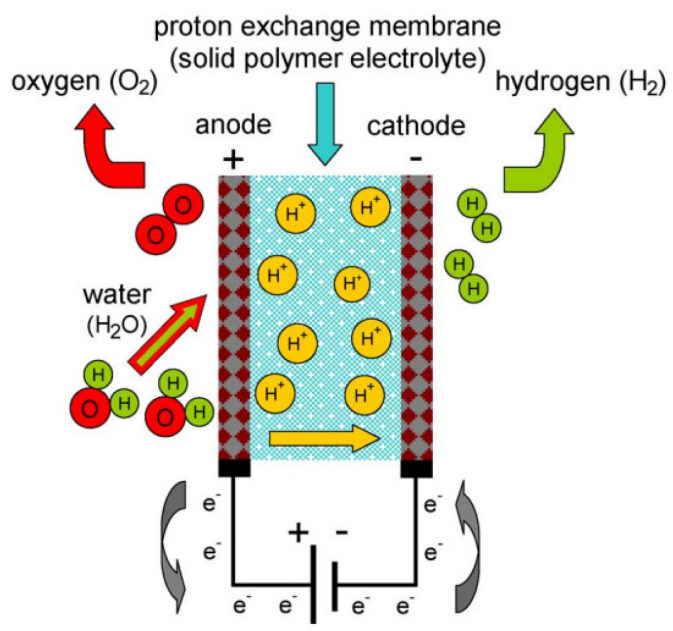

Fig. 2: PEMWE with migration of chemical species ${ }^{[10]}$; reprinted with permission from IEEE

$$
\begin{gathered}
\mathrm{H}_{2} \mathrm{O}(\mathrm{l}) \rightarrow \frac{1}{2} \mathrm{O}_{2}(\mathrm{~g})+2 \mathrm{H}^{+}(\mathrm{aq})+2 e^{-}(3) \text { [anode, } \mathrm{E}_{\mathrm{ox}}^{\circ}=1.23 \mathrm{~V} \text { vs. SHE] } \\
2 \mathrm{H}^{+}(\mathrm{aq})+2 e^{-} \rightarrow \mathrm{H}_{2}(\mathrm{~g})(4)\left[\text { cathode, } \mathrm{E}_{\text {red }}^{\circ}=0.00 \mathrm{~V}\right]
\end{gathered}
$$


Some immediate benefits of PEMWE are higher hydrogen production capacities, higher maximum allowable current densities, higher conversion, and higher gas purities as shown in Table 1. ${ }^{[12]}$

Table 1: State-of-the-art specifications for alkaline and PEM electrolyzes adapted from ${ }^{[12]}$. Reprinted with permission from Elsevier

\begin{tabular}{|c|c|c|}
\hline Specifications & Alkaline Electrolysis & PEM Electrolysis \\
\hline Cell temperature $/{ }^{\circ} \mathrm{C}$ & $60-80$ & $50-80$ \\
\hline Cell pressure / bar & $<30$ & $<\mathbf{3 0}$ \\
\hline Current Density / $\mathrm{A} \mathrm{cm}^{-2}$ & $0.2-0.4$ & $0.6-2.0$ \\
\hline Cell Voltage / V & $1.8-2.4$ & $1.8-2.2$ \\
\hline Power Density / W cm ${ }^{-2}$ & $<1$ & $<4.4$ \\
\hline Voltage efficiency HHV / \% & $62-82$ & $67-82$ \\
\hline $\begin{array}{l}\text { Specif. energy consumption: } \\
\text { Stack / } \mathrm{kW} \mathrm{h} \mathrm{Nm}{ }^{-3}\end{array}$ & $4.2-5.9$ & $4.2-5.6$ \\
\hline $\begin{array}{l}\text { Specif. energy consumption: } \\
\text { System / kW h Nm}\end{array}$ & $4.5-7.0$ & $4.5-7.5$ \\
\hline Lower partial load range / \% & $20-40$ & $0-10$ \\
\hline Cell area $/ \mathrm{m}^{2}$ & $>4$ & $<0.03$ \\
\hline $\begin{array}{l}\mathrm{H} 2 \text { production rate: } \\
\text { Stack-system } / \mathrm{Nm}^{3} \mathrm{~h}^{1}{ }^{2}\end{array}$ & $<760$ & $<10$ \\
\hline Stack lifetime / h & $<90,000$ & $<20,000$ \\
\hline System lifetime / years & $20-30$ & $10-20$ \\
\hline Degradation rate / $\mu V \mathrm{~h}^{-1}$ & $<3$ & $<14$ \\
\hline
\end{tabular}

A wider adoption of PEMWE technology requires further cost reduction, increased durability, and improved responses to fluctuating loads. ${ }^{[9 a, 13]}$ In particular, the anodic reaction, where water oxidation occurs, requires very active and stable catalysts because of the sluggish kinetics of the 4-electron OERprocess. ${ }^{[14]}$ Density Functional Theory (DFT) calculations have shown that the slow kinetics of OER can be largely attributed to the weak adsorption of $\mathrm{OOH}_{(\mathrm{ads})}$ on the surface of the catalyst. ${ }^{[14 \mathrm{~d}, 15]}$ Relatively high kinetic activities of state-of-the-art noble metal catalysts such as Ru and Ir-based catalysts are linked to a near-optimal binding energy of the $\mathrm{OOH}_{(\text {ads })}$ and the good metallic conductivity of their oxides. ${ }^{[16]}$ According to Bertuccioli et al. the anode catalyst only constitutes $6 \%$ of the overall system cost. ${ }^{[17]}$ Nonetheless, several reasons drive the reduction of noble-metal loading. Vesborg and Jaramillo report the scalability of PEM electrolysis at the TW level to be limited by the short and inelastic (coupled to Pt production) supply of Ir. $^{[18]}$ Recent numbers by Ayers et al. also state the catalyst coated membrane $(\mathrm{CCM})$ and within that the noble metal loading to become a major cost driver at MW scales and above. ${ }^{[19]}$

A common approach in OER catalyst design has been the use of mixed metal oxide catalysts (MMO), particularly the oxides of Ir-Ru. ${ }^{[20]}$ Other methods include mixed noble metal and transition metal oxides or completely noble-metal free oxides for OER. Currently, active development areas include using a corrosion resistant support material for OER catalysts in order to enhance the specific surface area and durability. ${ }^{[21]}$ 
The growing plethora of prototype catalyst materials, synthesis methods and architectures, demands a logical and rigorous set of characterization methods which will ensure meaningful and continuous improvement in this area of research. McCrory et al. have emphasized the current lack of standardized tests with respect to OER stability results. ${ }^{[22]}$ In the case of integrated photoelectrochemical cells (PECs), this was demonstrated via a stability-reactivity plot and has provided a motivation to develop a universal OER catalyst evaluation scheme. McCrory et al. plot the overpotential after $2 \mathrm{~h}$ of operation at $10 \mathrm{~mA} \mathrm{~cm}^{-}$

${ }^{2}$ vs. the initial overpotential at same current density (x-axis). A diagonal line through the origin, in such a plot, represents ideal stability corresponding to zero change in overpotential. Each catalyst point is colored according to the calculated roughness factor. This diagram allows one to easily assess a catalyst's activity and stability at a glance. The closer to the origin a catalyst appears, the more active it is, whereas the distance to the line through the origin shows stability.

In this paper, we critically review literature-reported methods of achieving and quantifying OER catalyst stability, then identify crucial parameters for the activity and stability of OER catalysts, and finally propose a standardized OER catalyst stability protocol for water electrolysis applications. It is our hope that the proposed protocol would help in bridging the current gaps that exist in the area of measuring OER catalyst stability, and provide the researchers a path to adopt and expand upon.

\section{Figures of merit / research targets}

Industrial targets, figures of merits and testing protocols for the oxygen reduction reaction (ORR) are generally quite well-established in the field of PEM fuel cells. The corresponding picture for OER catalysts in PEM electrolyzers is quite different: i) catalytic activities are reported as current densities with different normalizations (geometric, mass, specific, charge normalized etc. ${ }^{[23]}$ ) at arbitrarily defined potentials, ii) stability is measured galvano- or potentio-statically over undefined periods of time with largely differing shut-off criteria. A catalyst is deemed unstable when the potential rises above a certain level with respect to the initial potential or when a fixed voltage (e.g., $5 \mathrm{~V}$ ) is reached. This will be addressed in section 5.c. It is our opinion that defining a set of common figures of merit for both activity and stability of OER catalysts is the first critical step for advances in the area of OER research.

The general test protocol for OER and HER catalysts proposed by McCrory et al. is well thought-out. Although the protocol was reported for use in alkaline water splitting, it can be generalized to acidic electrolysis as well. ${ }^{[22]}$ The applied figures of merit are the overpotential $(\eta)$ as a measure of activity and the initial stability after $2 \mathrm{~h}$ (given as comparison of initial and final $\eta$ ), both at a geometric current density of $10 \mathrm{~mA} \mathrm{~cm}$. The authors emphasize that their protocol is specifically targeted for testing catalysts for integrated photo-electrochemical cells (PEC) under an illumination equivalent to that of 1 sun $(1.36 \mathrm{~kW}$ $\left.\mathrm{m}^{-2}\right) \cdot{ }^{[24]}$

More specifically-defined targets for the figures of merit should be developed to compare OER catalysts for different applications such as photoelectrochemistry, electrolyzer technology and metal-oxygen batteries. The activity measured at $10 \mathrm{~mA} \mathrm{~cm}^{-2}$ does not necessarily lead to predictions of the very high current densities reached in PEM electrolyzers. Since varying Tafel slopes in the high potential regions 
are often observed $\left(40-200 \mathrm{mV} \mathrm{dec}^{-1}\right)^{[14 \mathrm{~d}]}$, an extrapolation to higher current densities will not yield accurate results. Additionally, electrode distances and geometries in PEM cells are substantially different compared to an RDE setup. In the case of the better-studied ORR, Kocha et al. discuss the impacts of these two different measurement approaches for PEM fuel cell and RDE . ${ }^{[25]}$ Thus, an adequate examination for testing of OER catalysts should include testing the activity at both low and high current densities.

According to the U.S. Office of Energy Efficiency and Renewable Energy, a hydrogen cost of 2-4 $\$ \mathrm{~kg}^{-}$ ${ }^{1} \mathrm{H} 2$ and an electrolyzer stack efficiency of $77 \%$ (referenced to the lower heating value LHV) would make hydrogen competitive to fossil fuels. ${ }^{[26]}$ The lower target of $2 \$ \mathrm{~kg}^{-1} \mathrm{H} 2$ for 2017 converts to a cell performance target of $1.5 \mathrm{~V}$ at $2 \mathrm{~A} \mathrm{~cm}^{-2}$ according to Ayers et al. ${ }^{[13 \mathrm{c}]}$ The European Union funded several studies on electrolysis and among these WELTEMP and NEXPEL contained more precise targets. ${ }^{[27]}$ In WELTEMP, the minimum durability requirement was rated low $(5,000 \mathrm{~h})$ due to targeted elevated temperatures $\left(120-200{ }^{\circ} \mathrm{C}\right)$ and pressures of up to 30 bar. $^{[27 \mathrm{a}]}$ NEXPEL targets a system efficiency of 75 $\%$ (LHV) and a lifetime of 40,000 h. ${ }^{[27 \mathrm{~b}]} \mathrm{NEXPEL}$ reported that during a $500 \mathrm{~h}$ stability test at $0.5 \mathrm{~A} \mathrm{~cm}^{-}$ ${ }^{2}$, the performance losses amounted to $3 \mu \mathrm{V} \mathrm{h}^{-1}$. However, the initial activity at $1.55 \mathrm{~V}$ RHE was only 0.12 $\mathrm{A} \mathrm{cm}^{-2}$ and thus far away from the DOE target. Further research efforts are currently ongoing in the follow-up project NOVEL, which is part of the Horizon 2020 programme of the EU. ${ }^{[28]}$ Table 3 summarizes the targets of these projects as well as a number of other OER studies reported in the literature.

Table 3: Compiled figures of merit of PEM WE studies; italics: elevated temperatures above $120{ }^{\circ} \mathrm{C}$

\begin{tabular}{|c|c|c|c|c|c|}
\hline $\begin{array}{c}\text { E / V } \\
\text { vs. RHE }\end{array}$ & $\mathbf{j}$ & $\Delta \eta / m V h^{-1}$ & $\begin{array}{c}\text { PGM loading / mg } \\
\mathbf{c m}^{-2}\end{array}$ & runtime / $\mathrm{h}$ & reference \\
\hline- & $10 \mathrm{~A} \mathrm{~g}^{-1}$ & - & - & - & Fabbri $^{[13 a]}$ \\
\hline- & $10 \mathrm{~mA} \mathrm{~cm}^{-2}$ & - & - & 2 & McCrory ${ }^{[22]}$ \\
\hline 1.65 & $1.6 \mathrm{~A} \mathrm{~cm}^{-2}$ & 0.006 & - & $60-80,000$ & SA Inc. ${ }^{[29]}$ \\
\hline 1.7 & $1 \mathrm{~A} \mathrm{~cm}^{-2}$ & $<0.02$ & $<0.5$ & - & Giner ${ }^{[30]}$ \\
\hline 1.5 & $2 \mathrm{~A} \mathrm{~cm}^{-2}$ & - & 2 & 50,000 & Ayers ${ }^{[13 c]}$ \\
\hline 1.55 & $1 \mathrm{~A} \mathrm{~cm}^{-2}$ & 20 & 2 & 5,000 & WELTEMP $P^{[27 a]}$ \\
\hline- & - & 0.015 & 0.8 & 40,000 & NEXPEL ${ }^{[27 b]}$ \\
\hline - & - & $<0.015$ & 0.5 & 40,000 & NOVEL ${ }^{[28]}$ \\
\hline
\end{tabular}

\section{Quantification}

Catalytic activity can either be reported as an intrinsic value (e.g., exchange current density, jo) or as a value at fixed condition(s) (e.g., current density at a fixed potential or vice versa). ${ }^{[23 b, 31]}$ A turnover frequency (TOF), as commonly used in catalysis, is difficult to measure, since the real surface area or the 
number of catalytically active sites is usually unknown. Although the determination of the electrocatalytically active area for OER is not the focus of this paper, it is worthwhile to mention its importance and associated challenges. ${ }^{[32]}$ Normalizing the current to a geometric surface area does not consider catalyst mass loading, porosity or the number of active sites. Thus, the geometric current density does not necessarily reflect the actual performance of an electrocatalyst, hence is of limited scientific value. For engineering purposes and stack design, this normalization can reflect the maximum current that can be drawn out of a specific cell design. However, for a rigorous comparison of real catalytic activities, normalization to a more specific measure such as an active surface area is preferred. A recently proposed method by Watzele and Bandarenka (discussed in section 5.b.i) appears to be the most promising attempt at finding a generalized surface area measurement. ${ }^{[33]}$ In the absence of a uniquely defined method for active area quantification which could ideally be generalized to different types of catalysts, normalization to the mass or molar loading of active material should yield the most comparable values.

Catalyst stability can either be represented by changes in the catalyst activity or by a more direct measure of the catalyst's physiochemical properties (e.g., dissolution of the active component or agglomeration). While the decay of activity is generally correlated to the stability, it may not always reflect the actual stability of the catalyst. If, for example, the catalyst dissolution creates a rougher surface with more active sites exposed to electrolyte, a decay in activity may not be observed. Thus, the onset of stability loss could be masked in this particular case. Similarly, if initial catalyst dissolution creates a more active catalyst structure (e.g., core-shell particles from an initial dealloying process), initial compositional instability manifests itself in an activity increase. Stability itself, in turn, can therefore be strongly dependent on the time of measurement.

Although the failure criteria for an unstable catalyst is easily determined by a sharp increase in overpotential (Fig. $3^{[34]}$ ), the stability test parameters are extremely varied with little to no justification. We summarize the most frequently occurring test parameters, reported in the literature in frequency histograms for cell temperature, experiment runtime, current density, choice of galvano- or potentio-static modes (see the supporting information). 


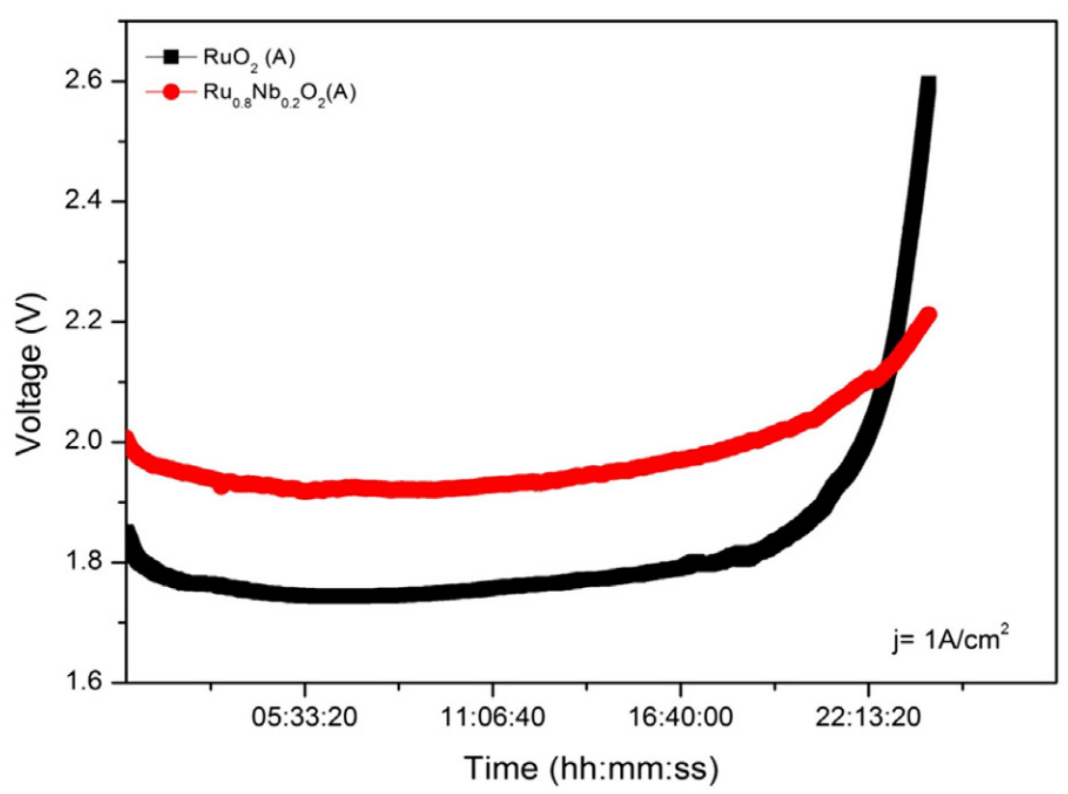

Fig. 3: MEA stability test of less stable $\mathrm{RuO}_{2}$ (black,) and more stable $\mathrm{Ru}_{0.8} \mathrm{Nb}_{0.2} \mathrm{O}_{2}$ (red) ${ }^{[34]}$; reprinted with permission from Elsevier

Even though PEM electrolysis operates in a fairly broad load range (see Table 1), the majority of published reports have focused on operation at $80^{\circ} \mathrm{C}, 1-2 \mathrm{~A} \mathrm{~cm}^{-2}$ in galvanostatic mode and duration of either 24 or $100 \mathrm{~h}^{[11,22,23 \mathrm{c}, 34-35]}$ This common combination serves as a basis for our proposed testing protocol.

Stability can be monitored by measuring the changes in the activity as measured by overpotential, for instance, over time (e.g., a maximum performance loss of $20 \mathrm{mV} \mathrm{h}^{-1}$ as targeted by WELTEMP). ${ }^{\text {[27a] }}$ Providing a current density loss (e.g., $\mathrm{mA} \mathrm{cm}^{-2} \mathrm{~h}^{-1}$ ), instead, may be suitable for integrated/portable devices which only operate in a limited range of operational voltage. Most research efforts tend to use voltage degradation (in $\mathrm{mV} \mathrm{h}^{-1}$ or $\mu \mathrm{V} \mathrm{h}^{-1}$ ) because performance loss can be reported during a period with constant flux of hydrogen production (i.e., constant current density operation). ${ }^{[27 a, 36]}$

While initial stability is usually assessed in galvanostatic mode, "quasi-stationary" scans with very low scan rates (1-6 $\left.\mathrm{mV} \mathrm{s}^{-1}\right)$ are used for initial evaluation of activity. Extensive cycling as an accelerated life test is common in ORR catalysis ( $>10,000$ cycles at high scan rates $\geq 500 \mathrm{mV} \mathrm{s}^{-1}$ ) but has not been applied to OER to the same extent. A stepped potential, duty-cycle protocol has been reported recently. ${ }^{[37]}$ Advantages of the two approaches will be discussed in the following sections.

While monitoring performance losses may be sufficient for an initial estimate for stability, it does not provide any insight into the degradation mechanisms (e.g., corrosion of the active sites). Understanding the catalyst degradation or physiochemical changes which occur during operation allows researchers to mitigate these issues and assists them with the catalyst design-by-rationale approach. These methods will be addressed in section 5 . 


\section{Degradation Mechanisms and Mitigation Strategies}

\section{a. Molecular Mechanisms of Degradation}

Defining dissolution pathways helps identifying major parameters affecting OER electrocatalyst stability. Although a limited number of studies in the literature have discussed this topic, such investigations have been published as early as $1994 .{ }^{[38]}$ Early studies differentiated between internal and external deactivation. Martelli et al. distinguish between (i) support passivation, (ii) catalyst consumption and (iii) detachment during extreme conditions such as start-up/shut-down procedures. ${ }^{[38 a]}$

\section{i. Support Passivation}

During passivation, the oxidation of an underlying metal support is considered to remove parts of the catalyst layer from the reaction regime by impeding current flow through a non/semi-conductive oxide layer. Additionally, oxidized support can grow into the catalyst and reduce the reaction rate by forming a new phase. As a result, the areas that are still in adequate contact will be subjected to a higher current if the overall current density is held constant. Higher currents result in faster support passivation, thus this self-accelerating process will eventually lead to a total deactivation of the catalyst. Two modes of support passivation are mentioned: i) the passivation layer may either grow into the support material or ii) a mixed oxide layer with the catalyst can form on top, thus reversing the direction of passive layer growth. For $\mathrm{IrO}_{2}$ supported on titanium, both modes could be observed for medium to high calcination temperatures, as reported recently by Reier et al. ${ }^{[39]}$ Martelli et al. concluded substrate passivation in dimensionally stable anodes (DSAs) for OER to be a direct function of current density. Additionally, certain impurities (e.g., fluorides) in the electrolyte or cell are reported to increase support passivation or destruction. In particular, $\mathrm{F}^{-}$is reported to dissolve Ti upon polarization even when present in ppm levels. ${ }^{[38 \mathrm{a}]}$ This leads directly to case (ii): catalyst consumption.

\section{ii. Catalyst Consumption}

Organic impurities, such as methanol or aliphatic $-\mathrm{CN}$ groups ${ }^{[38 \mathrm{a}]}$, are often good chelating or complexing agents for metal ions and thus may enhance catalyst consumption by dissolution. Organic or inorganic impurity-driven dissolution emphasizes the need for clean electrolytes and materials. Potential-driven catalyst dissolution is known for ruthenium oxide by the formation of soluble $\mathrm{RuO}_{4}$ at high potentials $(\geq$ $\left.1.4 \mathrm{VRHE}^{[40]}\right)$. A volatile $\mathrm{IrO}_{3}$ species is known, and reported to exist at a high potential value of $2.05 \mathrm{~V}_{\text {RHE }}$ (see Fig. 4). 

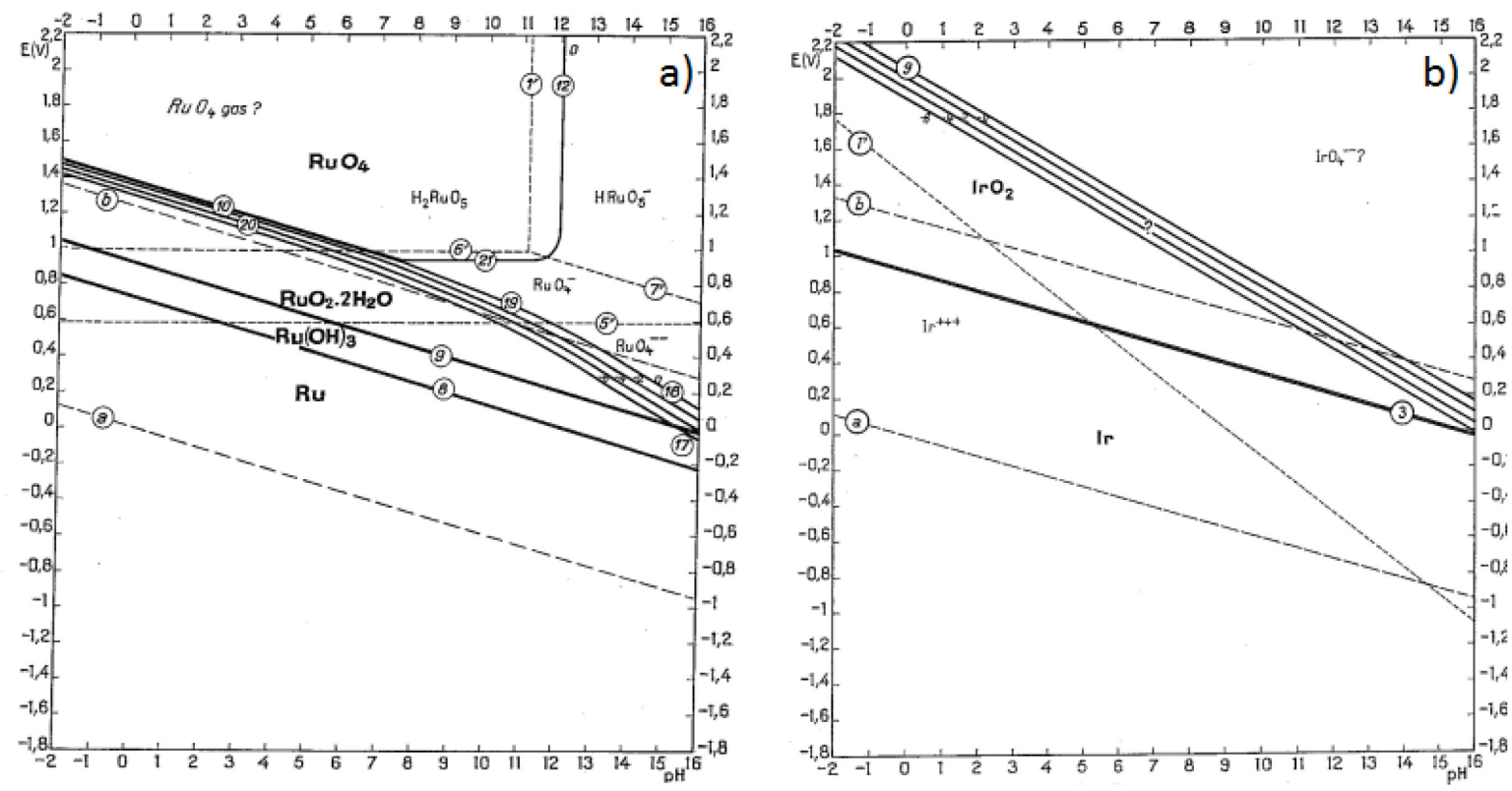

Fig. 4: Pourbaix diagram of a) ruthenium and b) iridium ${ }^{[41]}$; reprinted with permission from Pergamon Press

An important concept often discussed for catalyst dissolution mechanisms is the fact that dissolution and the OER share an intermediate species and therefore occur simultaneously.

A publication by Cherevko et al. compares Tafel slopes with the dissolution rate. ${ }^{[42]}$ An almost linear correlation is revealed in the range of $0.1-1.6 \mathrm{~mA} \mathrm{~cm}^{-2}$, which can serve as an indicator for the apparent mechanism and thus stability. This correlation also shows that activity and stability are not necessarily inversely related. If oxygen evolves through a "solution route" without the interaction of the oxide layer, the Tafel slope will be high $\left(\geq 100 \mathrm{mV} \mathrm{decade}^{-1}\right)$ but the dissolution rate will be low $\left(\leq 0.1 \mathrm{ng} \mathrm{cm}^{-2} \mathrm{~s}^{-1}\right)$, because the oxide structure is less stressed in this process. For lower Tafel slopes of $\leq 50 \mathrm{mV} \mathrm{decade}{ }^{-1}$, an "oxide route", with participation of lattice oxygen (i.e., lattice oxygen evolution reaction, LOER), exerts more stress on the oxide layer. This stress will lead to higher dissolution rates by the necessary restructuring mechanism. Both pathways have been proven to exist on different oxide surfaces by isotope labelling experiments. ${ }^{[31 \mathrm{a}, 43]}$

Thermodynamic considerations by Binninger et al. explain the stability differences between the "solution route" and "oxide route" (OER and LOER respectively). ${ }^{[38 b]}$ In contrast to the OER, the LOER is driven by the oxidation of the lattice oxygen and leaves the metal ion oxidation state unchanged. The first important conclusion, here, is that the OER and LOER possibly share a reaction intermediate, which agrees very well with observations made in dissolution experiments. ${ }^{[44]}$ In conclusion, when considering free reaction enthalpies in the proposed reaction scheme, the OER and LOER were found to be invariably related. Consequently, this leads to a fixed relation of LOER and OER to dissolution, if only thermodynamics are considered. The second finding correlates the observed bulk oxidation by the LOER to the formation of a three-dimensional hydrous surface oxide regime on the surface of many OER catalysts. And the third conclusion is that the formed metal cation in the LOER can either dissolve, by different mechanisms, or recombine with hydroxide anions to return to its initial state and close the cycle. 
A closed cycle yields a metastable state and, if the recombination is favored over the dissolution, this kinetic control, in principle, would lead to a stable OER catalyst material. Fig. 5 shows the suggested oxidation mechanism at the catalyst surface. Binninger et al. suggest inhibiting the LOER and dissolution by either reducing the oxygen anion mobility in a catalyst material or by replacing the oxygen anions with anions with a very high oxidation potential (e.g., $\mathrm{F}^{-}$).

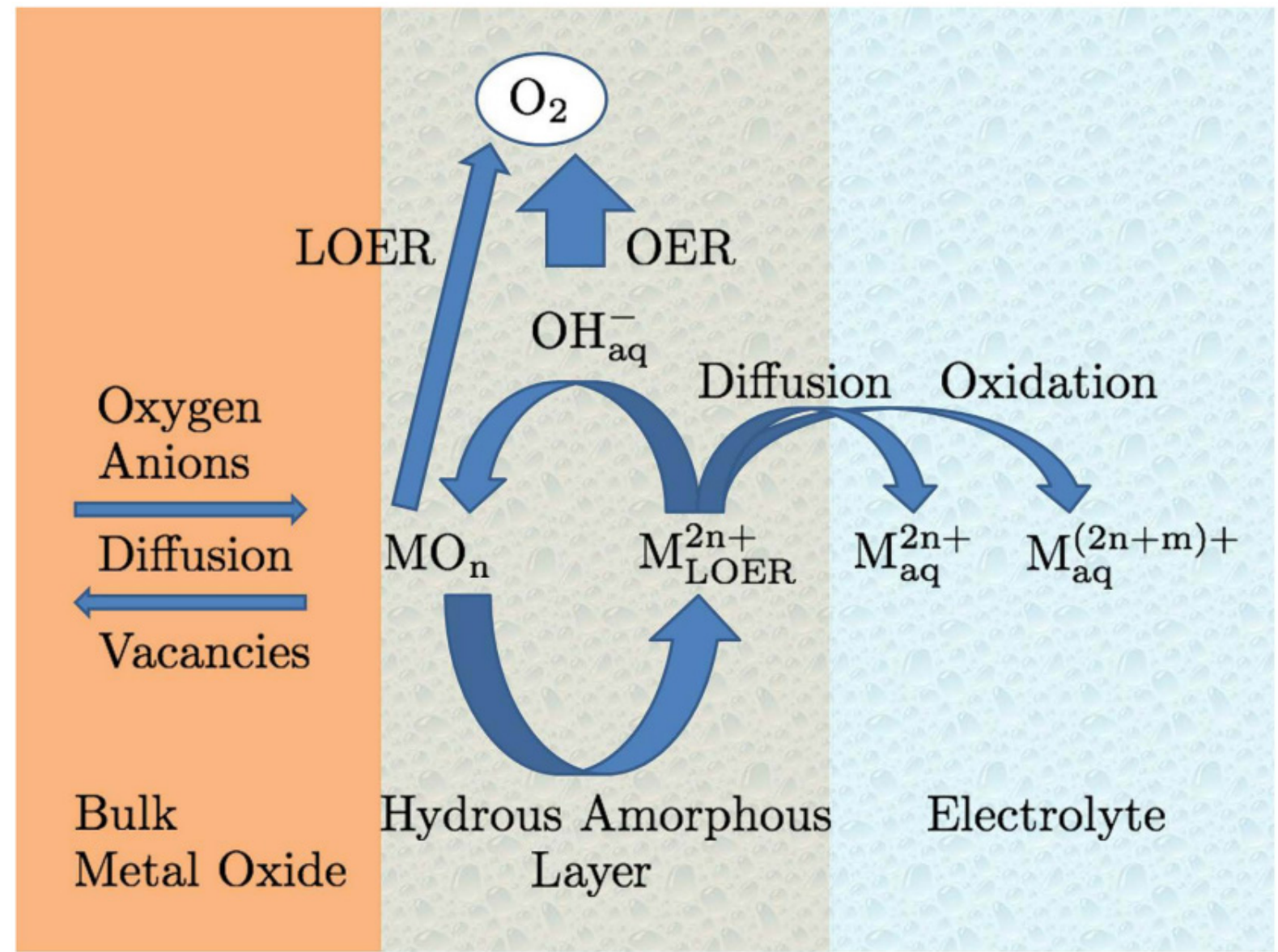

Fig. 5: Suggested schematic of oxidation mechanism at the catalyst surface by Binninger et al. ${ }^{[38 b]}$ LOER leads to the formation of a 3D-reaction regime but with proper recombination dissolution could be prevented; reprinted under CC BY 4.0 with permission from NPG

In contrast to the general reaction scheme presented in Fig. 5, Cherevko et al. suggested that the shared intermediate between the OER and dissolution to be an $\operatorname{~Ir}^{3+}$ species. ${ }^{[4]}$ In agreement with other publications, it was suggested that OER occurs by a cyclic transition between $\operatorname{Ir}(\mathrm{V}) / \mathrm{Ir}(\mathrm{III})$ states, where Ir(III) forms the common intermediate of OER and dissolution. ${ }^{[44-45]}$ For hydrous iridium oxides and their dry thermally prepared counterparts, distinctly different compounds were suggested as the critical $\operatorname{Ir}(\mathrm{III})$ species, reflecting the differences in the Tafel analysis of the solution and oxide routes (OER and LOER). In contrast to the Tafel relations, the authors did not find any correlation between exchange current density, $\mathrm{j}_{0}$, and the dissolution rate. This implies that, in principle, a catalyst system with high activity and low dissolution rate could exist. Besides the differences in their oxidation states, both theories agree on a shared intermediate and that the dissolution process is somehow related to the formation of a 3-dimensional hydrous reaction regime for the OER. The proposed reaction scheme by Cherevko et al. is 
shown in Fig. 6. The authors suggest that dissolution prior to OER is possible by formation of a metastable $\operatorname{Ir}(\mathrm{V})$ complex which can originate from single $\operatorname{Ir}(\mathrm{V})$ sites at lower potentials. Ir(III) forms only by disproportionation of a higher oxidation state iridium at higher potentials according to the authors.

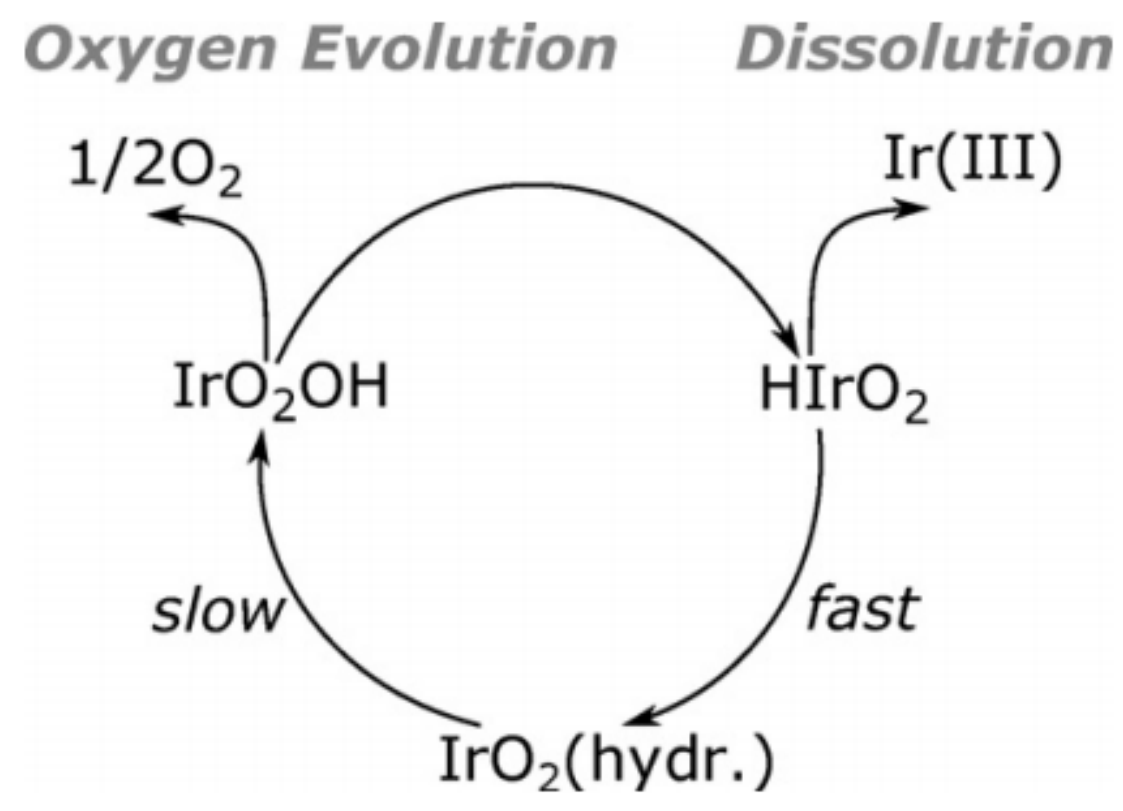

Fig. 6: Simplified Ir dissolution scheme during OER, as proposed by Cherevko et al. ${ }^{[44]}$; reprinted with permission from Elsevier

iii. Catalyst Surface Blocking, Catalyst Particle Growth and Layer Detachment

Martelli et al. have considered a possible current reversal which occurs as a result of water starvation during start-up and shut-down procedures. ${ }^{[38 \mathrm{a}]}$ This phenomenon is widely known from $\mathrm{H} 2 / \mathrm{O} 2$ fuel cell studies. In the presence of metal impurities, during current reversal mode, the anode catalyst surface can become blocked by cathodic metal deposition blocking active surface sites. A constant deposition and dissolution of electrolyte impurities and catalyst particles can initially promote catalyst porosity, hence activity, but its continuation will eventually lead to damaging the catalyst layer and catalyst detachment. In more recent investigations, it was found that reductive treatment can lead to even more severe intrinsic dissolution of the catalyst layer. ${ }^{[42]}$ This could be the dominating mechanism during start-up and shutdown procedures.

Other reasons for particle loss or layer detachment are mechanical damage by bubble formation or the induced stress by blocked active sites that cannot participate in the reaction. ${ }^{[46]}$ Chandesris et al. have investigated membrane thinning processes, by oxygen crossover, and temperature induced membrane degradation. ${ }^{[13 \mathrm{~d}]}$ The authors observed a dramatic increase in membrane thinning (50\% loss after 10,000 h), when the electrolyzer cell was operated at temperatures of $80^{\circ} \mathrm{C}$ or higher. Membrane degradation and thinning processes can reduce the catalyst layer adhesion thus inducing layer detachment. 
Nanoparticles are intrinsically unstable with respect to their nanoscale size, as particle growth invariably decreases their total interfacial energy. A reaction-specific particle growth mechanism has not been identified for water electrolysis so far. In PEM fuel cells, three major modes of particle growth exist that may be applied to electrolysis as well. ${ }^{[4]}$ These are: i) Ostwald ripening ii) reprecipitation, as well as iii) coalescence, all of which can occur simultaneously or alone. The first two mechanisms are related to catalyst dissolution described in section 4.a.ii. In Ostwald ripening, dissolved ions are redeposited on existing particles, thus increasing the average size of the particles, which is reflected in the particle size distribution (PSD). During re-precipitation or redeposition, however, particles form at other nucleation sites (e.g., defects in the support or in the ionomer). Thus, the PSD broadens indicating the variance in the sizes of formed small particles. In the latter case of redeposition in the ionomer, particles are being removed from the PSD, since usually only the catalyst layer is investigated in the TEM imaging and PSDs determination. The third case, i.e coalescence, is sintering of closely positioned particles. Here, the PSD is affected similarly to Ostwald ripening (i.e., average particle size increases), but since only particles in the vicinity of each other are growing, a bimodal PSD can be expected. Fig. 7 presents a schematic of the three modes discussed here.

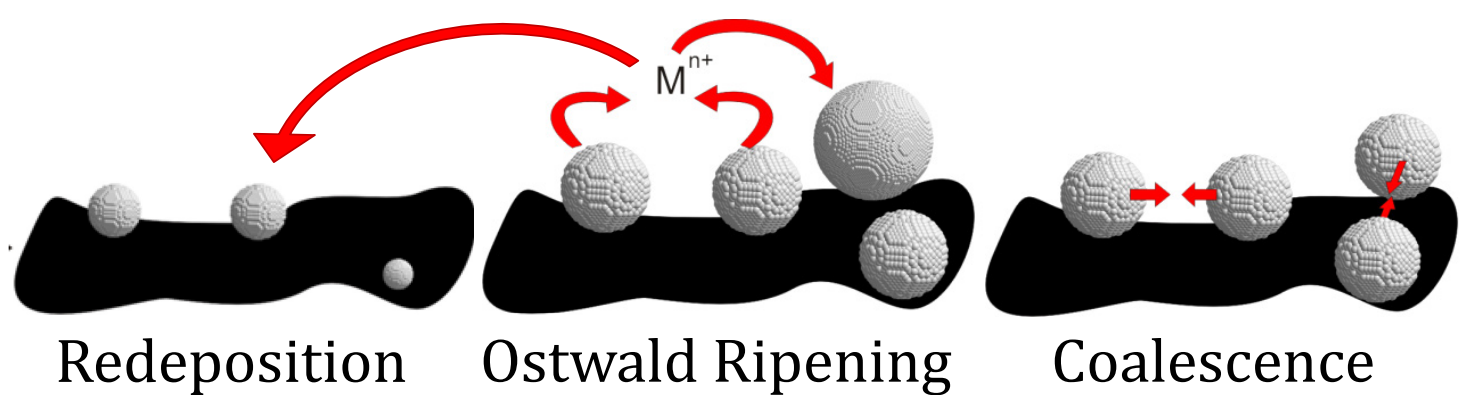

Fig. 7: Schematic of particle coarsening modes

These modes of changing PSDs can indicate the active mechanism of particle growth. However, some ambiguity could arise because a combination of these mechanisms could also lead to the same results. Additionally, these mechanisms may work differently for dissolution/redeposition of metal ions from the oxide, especially if only partially oxidized particles are considered. Deposition of dissolved iridium particles in the membrane after electrolyzer tests has been observed by Thomassen et al. in NEXPEL and NOVEL. ${ }^{[36]}$ Iridium transport mechanisms inside the membrane and a possible Ir-band formation after prolonged testing could provide additional information on degradation mechanisms but have not been investigated so far.

\section{b. Composition and Doping}

Empirical attempts to improve the properties of OER catalysts by mixing the two best-known materials date back several decades. ${ }^{[48]}$ For example, iridium oxide was added to ruthenium oxide to obtain an enhanced catalyst with improved activity and stability. ${ }^{[49]}$ It was found that adding as little as 20 mol-\% of iridium increased the stability of the mixed oxide. However, neither stability exceeded iridium oxide 
nor did the activity outperform ruthenium oxide ${ }^{[49]} \mathrm{Ahn}$ et al. report a $\mathrm{Ru} / \mathrm{Ir}$ mixed oxide running for over $700 \mathrm{~h}$ in a PEM cell at $1 \mathrm{~A} \mathrm{~cm}^{-2}$ and $80^{\circ} \mathrm{C}^{[35 \mathrm{a}]}$

The formation of a solid solution / single phase alloy is usually considered a critical prerequisite for the stability of binary or ternary catalysts. Often, mixed oxide catalysts are prepared by oxidizing the metal alloys. Alternatively, direct decomposition of precursor mixtures can also be used which may avoid the problem of forming a solid solution first. ${ }^{[50]}$ For single phase substitutional alloys, the four Hume Rothery (HR) rules can indicate whether the formation of a single binary phase is possible. ${ }^{[51]}$ Although these empirical rules were developed for metal alloys, they could be applied to oxides as well. ${ }^{[52]}$ If no solid solution is achieved, the formation of large single phase domains is very likely. The different activity and conductivity of the compounds will preferably corrode the less stable oxide. At first, this may function as a sacrificial agent, but severe degradation may lead to structural damage of the catalyst layer. Additionally, the actual current density at the remaining active domains will increase and therefore speed up dissolution. Grain or domain boundaries within a catalyst can decrease the material conductivity because of additional contact resistances. ${ }^{[53]}$ As iridium and ruthenium perfectly fulfill the aforementioned HR criteria, early observation of Ir surface enrichment in IrRu oxides was at first unexpected. The effect was initially attributed to different crystallization kinetics of the oxides. Later, it was found by DFT calculations that iridium would preferably segregate to the surface and as a side-effect protect most of the ruthenium from dissolution, thus explaining the stability improvements. ${ }^{[54]}$

Besides intermixing, iridium and ruthenium oxides have been investigated in mixtures with an extensive amount of other (mostly transition) metals such as Nb, Ta, Co, Ni and Sn. ${ }^{[55]}$ Although most OER studies focus on improving or maintaining the activity, while decreasing the noble metal content, a few studies have addressed the stability issues. ${ }^{[35 c, 56]}$ Binary mixtures with $\mathrm{Sn}$ have been a controversial topic in the field of OER catalysis. Several works investigate Sn mixtures with Ir or Ru and report good to outstanding effects on activity and stability during different operation periods ranging from $250 \mathrm{~h}$ at $0.25 \mathrm{~A} \mathrm{~cm}^{-2}$ to $500 \mathrm{~h}$ at $0.5 \mathrm{~A} \mathrm{~cm}^{-2}$ in a PEM electrolyzer cell $\left(80^{\circ} \mathrm{C}\right) .{ }^{[35 \mathrm{i}, 35 \mathrm{j}]}$ However, in a conventional solution-based $\mathrm{H}$-cell $\left(50{ }^{\circ} \mathrm{C}, 6 \mathrm{~N} \mathrm{H}_{2} \mathrm{SO}_{4}\right), \mathrm{Ir}_{0.5} \mathrm{Ru}_{0.5} \mathrm{O}_{2}$ outperforms the ternary mixture with 50 wt.- $\%$ tin by several hundred hours $\left(1,200 \mathrm{vs} .800 \mathrm{~h}\right.$ at $\left.1 \mathrm{~A} \mathrm{~cm}^{-2}\right) \cdot{ }^{[16]}$ Despite these reports, formation of a single-phased alloy of $\mathrm{Ru} / \mathrm{Ir} / \mathrm{Sn}$ is highly debated. The reported catalytic results vary from greatly reducing the noble metal content, without any activity loss, to a total loss of activity. ${ }^{[35 \mathrm{j}, 57]}$ Fig. 8 shows the phase diagram for rutile phase, iridium tin oxides calculated by Wang et al. ${ }^{[58]}$ A major miscibility gap covers most of the compositional range, but calculations and experimental results suggest a metastable solid solution phase for catalysts synthesized below $450{ }^{\circ} \mathrm{C}$ for sufficiently short calcination times (e.g., 10 min). ${ }^{[57 a]}$ Again, this emphasizes the importance of choosing the right synthesis parameters. 


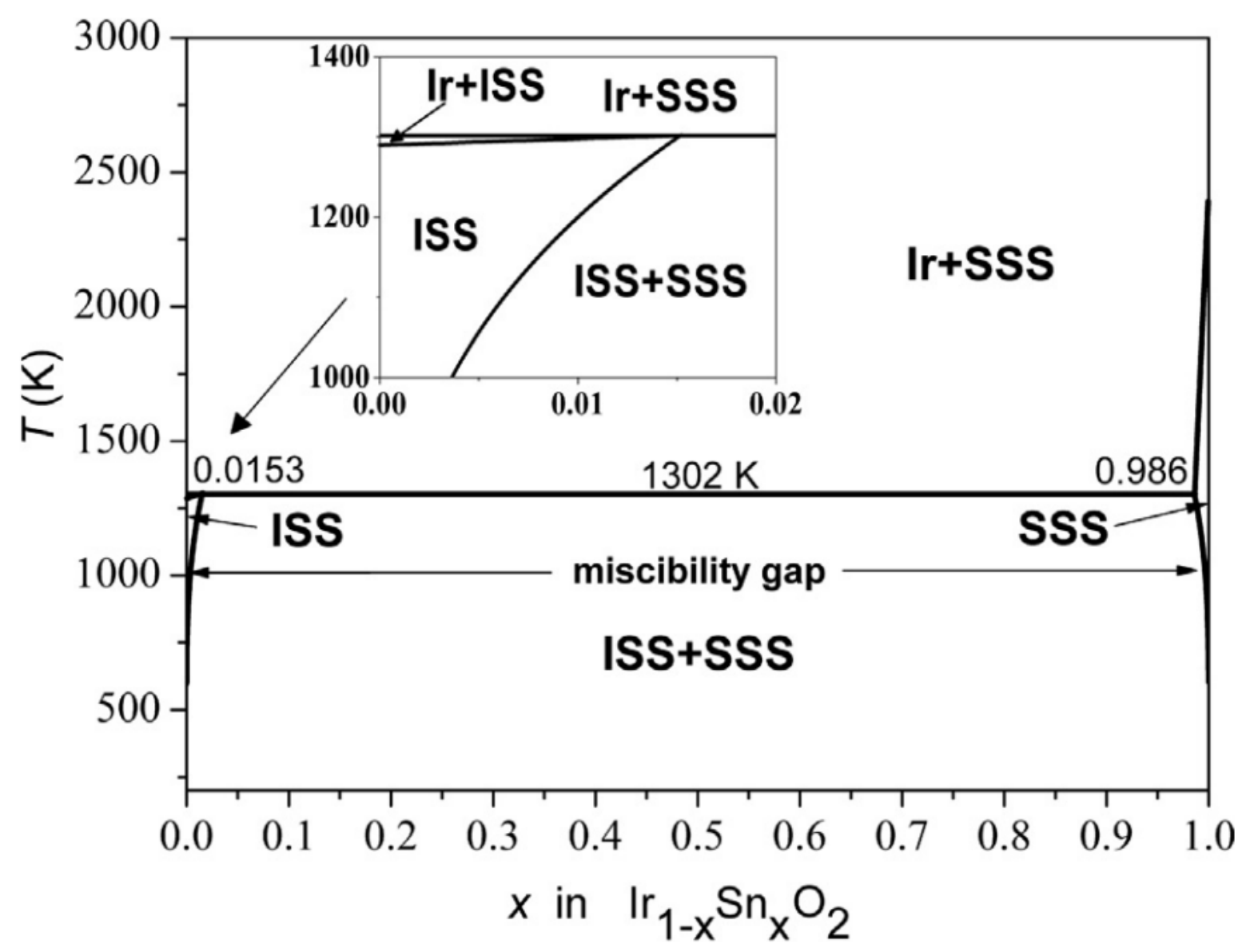

Fig. 8: Ir-Sn-oxide equilibrium phase diagram, ISS: iridium-rich solid solution; SSS: tin-rich solid solution; ${ }^{[58]}$ reprinted with permission from Elsevier

$\mathrm{IrO}_{2}$ and $\mathrm{Ta}_{2} \mathrm{O}_{5}$ composite materials with up to $30 \mathrm{wt} .-\% \mathrm{Ta}_{2} \mathrm{O}_{5}$ are reported to exhibit excellent anodic stability $\left(15,000 \mathrm{~h}\right.$ runtime at $1 \mathrm{~A} \mathrm{~cm}^{-2}$ and $\left.60{ }^{\circ} \mathrm{C}\right)$ explained by promoting the dispersion and adhesion of crystalline $\mathrm{IrO}_{2}$ by amorphous tantalum oxide regions. ${ }^{[38 \mathrm{a}]}$ Unfortunately, the promising results have not been confirmed in a PEM electrolyzer setup yet. ${ }^{[59]}$

$\mathrm{Nb}$ in a ternary catalyst structure with $\mathrm{Sn}$ and $\mathrm{Ir}$ was found to enhance the stability of iridium oxide. At 40 mol-\% Ir, the mixed oxide exhibits similar activity $\left(11 \mathrm{~mA} \mathrm{~cm}{ }^{-2}\right.$ at $\left.1.75 \mathrm{~V}_{\mathrm{RHE}}\right)$ and a reduced voltage loss over $44 \mathrm{~h}$ of OER at $11 \mathrm{~mA} \mathrm{~cm}^{-2}$, in a $1 \mathrm{M} \mathrm{H}_{2} \mathrm{SO}_{4}$ electrolyte at $40^{\circ} \mathrm{C} .{ }^{[60]}$ Subsequent studies, which combined the experimental approach with DFT-based calculations, showed that the activity loss may result from a change of the d-band structure and shift of the d-band center closer to the Fermi level. The metallic conductor-based theory is thought to be applicable to iridium and ruthenium oxide catalysts because of their metallic conductivity behavior. Doping the oxide catalyst with small amounts (up to 10 mol-\%) of fluoride has been reported to reverse the d-band center shift both theoretically and experimentally. This effect is hypothesized to maintain the stability gain but promote the original activity. Proper PEM-based tests or ALTs are required in order to show whether the runtime improvement in the F-doped catalyst is based on the higher activity or on intrinsically higher corrosion stability. ${ }^{[35 f, 61]}$ 
To this date, a unified understanding of the OER mechanism and interactions in mixed oxide catalysts is missing, rendering the selection and synthesis of new materials a very difficult task. Recently, the use of non-precious metal Mn-based oxide catalysts in acidic media has been reported with promising approaches to obtain non-noble metal oxide stability in this corrosive environment. ${ }^{[62]}$ Although these OER electrocatalysts are potentially cheaper, further improvements in their activity and stability are required. The initial commercialization and wide spread deployment of PEM electrolyzers will rely on commercially available OER catalysts which use precious metals such as iridium.

\section{c. Morphology}

Tailoring the morphology of OER catalysts is a key factor in controlling the accessible active sites and catalyst utilization. The available active area determines mass transport phenomena such as bubble detachment which plays an important role in the stability and activity of an OER catalyst. ${ }^{[63]}$

Fundamental studies focusing on the catalytic performance of isolated crystal facets of a catalyst have helped in the understanding and improving the design of catalysts for reactions such as the ORR. ${ }^{[64]}$ The same principles are being employed towards a deeper understanding of the OER, for instance tailoring the exposed facets of nanostructured catalysts for their increased performance. ${ }^{[65]}$

$\mathrm{Ir} / \mathrm{Ru}$ based materials have been investigated in different morphologies revealing size and structure dependent effects. While thin-film $(<100 \mathrm{~nm})$ model catalysts allow studying the activity and dissolution in a controlled environment, size-controlled nanoparticles reflect the actual catalyst structure in a PEM electrolyzer. A size-effect, i.e. increasing activity with decreasing particle size $(<45 \mathrm{~nm})$, for the OER has been observed for $\mathrm{RuO}_{2}$ particles, but was not found for Co-doped $\mathrm{RuO}_{2}$, showing that morphology and doping effects can be intertwined. ${ }^{[13 \mathrm{~b}]}$ Another more recent example is that of the IrNi oxide films for which both calculations and experimental results show a highly increased catalytic activity (20-fold higher mass activity than $\mathrm{IrO}_{2}$ at $1.53 \mathrm{VRHE}$ ) coupled with a strong $\mathrm{Ni}$ dissolution (up to $80 \%$ loss of $\mathrm{Ni}$ content) in the initial OER scans. According to Reier et al. this results in a beneficial surface modification responsible for the increase of the activity. ${ }^{[66]}$ The remaining $\sim 12 \% \mathrm{Ni}$ content is seemingly stabilized by the Ir oxide matrix and, although the steady state content of $\mathrm{Ni}$ appears to be independent of the initial composition, the resulting morphology is not. In the case of IrNi oxide nanoparticles a metallic alloy is formed and oxidized electrochemically while nickel atoms leach out of the particles' surface. ${ }^{[37]}$ This selective leaching leads to particles with a core-shell structure similar to advanced ORR electrocatalysts ${ }^{[67]}$, but with an Ir-rich, oxidized shell and a metallic IrNi core. The particles form in a diameter range of $5-10 \mathrm{~nm}$ with a $2 \mathrm{~nm}$ oxide shell after the oxidation/leaching step. During these steps, the surface $\mathrm{Ni} / \mathrm{Ir}$ ratio decreases tremendously while the $\mathrm{O} /(\mathrm{Ir}+\mathrm{Ni})$ ratio increases. Together with XPS and EXAFS data, which show a remaining Ni species in the surface region, a similar surface structure as in the thin-film catalysts can be proposed. Additionally, an additional influence by the electronic and strain effects from the underlying metallic core-structure is possible. In a preliminary stability test in a three-electrode cell, the IrNi3.3 core-shell particles showed a 10-fold improvement in performance at 1.47 $V_{\text {RHE }}$ compared to pure iridium oxide nanoparticles rendering them a better electrocatalyst candidate for use in a PEM-electrolyzer cell. Similar effects have also been reported for RuNi nanoparticles. ${ }^{[68]}$ 
Morphology can be controlled in several ways. Oh et al. report the synthesis of nanodendritic iridium oxide particles (15-20 nm), comparable to the structure of 3M's nanostructured thin-film (NSTF) electrodes. ${ }^{[69]}$ These catalysts have exhibited an eight-fold increase in mass-based activity over iridium black thereby outperforming even high-surface area colloidal iridium oxide nanoparticles and recently reported Ir-based double perovskites in activity and stability by at least a two-fold improvement. ${ }^{[23 c, 70]}$ The observed improvement has been explained by an increased number of accessible active sites with a $(1.7 \times)$ higher surface-to-volume ratio. However, this alone could not fully account for the stability increase. Several possible explanations exist for the simultaneous increase in activity and stability. A possible stabilization of the $\operatorname{Ir}(\mathrm{III})$ intermediate to close the LOER cycle (see Fig. 5 and Fig. 6) would explain the stability increase but no attempt at identifying the intermediates has been made in this case. Other reasons include better electron transport in the dendritic structure or the apparent porosity of the nanodendrite particles. If in the right size, the latter could promote bubble detachment at an earlier stage and thus reduce stress on the catalyst.

A recent study by Zeradjanin et al. shows that a cracked surface exhibits preferred and faster bubble detachment as well as significantly reduced catalyst dissolution (50\% lower) rates during OER. ${ }^{[46]}$ The authors optimized the size of the cracks formed during the calcination step by first modelling the film strain according to coating thickness and composition in order to match the critical radius for gas bubble nucleation $(\sim 1 \mu \mathrm{m}) .{ }^{[71]}$ These examples show that a high surface area structure with preferential surface sites can simultaneously improve activity and stability. Lee et al. ${ }^{[72]}$ found that limiting size of the bubbles effectively promotes their detachment, hence increasing the stability. Electrode surfaces blocked by gas bubbles will not participate in the reaction leading to an increase in the current passing through the remaining catalytically active sites causing a higher stress on these active parts of the electrode.

Altering surface functional groups has been reported to activate the proton acceptor functionality of the oxygen atoms at the rutile bridge sites of $\mathrm{Ir}$ - and $\mathrm{Ru}$-based catalysts. This changes the energies of the $\mathrm{OH}^{*}$ and $\mathrm{OOH}^{*}$ surface states next to the bridge sites in rutile structures. ${ }^{[68 \mathrm{a}]}$ For other structures, it has also been suggested that the amount of surface $\mathrm{OH}^{*}$ species increases by the leaching of less noble surface metal atoms (e.g., Ni) and that these species are directly correlated to the catalytic activity (higher $\mathrm{OH}-$ fraction increases activity). ${ }^{[66]}$ Additionally, the remaining surface concentration of the less noble compound reaches a steady state.

Frydendal et al. propose the deposition of small islands of stable compounds (e.g., $\mathrm{TiO}_{2}$ ) on top of defect sites of the catalyst surface $\left(\mathrm{MnO}_{2}\right.$ in this case), thereby protecting the vulnerable sites for corrosion (e.g., kinks and edges) with minimum reduction of the accessible active sites. ${ }^{[62 \mathrm{~b}]}$ This approach combines precise design of morphology and composition to control stability.

\section{d. Support Materials}

In general, catalysts in a PEM electrolyzer consist of nanoparticulate structures dispersed on an electrically conductive support to maximize catalyst utilization and decrease the noble metal consumption 
in the production of membrane electrode assemblies (MEA). Thus, the choice of support, its conductivity, stability and catalyst-support interactions play a very important role in catalyst stability.

Carbon based materials, which are commonly used in fuel cell research ${ }^{[73]}$ (e.g., Vulcan XC-72; BETsurface area: $\sim 235 \mathrm{~m}^{2} \mathrm{~g}^{-1}$; conductivity: $\sim 21 \mathrm{~S} \mathrm{~cm}^{-1}$ ), are not sufficiently stable under the harsh oxidizing conditions of OER and the weak interaction between support and catalyst can lead to sintering and particle detachment. ${ }^{[74]}$ On the other hand, supports with conductivities of as low as $0.1 \mathrm{~S} \mathrm{~cm}^{-1}$ have been used in OER electrocatalysis ${ }^{[75]}$ and can be taken as a minimum conductivity required for OER catalyst support structures. Conductivities of $\mathrm{IrO}_{2}$ vary between $2.7 \times 10^{4} \mathrm{~S} \mathrm{~cm}^{-1}$, for thin $\mathrm{IrO}_{2}$ films ${ }^{[76]}$, and $10^{-2} \mathrm{~S} \mathrm{~cm}^{-1}$, for electroflocculated and unsupported $\mathrm{IrO}_{2}$ nanoparticle films. ${ }^{[77]}$ Common catalyst supports are based on titanium and its oxides as well as conductive transparent oxides such as antimony- or fluorine-doped tin oxide and tin-doped indium oxide (ATO, FTO and ITO, respectively). ${ }^{[35 e, 53,78]}$

Oh et al. report the synthesis of mesoporous and conductive transparent oxides. Among the investigated oxides, mesoporous ATO (meso-ATO) shows the highest conductivity $\left(0.29 \mathrm{~S} \mathrm{~cm}^{-1}\right)$ and a highly stable cyclability $(>10,000$ cycles $) .{ }^{[79]}$ Similar results $\left(0.83 \mathrm{~S} \mathrm{~cm}^{-1}\right)$ were reported for electrospun crystalline ATO nanowires (nw). ${ }^{[80]}$ The outstanding stability of $\mathrm{IrO}_{2}$ nanodendrites and $\mathrm{IrNi}$ oxide core-shell particles mentioned in section 4.c is further improved when supported on nanostructured ATO. ${ }^{[23 \mathrm{~b}, 23 \mathrm{c}, 37]}$ In a PEM electrolyzer cell test, the $\mathrm{IrO}_{2} / \mathrm{ATO}-\mathrm{nw}$ catalyst reached $2 \mathrm{~A} \mathrm{~cm}^{-2}$ at $1.62 \mathrm{~V}_{\mathrm{RHE}}\left(80{ }^{\circ} \mathrm{C}\right)$ with an activity loss of $0.76 \mathrm{mV} \mathrm{h}^{-1}$ after $646 \mathrm{~h}$ at $450 \mathrm{~mA} \mathrm{~cm}{ }^{-2}\left(35^{\circ} \mathrm{C}\right) \cdot{ }^{[80]} \mathrm{In}$ a preliminary $15 \mathrm{~h}$ rotating disk electrode (RDE) test of stability, Oh et al. maintained a working potential of $\sim 1.5 \mathrm{VRHE}$ at $10 \mathrm{~mA} \mathrm{~cm}$ with $\mathrm{IrO}_{2}$ nanodendrites supported on meso-ATO. Their study showed that the stability of supported $\mathrm{IrO}_{2}$ nanostructures increased the order unsupported $<$ carbon $<$ commercial ATO $<$ nanostructured ATO. ${ }^{\text {[4] }}$

In the case of thermally oxidized catalysts, the stability of bulk titanium supports strongly depends on the synthesis temperature of catalysts. At temperatures greater than $450{ }^{\circ} \mathrm{C}$, the titanium support oxidizes. The oxide layer dramatically decreases performance due to higher resistance and damage to the catalyst structure by intergrowing $\mathrm{TiO}_{2}$ seeds. ${ }^{[39,81]}$

The low conductivity (usually $\left.\sim 10^{-6} \mathrm{~S} \mathrm{~cm}^{-1}\right)^{[82]}$ of titanium oxide renders pure $\mathrm{TiO}_{2}$ unfeasible as a support in PEM electrolysis. Employing titanium suboxides ${ }^{[83]}$ or doping with different transition metals (e.g., W, $\mathrm{Ta}$ and $\mathrm{Nb}$ ) have been investigated to improve the conductivity. ${ }^{[21 \mathrm{a}, 84]}$ Out of these options, Nb-doped titanium dioxide (NTO) has been reported to tremendously increase the conductivity by a factor of $10^{5} .{ }^{[85]}$ A comprehensive overview of sputtered NTO films emphasizes the need for precise oxygen control during synthesis to obtain conductivities of up to $1.5 \times 10^{3} \mathrm{~S} \mathrm{~cm}^{-1}{ }^{186]} \mathrm{Hu}$ et al. have evaluated the OER performance of $\mathrm{IrO}_{2}$ nanoparticles supported on $\mathrm{Nb}$-doped $\mathrm{TiO}_{2} .{ }^{[21 \mathrm{e}]}$ They report higher conductivity but a strong reduction in surface area when NTO is crystallized in the rutile phase but claim a good compromise for conductivity and surface area (BET, $82 \mathrm{~m}^{2} \mathrm{~g}^{-1}$ ) while not stating the conductivity values for the anatase NTO. With a loading of $26 \mathrm{wt} .-\% \mathrm{IrO}_{2}$ their NTO exhibits a 2.4-fold increase in massnormalized current density over pure $\mathrm{IrO}_{2}$. In a preliminary stability test ( $4 \mathrm{~h}$ at $1.6 \mathrm{VRHE}$ ) $\mathrm{IrO}_{2} / \mathrm{NTO}$ showed a drastically reduced loss of ECSA versus pure $\mathrm{IrO}_{2}$ (6\% and $51 \%$ loss, respectively). 
Transition metal carbides have been suggested as alternative acid-stable supports. For example, bulk TaC can reach conductivities of up to $10^{4} \mathrm{~S} \mathrm{~cm}^{-1} \cdot{ }^{[87]}$ Even though the surface area is very low $\left(0.7 \mathrm{~m}^{2} \mathrm{~g}^{-1}\right)$, the synthesis of $\mathrm{IrO}_{2}$ supported on $\mathrm{TaC}$ was reported recently. ${ }^{[88]}$ Unfortunately, the conductivity approaches zero for $\mathrm{IrO}_{2}$ loadings below $50 \mathrm{wt} .-\% \mathrm{IrO}_{2}$. This is explained by formation of an insulating $\mathrm{NaTaO}_{3}$ surface layer. Higher Ir loadings reach reasonable conductivities $\left(\sim 6 \mathrm{~S} \mathrm{~cm}^{-1}\right)$ which has been attributed to a conductive $\mathrm{IrO}_{2}$ layer rendering the TaC support redundant. Most carbides turn out to be unstable or easily oxidized in OER-relevant potential regions, limiting their use as supports. ${ }^{[89]}$

The degree of catalyst immobilization on the support influences the extent of particle detachment or dissolution during operation. This is defined by interaction between the support surface (groups) and the catalyst. Interactions range from weak electrostatic attraction to stronger connection by surface chemical bonds or overlayer formation of the support. These can also influence the activity, e.g., by reducing or adding to the electron density in the catalyst surface. By changing the activity, the catalyst may experience less stress because a lower potential is sufficient to induce the desired current density. This ultimately leads to improved stability. Additionally, as in strong metal-support interactions (SMSI) for metal catalysts, strong oxide metal interactions (SOMI) have been observed that could be beneficial for catalyst stability. ${ }^{[90]}$ The formation of a thin porous oxide layer of support material on top or at the boundary of each catalyst particle may act as an anchor to avoid particle detachment (see Fig. 9). A partially covering oxide overlayer has been observed for $\mathrm{Pt}$ supported on $\mathrm{TiO}_{2}$ as pointed out in a recent review. ${ }^{[91]}$ It is possible that similar effects may exist for OER catalysts as stability on ATO is significantly increased when the catalyst is synthesized with the support instead of a post-synthesis deposition. Plessow et al. calculated the adsorption energy of metal atoms (e.g., Ti) from an oxide (e.g., TiO) on a support metal (e.g., Ir) by DFT and conclude that this adsorption energy could be used as a valid indicator of stability of the oxide layer. ${ }^{[92]}$ Even though oxide and support are layered in reverse order as in OER catalysts, conclusions can be drawn for their use in PEM electrolysis. Especially for different titanium oxide phases (e.g., hexagonal $\mathrm{TiO}$ or $\mathrm{Ti}_{2} \mathrm{O}_{3}$ ) a strong attractive interaction with $\mathrm{Ir}$ and $\mathrm{Ru}$ was found, which could explain the good stability on Ti-based supports. Unfortunately, the study was not extended to ATO and other transparent oxides. Extensive investigation of catalyst-support interactions for $\mathrm{IrO}_{\mathrm{x}}$ on ATO were recently reported by $\mathrm{Oh}$ et al. ${ }^{[7]}$ The authors observed a reduced average oxidation state of $\mathrm{IrO}_{\mathrm{x}}$ on ATO $\left(+3.2\right.$ vs. +4.0 for $\left.\mathrm{IrO}_{\mathrm{x}} / \mathrm{C}\right)$, together with an amorphous $\mathrm{IrO}_{\mathrm{x}} \mathrm{H}_{\mathrm{y}}$ surface species and metallic Ir by depthprofile XPS (features which do not appear for $\mathrm{IrO}_{\mathrm{x}} / \mathrm{C}$ ). The observed interactions are termed MMOSI (metal/metal-oxide support interactions) and are used to explain the increased stability of $\mathrm{IrO}_{\mathrm{x}} / \mathrm{ATO}(21.4$ $\%$ vs. $71.6 \%$ mass loss for $\mathrm{IrO}_{\mathrm{x}} / \mathrm{C}$ after $15 \mathrm{~h}$ stability test) that cannot only be accounted for by increased stability of the support. According to $\mathrm{Oh}$ et al. strong electronic interactions by charge donation from ATO to $\mathrm{IrO}_{\mathrm{x}}$ nanoparticles lead to the reduced Ir oxidation state and a decreased oxide layer thickness. The authors correlate the anodic metal dissolution rate to the oxidizability of the metal. Thus, stabilization of a lower oxidation state by MMOSI could slow down Ir dissolution. This often-overlooked effect on OER catalysis could provide important insight for a deeper understanding of the OER catalyst degradation mechanism(s). 


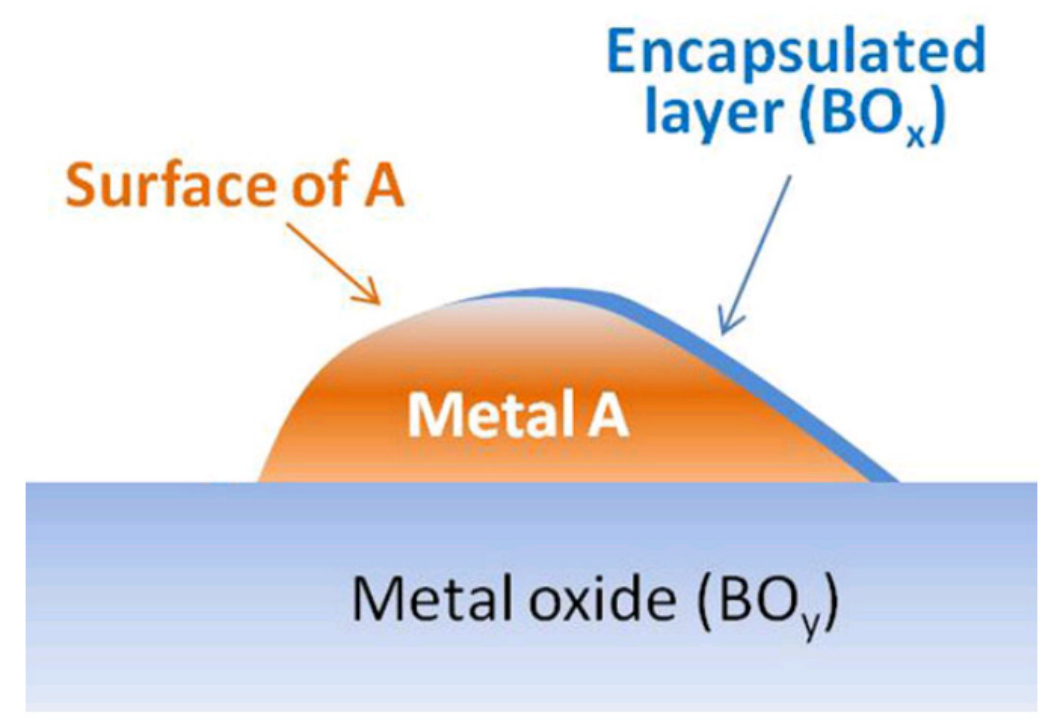

Fig. 9: Schematic of SMSI ${ }^{[11]}$; Reprinted with permission from Wiley

e. Synthesis Parameters

\section{i. Synthesis Temperature}

Temperature studies on pure Ir oxide catalysts have been performed in the range of 250 to $1100{ }^{\circ} \mathrm{C} .{ }^{[81,93]}$ Higher temperatures during calcination lead to better crystallization, accelerated crystal growth and lower hydration of the obtained oxide. ${ }^{[81,93 b]}$ Low temperatures $\left(\leq 400{ }^{\circ} \mathrm{C}\right)$ yield XRD-amorphous catalysts that are believed to form the active phase of the oxide, but are more challenging to characterize. ${ }^{[38 b, 94]} \mathrm{A}$ high degree of crystallinity is generally attributed to higher stability of the oxide, whereas well-hydrated, amorphous oxides have shown superior activity over the former. ${ }^{[95]}$ Among other theories, an increased $\mathrm{OH}^{*}$ surface-fraction in the hydrated oxides is reported to be a factor for better activity. These results are usually interpreted as a universal inverse relation between activity and stability (see 4.a.ii). ${ }^{[38 b, 96]}$ Recent findings have shown that even for monometallic oxides there are exceptions where the thermodynamic relation is overruled by effects that are not completely understood yet. ${ }^{[55 a]}$ Similar observations have been reported for mixed oxides. ${ }^{[37,97]}$ The latter studies focused on the activity increase, but they can also hint about stability effects. There, changes in the activity are made without changing the crystallinity and therefore show deviations from the universal, inverse relation of crystallinity, activity and stability. In the former case, the stability of an $\mathrm{Ir}$ oxide film calcined at $250^{\circ} \mathrm{C}$ was higher than that of a similarly active one calcined at $350^{\circ} \mathrm{C}$, even though the crystallinity increased for the higher temperature calcined film. ${ }^{\text {[39] }}$ Films calcined at $450{ }^{\circ} \mathrm{C}$ and higher showed the expected inverse behavior. This intermediate state between low and high stability is an indication that it is possible to decouple corrosion from the OER. Comparing dissolution on electrochemically and thermally oxidized $\mathrm{IrO}_{2}$ films, reveals that thermally oxidized films exhibit strongly increased stability. A hydrous, highly active oxide film calcined at $250{ }^{\circ} \mathrm{C}$ is still 1-2 orders of magnitude more stable than an electrochemically oxidized film with similar activity. ${ }^{[44,95 a]}$ These findings suggest that more factors are governing the stability of an OER catalyst and 
that the inverse relation may be not necessarily true. ${ }^{[39,66,95 a]}$ In mixed catalysts, temperature is also a crucial factor in obtaining a single phase structure or a metastable phase as a synthesis intermediate. ${ }^{[58,98]}$

It has been shown that precise temperature control (within a few ${ }^{\circ} \mathrm{C}$ ) and reduction of synthesis temperature (from 450 to $250{ }^{\circ} \mathrm{C}$ for $\mathrm{IrO}_{2}$ ) can produce more active catalysts which can simultaneously be more stable in comparison to their counterparts calcined at medium temperatures.

\section{ii. Synthesis Atmosphere}

During thermal or electrochemical oxidation of Ir different surface oxides can be formed depending on the oxygen partial pressure or the electrochemical protocol used for the oxidation process. ${ }^{[65 b, 99]}$ Other studies on MMOs have shown that controlling the gas environment and thereby the oxygen content during calcination allows one to control the structure of the catalyst. ${ }^{[52]}$ While these studies did not cover catalyst stability, Nong et al. have recently proposed that heat treatment under a $\mathrm{N}_{2}$ atmosphere leads to better stability for $\mathrm{IrO}_{2}$ supported on oxide catalysts. ${ }^{[37]}$ A comparative study of the synthesis atmosphere influence on surface termination and activity-stability relations has not been done but would provide additional insight in this respect.

\section{iii. Precursors and Chemical Additives}

The decomposition temperature of precursors restricts the synthesis temperature range. Furthermore, their decomposition products can influence the crystallographic structure of the catalysts. These products can block access to metastable low-temperature structures of a catalyst or to more hydrated surface terminations as shown in section 4.e.i. The latter can be either beneficial, e.g., a decomposition product yielding a specific porosity or detrimental, e.g., a porosity increase causing structural instability, or if the decomposition products block the active surface sites. Chloride impurities, for example, can be leached out during electrolysis. The catalyst layer will be damaged during this leaching or the dissolved $\mathrm{Cl}^{-}$will react in the competing chlorine evolution reaction (ClER). It has also been reported that $\mathrm{Cl}^{-}$could form soluble $\mathrm{IrCl}_{\mathrm{x}}$ species promoting dissolution. ${ }^{[100]}$

In wet synthesis methods, additives (e.g., TTAB) can coordinate a specific crystal growth of nanoparticles ${ }^{[97]}$ or determine the porosity of a catalyst by templating and thus influence the mass transport phenomena at the surface. This is an important factor in the promotion of early bubble detachment. ${ }^{[63 \mathrm{~b}]}$

\section{iv. Deposition / Adhesion Methods}

Catalyst adhesion onto the support, or on the ionomer in MEAs, plays a significant role in long-term stability. Mechanical stress due to bubble formation and detachment, electronic stress by the applied current and increased current by blocked sites, the contact resistance between the catalyst and support as well as support oxidation can all negatively affect the adhesion of the catalyst.

With catalysts directly synthesized on bulk support materials (e.g., Ti plates), adhesion is usually achieved by the calcination process and is sufficiently strong. This allows for more sophisticated studies of stability properties with simplified systems (e.g., thins films, model catalysts). In PEM electrolyzers, catalyst 
layers are deposited directly on the membrane to increase proton conductivity from catalyst layer to membrane.

Nanoparticle catalysts can be deposited on the corresponding supports by electrostatic attraction, usually over long periods of stirring the two materials together in a suitable medium. Alternatively, the catalyst can be synthesized directly onto the support ${ }^{[23 c]}$. The latter allows a better catalyst adhesion because a chemical bond is reportedly formed which has shown to improve the catalyst performance. ${ }^{[37]}$ Recently, Bernsmeier et al. reported a method that allows the simultaneous synthesis of a porous support and size controlled nanoparticles inside the pores, opening up new possibilities for maximized catalyst utilization and possibly decreasing the dissolution rate by trapping the nanoparticles inside the pores. ${ }^{[101]}$

For commercial application in a PEM electrolyzer setup, an additional adhesion of catalyst is required, namely that of the catalyst to the membrane. There are a number of different methods for depositing a catalyst layer on a membrane (e.g., decal or spray coating method etc.). While these methods involve catalyst synthesis and deposition on the support prior to coating the membrane, other approaches have been published where the catalyst and ionomer layer are formed simultaneously. For example, Wang et al. report mild co-crystallization $\left(120^{\circ} \mathrm{C}, 4 \mathrm{~h}\right)$ of a partially pre-crystallized Nafion membrane with catalyst suspensions sprayed on both sides (see Fig. 10). These show increased stability at a high current density of $2 \mathrm{~A} \mathrm{~cm}^{-2}$ at $80^{\circ} \mathrm{C}$ when compared to a commercial membrane. ${ }^{[35 r]}$ The increased stability is attributed to much stronger catalyst-membrane adhesion and an interweaving of the membrane and catalyst layer.

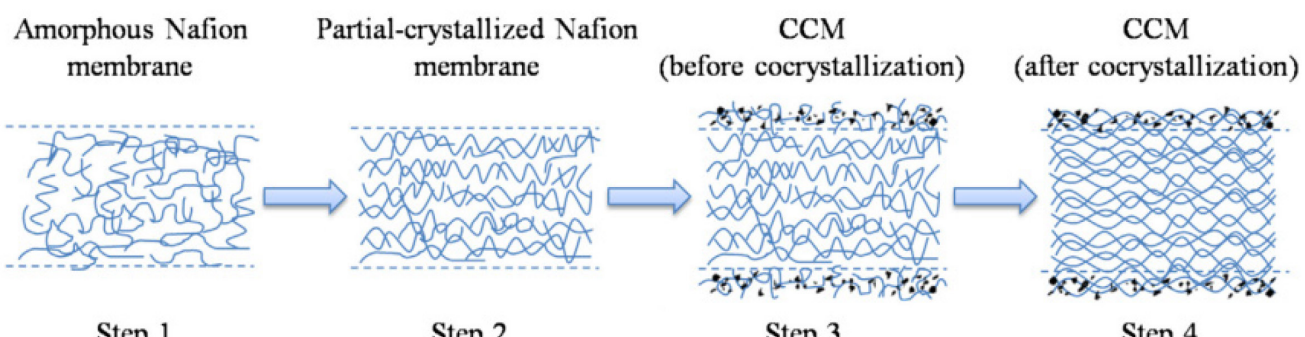

Fig. 10: Steps of cocrystallizing catalyst and nafion membrane leading to high catalyst adhesion ${ }^{[35 r]}$, reprinted with permission from Elsevier

Su et al. have developed the "catalyst sprayed membrane under irradiation" (CSMUI) method, where the catalyst suspension is dried immediately while spraying under UV light. ${ }^{[102]}$ The direct evaporation of solvent supposedly prevents membrane swelling and cracks in the catalyst layer, while increasing the adhesion of the catalyst layer to the membrane. While reasons for better adhesion are not reported, the MEAs prepared by CSMUI show good performance at $1 \mathrm{~A} \mathrm{~cm}^{-2}$ at $80^{\circ} \mathrm{C}$, and SEM cross section images show no signs of delamination or catalyst layer damage after OER testing for more than 100 h. ${ }^{[35 \mathrm{p}]}$ Fig. 11 shows excellent stability for a catalyst loading of $0.4 \mathrm{mg} \mathrm{cm}^{-2}$, similar to that for a much higher loading of $2 \mathrm{mg} \mathrm{cm}^{-2}$. 


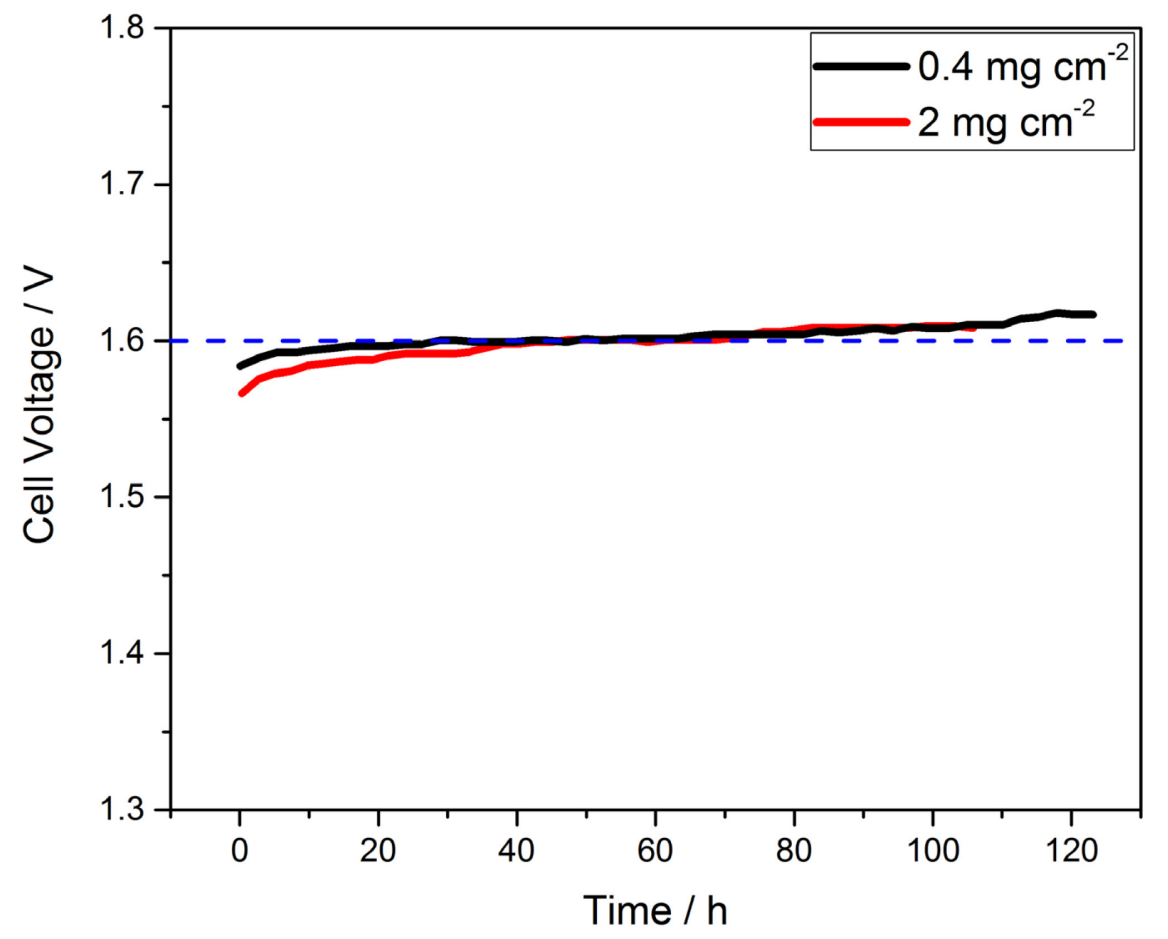

Fig. 11: Stability test of a CSMUI membrane with standard and low iridium oxide loading ( 2 and $0.4 \mathrm{mg} \mathrm{cm}^{-2}$ respectively); operated at $1 \mathrm{~A} \mathrm{~cm}^{-2}, 80^{\circ} \mathrm{C}$ and 1 bar; compiled from ${ }^{[35 p, 102]}$; reprinted with permission from Elsevier

In light of these two developments, it seems plausible that another technique published for the fabrication of CCMs for fuel cells may be suitable to yield promising results for electrolyzer MEAs as well. Controlled synthesis of Pt nanostructures within the first 100-200 nm of the Nafion surface by electroless reduction in a simple two-step process was reported. ${ }^{[103]}$ Transferring this method to Ir oxide based catalysts may improve the stability over the methods presented by Su and Wang. Given that the catalyst is dispersed in the outermost layers of Nafion only, this could eliminate problems of delamination. For all methods presented, sufficient conductivity has to be assured. Bernt et al. report the ideal ionomer loading in $\mathrm{IrO}_{2}$ catalyst inks for PEM electrolyzers to be $11.6 \mathrm{wt.}$-\% ${ }^{[104]}$

\section{Following Degradation by Materials Characterization and in-situ Techniques}

a. The Merit of Ex-situ Pre- and Post-Characterization of OER Catalyst Layers

Inspired by the stability plot by McCrory et al. ${ }^{[22]}$, we have compiled a first-of-its-kind stability chart for PEM electrolysis catalysts tested at $1 \mathrm{~A} \mathrm{~cm}^{-2}$ (Fig. 12). In Fig. 12, the figure of merit for activity is still the same (i.e., the closer the catalyst is to the origin, the higher the activity). However, the y-axis is modified such that the difference in overpotential $\left(\Delta \eta=\eta_{\text {final }}-\eta_{\text {inital }}\right)$ is shown instead of the end of experiment overpotential. This allows one to directly read the activity decay from the figure. Using the difference in overpotential instead of just the final test overpotential changes the reference point for 
reading stability. This reorients the graph such that the farther the catalyst is from the $\mathrm{x}$-axis, the more unstable it is. Scatter points were colored by their base component $(\mathrm{Ir}=$ green, $\mathrm{Ru}=$ blue; $\mathrm{Rh}=\mathrm{red} ; \mathrm{Pt}=$ black).

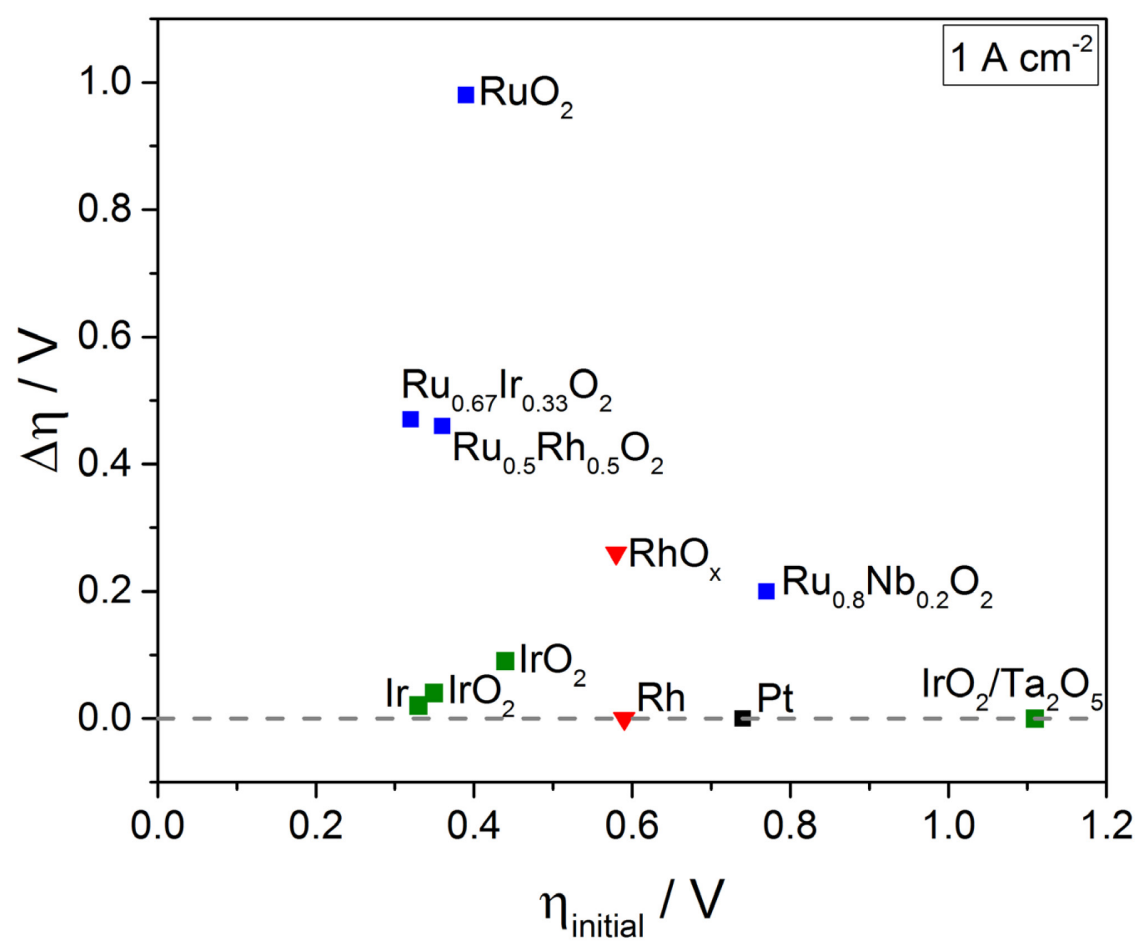

Fig. 12: Stability deviation in PEM electrolysis tests at $1 \mathrm{~A} \mathrm{~cm}^{-2}$; compiled from Refs ${ }^{[34-35,35 p, 35 q]}$

Any catalyst material should be extensively characterized before and after testing the catalytic activity and stability. The resulting data will provide a base set of information to evaluate governing factors of stability. Among the properties that should be investigated, composition and morphology play a major role.

\section{i. Morphology}

Morphology can be investigated by means of electron microscopy (SEM/TEM) The surface area can additionally be quantified by physisorption experiments such as BET but it should be kept in mind, that the BET surface area does not necessarily reflect the electrochemically active surface area. Transmission electron microscopy (TEM) adds information about the catalyst dispersion on the support and crystallite size and shape. ${ }^{[105]}$

Earlier publications have reported membrane thickness after prolonged testing (for tens of thousands of hours) in order to investigate issues of cell failure but the overall conclusion was that these effects were mostly due to membrane degradation or handling of the test cell hardware, e.g., uneven compression when tightening the cell. ${ }^{[106]}$ A more recent study correlates the observed membrane thinning to ionomer 
corrosion measured by the fluorine release rate. ${ }^{[107]}$ The peroxide intermediate of the OER is thought to be able to release $\mathrm{OH}$ radicals upon decomposition which can attack the membrane backbone and release fluorine during the backbone degradation reaction. ${ }^{[106 b]}$ Membrane thinning and subsequently catalyst layer damage should be expected at high current densities but are currently not well understood. ${ }^{[108]}$

\section{Scanning Electron Microscopy}

Scanning electron microscopy (SEM) is the most commonly used method of visual post-mortem analysis. ${ }^{[35 \mathrm{p}, 35 \mathrm{r}]}$ Fig. 13 shows SEM cross-sections of an MEA before and after durability testing with highlighted catalyst layer damage, delamination and membrane thinning.

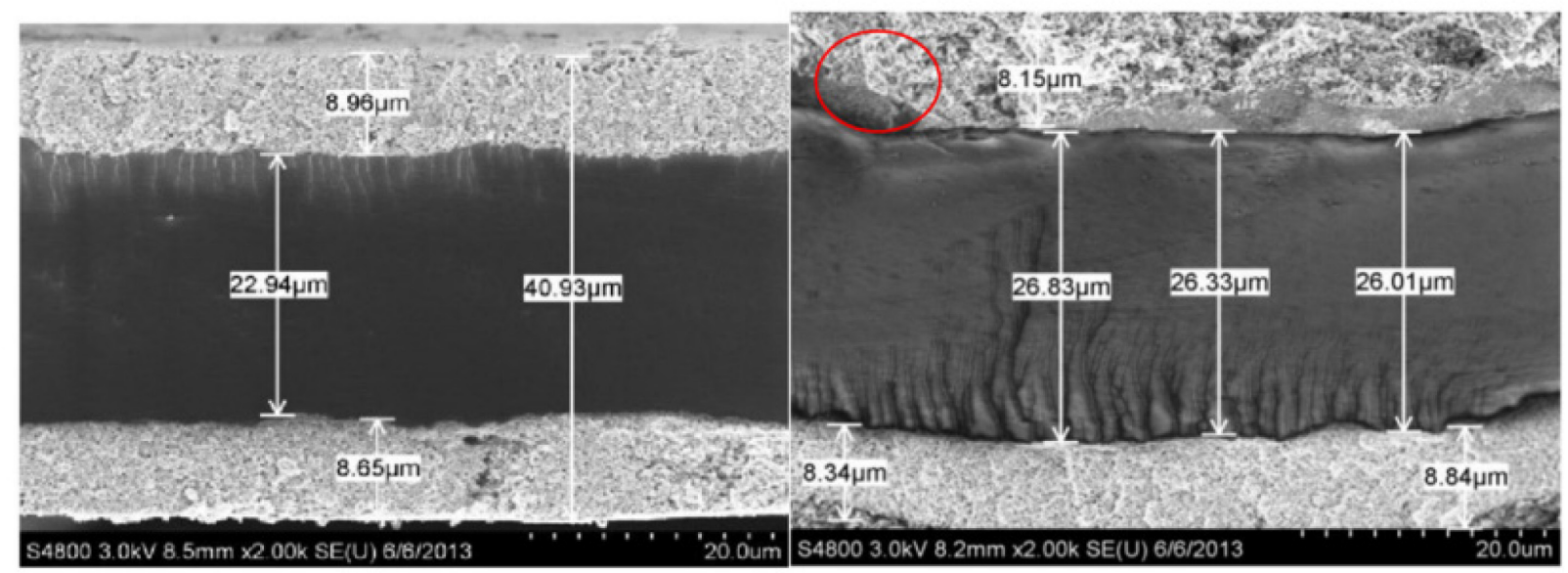

(a) Fresh MEA

(b) After 200 cycles

Fig. 13: SEM cross-sectional micrographs showing an MEA before (a, left) and after (b, right) the durability test revealing membrane thinning and delamination (red circle); ${ }^{[109]}$ reprinted with permission from Elsevier

$\mathrm{Xu}$ 's work focused on the role of Ir-Ti oxide interlayers between a Ti substrate and an $\mathrm{IrO}_{2}$ electrode. The extent of delamination of the baseline $\mathrm{Ti} / \mathrm{IrO}_{2}$ electrode was more severe than compared to the $\mathrm{Ti} / \mathrm{IrO}_{\mathrm{x}}-$ $\mathrm{TiO}_{2} / \mathrm{IrO}_{2}$, with the latter lasting 420 hours more at $3 \mathrm{~A} \mathrm{~cm}^{-2}$ in a $4 \mathrm{M} \mathrm{H}_{2} \mathrm{SO}_{4}$ solution at $30{ }^{\circ} \mathrm{C}$. SEM confirmed that delamination for the interlayer electrode was not as pronounced as evidenced by the relative sizes of delaminated and catalyst-free spots supposedly lost during the ALT process (up to $50 \times$ $50 \mu \mathrm{m}$ vs. $500 \times 600 \mu \mathrm{m}$ for the interlayer sample and base case, respectively). ${ }^{[35 \mathrm{t}]}$

\section{Transmission Electron Microscopy}

TEM analysis allows for observation of particle agglomeration or corrosion of the support. Ir particle agglomeration was observed in $\mathrm{Li}$ et al.'s work, where an $\mathrm{Ir}_{\mathrm{x}} \mathrm{Sn}_{1-\mathrm{x}} \mathrm{O}_{2}$ catalyst showed $\mathrm{Sn}$ dissolution (lighter areas) and Ir agglomeration (dark areas) after 2,000 CV cycles resulting in changes in surface roughness (see Fig. 14). ${ }^{[110]}$ 

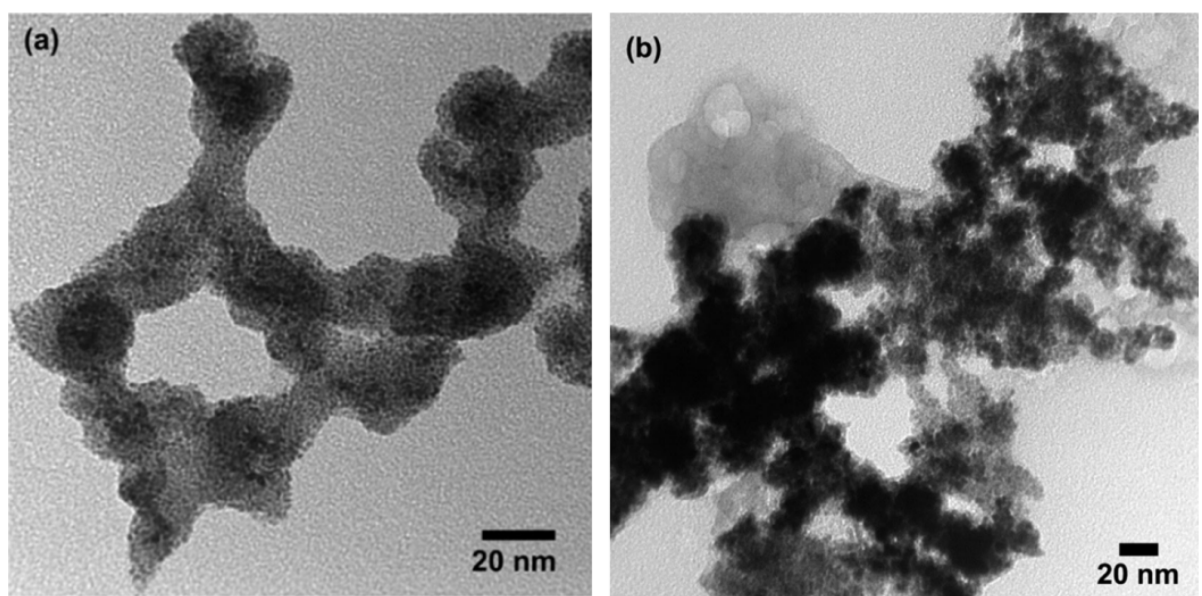

Fig. 14: TEM images of $\operatorname{Ir}_{0.67} \mathrm{Sn}_{0.33} \mathrm{O}_{2}$ a) before and b) after 2000 cycles $^{[110]}$; reprinted with permission from RSC

\section{ii. Composition}

Accurate determination of catalyst composition and loading are of paramount importance for both fundamental and applied studies of electrocatalysis and degradation.

\section{ICP-OES and XRF}

Inductively Coupled Plasma Optical Emission Spectroscopy (ICP-OES) or X-Ray Fluorescence (XRF) measurements quantify the composition as well as the catalyst loading. In ICP-OES (or-MS) the catalyst has to be completely dissolved in order to be quantified. Loss of catalyst during the OER can be assessed either by: i) measuring the amount of dissolved catalyst present in the electrolyte after operation, or ii) dissolving the catalyst layer after the stability tests and comparing it with the initial composition. ${ }^{[23 b, 111]}$

X-ray fluorescence (XRF) detects elemental composition using the characteristic X-rays, rendering XRF a non-destructive method. In Total-Reflection XRF (TXRF) only the evanescent wave penetrates the sample and thus a depth of just a few nanometers of the sample surface is analyzed. ${ }^{[35 e, 112]}$

\section{Energy-Dispersive X-Ray Spectroscopy (EDX)}

SEM is often coupled with EDX to determine the bulk composition of a sample. A number of scanning procedures, including point, line, or box scan as well as elemental maps which provide more detailed information regarding the homogeneity and particle type are possible (see Fig. 15). EDX analysis of fresh and tested MEAs can provide important information on dissolution and segregation. ${ }^{[13]}$ To obtain a good comparison of EDX spectra, the same area (by identical location SEM, IL-SEM, or scanning the whole MEA) must be sampled in both cases as the catalyst concentration may vary across the surface ${ }^{[114]}$ The latter presents sizing constraints of the SEM itself and is therefore not always feasible. IL-SEM requires a gentle, non-intrusive and non-contaminating marking method to not affect the catalyst performance. A potential disadvantage of EDX analysis is that the electron beam may penetrate the MEA and provide an aggregate spectrum for both anode and cathode or damage the catalyst layer before operation. 
(a)

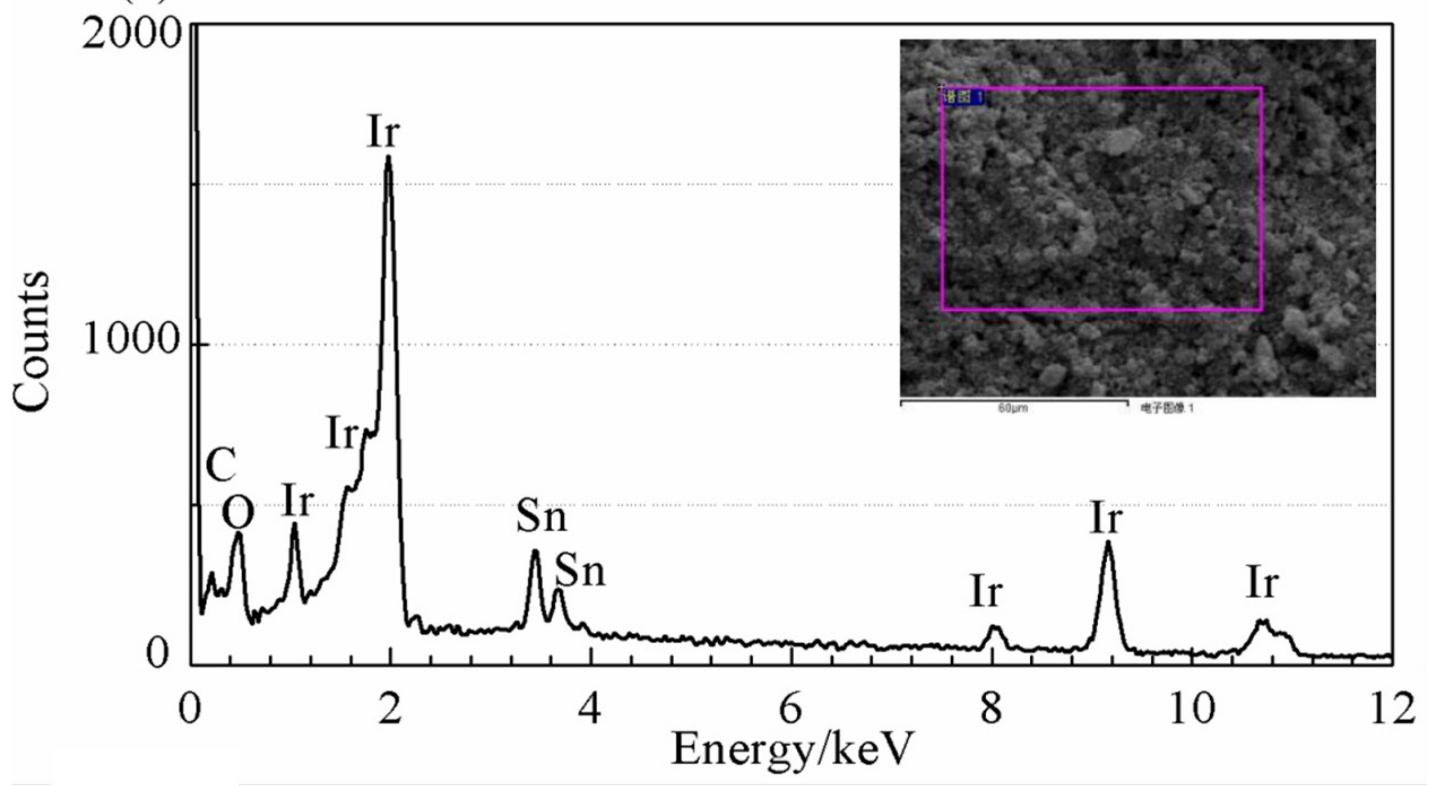

Fig. 15: Example of an EDX scan of an $\operatorname{Ir}_{0.69} \mathrm{Sn}_{0.31} \mathrm{O}_{2}$ catalyst on carbon ${ }^{[110]}$; reprinted with permission from RSC

\section{X-Ray-Photoelectron Spectroscopy (XPS)}

XPS can be used to measure the surface composition and surface species of a sample, such as the various forms of oxygen on the surface of an oxide catalyst. ${ }^{[50 a, 54 a]}$ By adjusting the incident beam energy the probing depth can be tuned and allows surface sensitive measurements. ${ }^{[45]}$ In-situ XPS is covered in section 5.b.iv.

iii. Crystallinity and Phase

X-Ray Diffraction (XRD) provides information on the crystal phase, crystallinity, ordering and average crystallite size. ${ }^{[115]}$ In some solid solution phases, the position of the Bragg peaks could exhibit a linear dependence on the extent of the dopant (Vegard's law). Knowledge of the formation of single or multiple phases, and a secondary method to measure the crystallite size are important to monitor the changes in the catalyst during or after the OER. Ferreira et al. used grazing incidence XRD (GI-XRD) to investigate changes in the anode and cathode of a fuel cell MEA after cycling. ${ }^{[16]}$ This method is applicable to electrolysis MEAs as well. Materials which show poor crystallinity by XRD may be characterized by selected area electron diffraction (SAED) in TEM. ${ }^{[66]}$

b. In-situ Techniques to Monitor and Understand OER Catalyst Degradation

Reversible changes which maybe experienced by the catalysts during the reaction, could only be observed by in-situ techniques. A brief overview of possible characterization methods for the OER is presented in the following sections.

i. Electrochemical Characterization 
Common PEM Electrolyzer stability assessment by galvanostatic testing provides information on performance losses under a given set of cell conditions (e.g., temperature, pressure, flow, current density, experiment runtime, etc.) but these measurements alone do not provide significant insight regarding the failure mechanism(s). Further electrochemical and physiochemical characterizations can address this issue. However, only about a third of the PEM tests reported in the literature give additional analysis such as cyclic voltammetry or impedance spectroscopy aside from the stability test itself.

\section{Cyclic Voltammetry (CV)}

With the appropriate potential limits, CVs can be recorded without irreversible changes in the catalyst structure/composition. This allows one to identify specific adsorption and oxidation state changes as well as quantification of the electrochemically active surface area. Currently, no general ECSA measurement (similar to that of the HUPD charge for platinum catalysts) exists for the OER catalysts. For Ir oxides, it is often accepted to relate the total anodic charge of a CV between 0.4 and $1.4 \mathrm{~V}_{\mathrm{RHE}}$ to the ECSA. However, this remains only a relative measure as long as data on completely planar single crystalline oxide surfaces is missing. Single crystalline IrOx films reported by Stoerzinger et al. would be the closest available in literature but have only been investigated in $\mathrm{KOH}$ and deviating potential limits. ${ }^{[117]}$ For mixed oxides, it is debatable whether this assumption can be valid. If visible, it is possible to integrate the Ir oxidation peak at 0.8-0.9 $\mathrm{V}_{\mathrm{RHE}}$ assuming one electron being transferred per Ir atom, but proper background subtraction can be difficult. ${ }^{[23 b]}$ This makes comparison to other catalyst families such as Ru-based catalysts difficult. Other methods (e.g., measuring the capacitive charge close to the open circuit potential) exist, but they have a relatively high uncertainty. ${ }^{[22]}$ The specific adsorption/desorption charge of probe molecules (e.g., $\mathrm{CO}$ ) is another method that has been widely utilized. Unfortunately, the active sites for $\mathrm{CO}$ adsorption may not be equivalent to the active sites for oxygen evolution. 


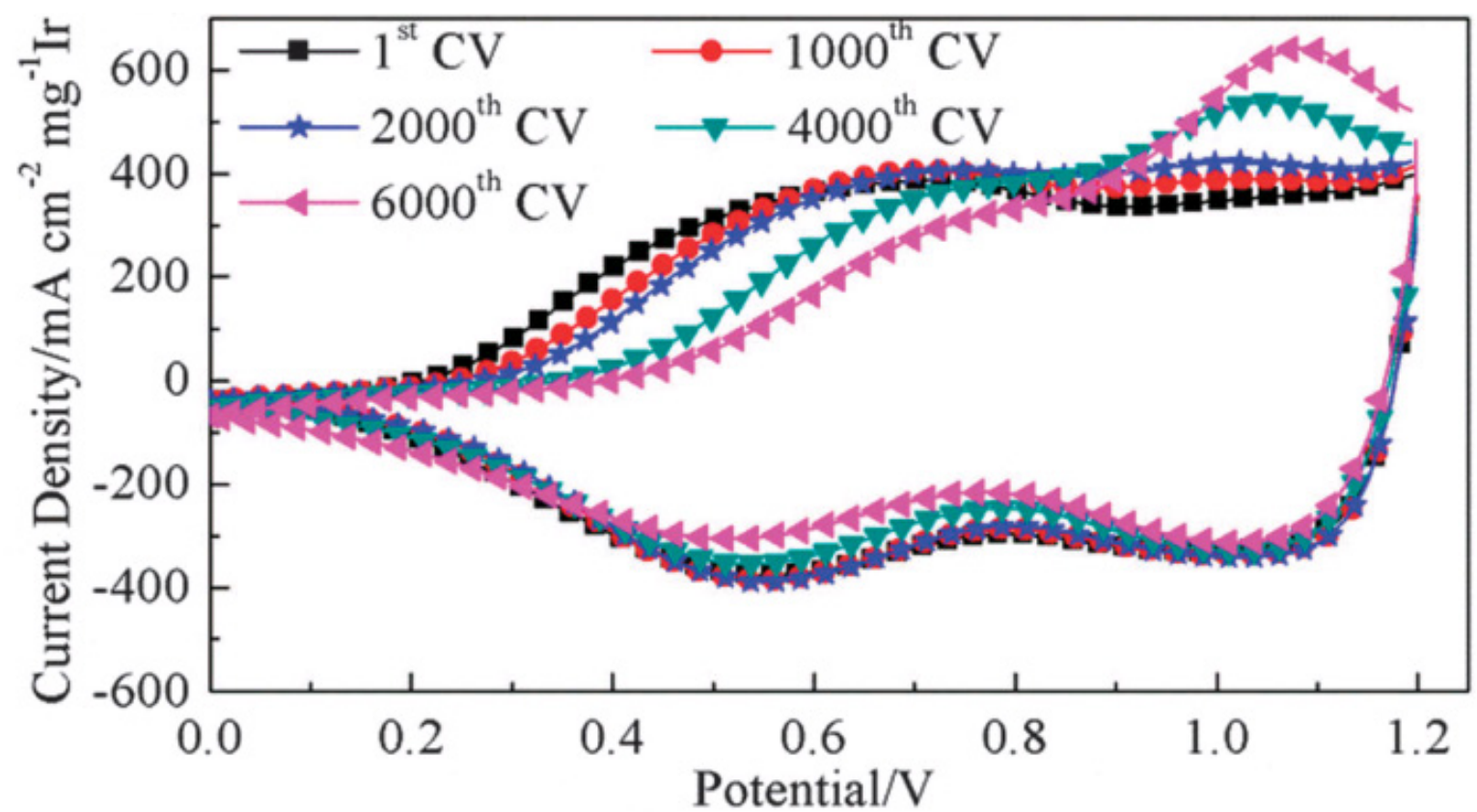

Fig. 16: Degradation of $\operatorname{Ir}_{0.67} \mathrm{Sn}_{0.33} \mathrm{O}_{2}$ after repetitive potential cycles; $100 \mathrm{mV} \mathrm{s}{ }^{-1} ; 0.5 \mathrm{M} \mathrm{H}_{2} \mathrm{SO}_{4}{ }^{[110]}$; reprinted with permission from RSC

CVs can be used to investigate stability or oxide formation by performing typically thousands of cycles at fast sweep rates (e.g., $500 \mathrm{mV} \mathrm{s}^{-1}$ ) and observing the changes in $\mathrm{CV}$ symmetry and peak shape. Continuous increases in current density during cycling up to 200 cycles have been reported for electrochemically oxidized, $\mathrm{IrO}_{2}$ based catalysts. ${ }^{[23 \mathrm{~b}]}$ For example, an $\mathrm{Ir}_{0.67} \mathrm{Sn}_{0.33} \mathrm{O}_{2}$ electrocatalysts has been cycled over 6,000 cycles with the end result showing a significant change in CV shape (see Fig. 16). ${ }^{[35 i]}$ Dissolution of less stable species can be observed by a loss of redox features and decreasing current densities as the number of $\mathrm{CV}$ cycles increases. The dissolution of $\mathrm{RuO}_{4}$ species formed at high anodic potentials is a well-known problem with ruthenium oxide-based catalysts. ${ }^{[34]}$ Surface roughening can be observed by a large increase in the capacitive currents in the CV. ${ }^{[65 b]}$

\section{Electrochemical Impedance Spectroscopy (EIS)}

Electrical conductivity can either be measured ex-situ and, in the case of MEAs, also probe the in-plane conductivity or in-situ by EIS. In addition, EIS allows one to correct in-situ the measured current densities for the ohmic losses in the electrochemical cell setup. The EIS should be, if possible, executed as a frequency scan from $\mathrm{MHz}$ to lower $\mathrm{Hz}$ or even $\mathrm{mHz}$. A full impedance spectrum provides additional information such as charge transfer and mass-transport resistances in the catalyst layer, and, it leads to a more accurate measure of the cell resistance than a one-point measurement. ${ }^{[118]} \mathrm{Oh}$ et al. report a mathematical correlation (see (5)) between the charge-transfer resistance $\left(\mathrm{R}_{\mathrm{ct}}\right)$ and catalyst loading $\left(\mathrm{L}_{\mathrm{IrOx}}\right.$ in $\mathrm{g}_{\mathrm{IrOx}} \mathrm{cm}_{\mathrm{geo}}^{-2}$ ) as well as electrochemically active surface area ( $\mathrm{A}_{\mathrm{IrOx}}$ in $\left.\mathrm{cm}^{2} \mathrm{IrOx}_{\mathrm{g}}{ }^{-1}{ }_{\mathrm{IrOx}}\right)$ that was confirmed experimentally. ${ }^{[74]}$ 


$$
R_{c t} \sim \frac{1}{A_{\text {IrOx }} L_{\text {IrOx }}}(\mathbf{5})
$$

Their results revealed a linear correlation between loading and $\mathrm{R}_{\mathrm{ct}}$ for different ATO and C supports. After $15 \mathrm{~h}$ of galvanostatic operation the remaining loading (obtained by EDX and ICP) of IrOx/C did not correspond to a similar initial loading highlighting the loss of accessible active sites by carbon corrosion. Watzele and Bandarenka recently proposed the determination of the adsorption capacitance $\left(\mathrm{C}_{\mathrm{a}}\right)$ from EIS spectra measured at low OER overpotentials as a promising alternative for surface area measurements of oxide electrodes. ${ }^{[33]}$ According to the authors, their method yields similarly reliable results as HUPD or CO adsorption measurements on metallic electrodes avoiding the uncertainties of the double layer capacitance method.

At high current densities in a PEM test station, the power source of an auxiliary EIS analyzer can influence the actual measurements performed by the test station, therefore alternative techniques such as current interrupt (CI) has been proposed. ${ }^{[118]}$ It is worth mentioning that the mass transport resistance is not accessible with the current mathematical models for CI, and EIS is required for this purpose. The same authors also discuss a sensor array for mapping the current density in order to identify "hot-spots" that potentially could cause dissolution. For a given water flow rate, current mapping shows a strong current dependence on dead zones that accumulate oxygen bubbles. A similar dependence on water starvation has been reported by other researchers as well. ${ }^{[119]}$

\section{ii. Lab-scale in-situ Techniques}

In-situ methods for studies of dissolution (degradation mechanism, sites vulnerable to corrosion) can provide a more detailed picture of degradation. Investigating isolated components in simplified systems first may give important insight here. ${ }^{[50]}$ As was recently pointed out by Frydendal et al., monitoring dissolution by mass-loss via electrochemical quartz-crystal microbalance (EQCM) measurements or mass spectrometry based techniques is very important in understanding the dissolution phenomena with respect to the applied electrochemical protocols. ${ }^{[120]}$

\section{EQCM}

EQCM setups have been widely employed ${ }^{[121]}$ including the application to degradation processes. ${ }^{[122]}$ For instance, $\mathrm{Li}$ et. al report the successful correlation of mass losses with potential while observing gasbubble effects. ${ }^{[123]}$ Drawbacks of EQCM are its limitation to small electrode areas $\left(\sim 1-2 \mathrm{~cm}^{2}\right)$ and very thin catalyst layers (monolayers to $\mathrm{nm}$ ), making it impossible to investigate PEM-catalysts in their usually applied form of an MEA. Because of the small electrode size, current densities are usually limited to the lower range $\left(\sim 1-2 \mathrm{~mA} \mathrm{~cm}^{-2}\right)$, although higher currents $\left(\sim 20 \mathrm{~mA} \mathrm{~cm}{ }^{-2}\right)$ have also been reported. The mass loss alone does not contain direct information on the nature of the lost species, and additional analytical tools are therefore required. EQCM, however, allows the detection of re-deposition of dissolved species which is unique to this method. This is shown in Fig. 17 where the cyclic voltammetry in a) is correlated to the mass changes of the working electrode as seen in b). It is evident that with the emergence of stronger currents above $1.0 \mathrm{~V} \mathrm{Ag} / \mathrm{AgCl}$ catalyst mass is lost even though the reductive peak at $0.6 \mathrm{~V} \mathrm{Ag} / \mathrm{AgCl}$ corresponds to a certain redeposition of dissolved material. 

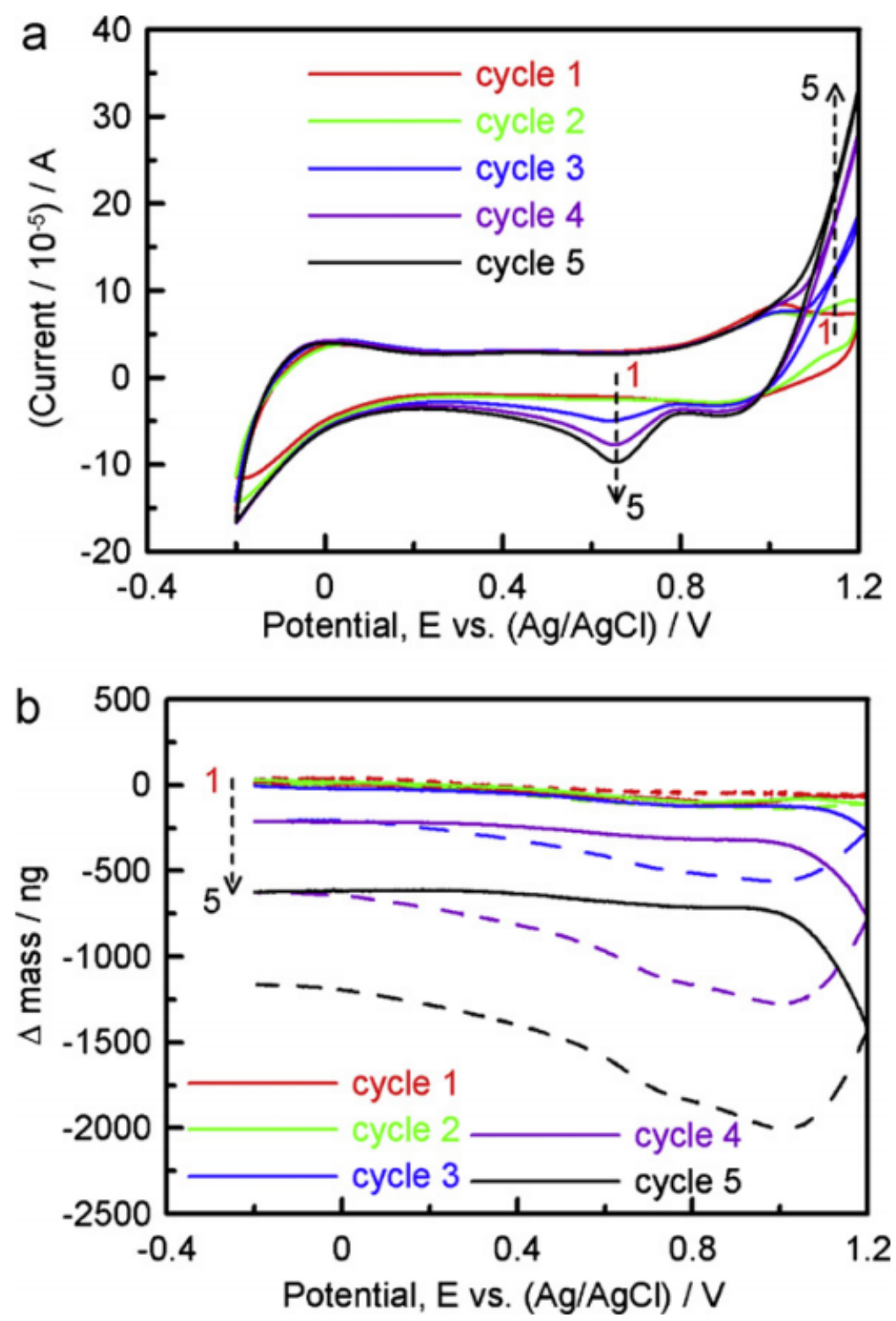

Fig. 17: Following MnOx degradation by EQCM; a) CVs with b) their corresponding mass change curves ${ }^{[122 b]}$; reprinted with permission from Elsevier

\section{SFC-ICP-MS}

A setup of a scanning flow cell (SFC) allowing for rapid sampling times and coupled with inductively coupled plasma-mass spectroscopy (ICP-MS) providing the extent of catalyst dissolution in real time has recently been presented by several groups. ${ }^{[124]}$ Mayrhofer et al. were able to quantify the iridium dissolution in an electrolyte in real time using the SFC-ICP-MS method. ${ }^{[124 a]}$ The obtained dissolution

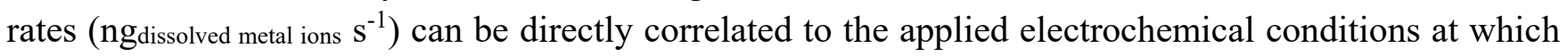
the dissolution occurs. With this knowledge, unstable potential regions can be avoided in real applications and thus extend the lifetime or the amount of information that can be used to design accelerated lifetime tests with maximized corrosion. Fig. 18 shows an example of the evolution of electrode potential and the 
corresponding Ir dissolution over time. Upon stepping the potential from OCP down to $0.0 \mathrm{~V}_{\mathrm{RHE}}(\mathrm{t} \sim 500$ s) a significant cathodic dissolution current is detected. When scanning the potential up to $1.2 \mathrm{~V}_{\mathrm{RHE}}$ only small amounts of Ir dissolution are measured. In the second cathodic scan dissolution is increased. Subsequently, stronger anodic dissolution is detected signaling a possible removal of a protective, passivating layer in the previous cathodic scans. The last cathodic dissolution peak can be explained by reduction of new oxide layers formed in the anodic scan.

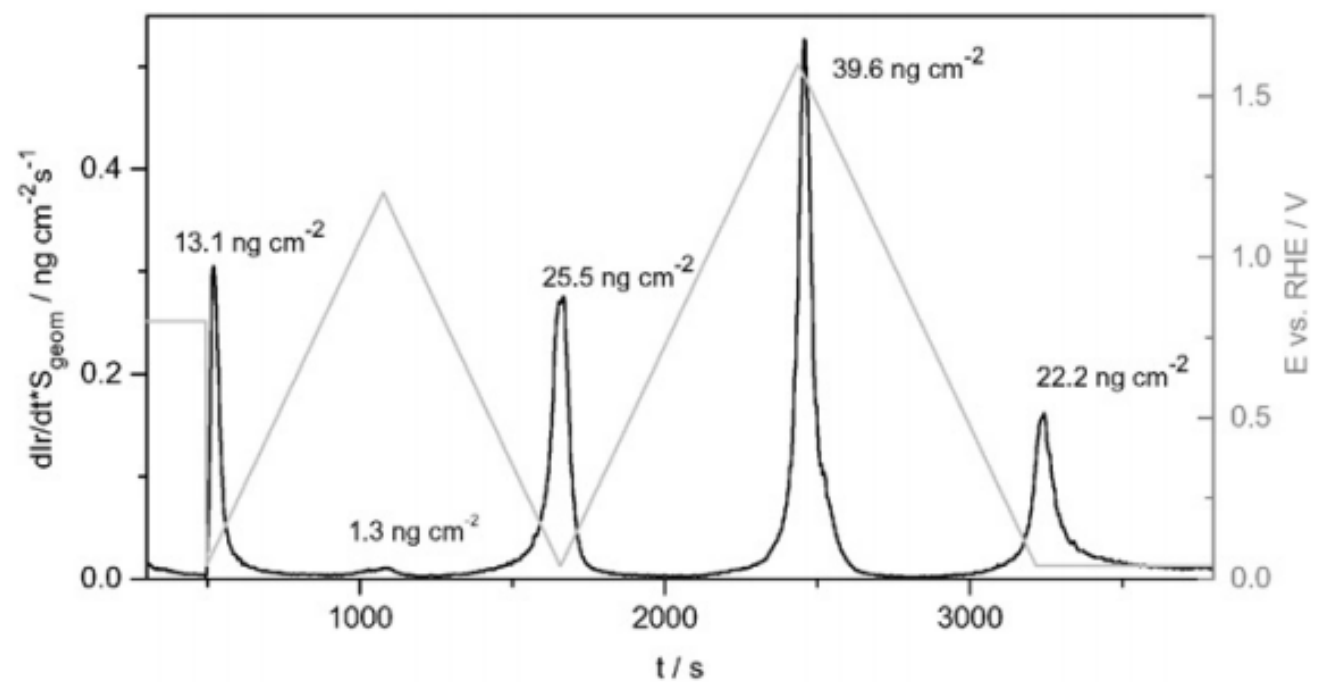

Fig. 18: Potential-Dissolution vs. Time Curve of an electrochemically oxidized iridium oxide as an example of SFC-ICP-MS measurements ${ }^{[44]}$; reprinted with permission from Elsevier

Cherevko et al. demonstrated that on noble metal surfaces, dissolution generally occurs upon electrode immersion and during dynamic operation. Static dissolution is reported to be much smaller than for dynamic operation. The actual dissolution profile varies greatly between the metals investigated. For iridium, transient dissolution during oxidation starts at potentials above 0.8 VRHE but the dissolution vs. potential curve exhibits changing slopes with increasing potential. This indicates multiple processes or a change in the dissolution mechanism. Upon reaching OER potentials $\left(\geq 1.4 \mathrm{~V}_{\mathrm{RHE}}\right)$ the dissolution rate increases rapidly, signaling a common intermediate in the OER and the corrosion reaction. During static operation (e.g., galvanostatic electrolysis) iridium shows lower (by at least $\sim 20 \%$ ) dissolution rates than compared to transient operation. A thick, hydrous iridium oxide shows comparable dissolution behavior to iridium metal as long as the potential is kept below the OER region $(\leq 1.2 \mathrm{VRHE})$. Several interesting differences for operation at higher potentials have been reported. During cycling, upper potential limits (UPL) of $>1.4$ VRHE seem to stabilize the hydrous oxide against cathodic dissolution of the oxide. Anodic dissolution of $\mathrm{IrO}_{\mathrm{x}}$ is stronger $(\sim 2 \mathrm{x})$, but exhibits the same trend with increasing UPL as metallic Ir. Two important observations about anodic dissolution are that the onset of severe dissolution does not scale with the amount of oxide (catalytic activity) but is fixed at $\sim 1.4 \mathrm{~V}_{\text {RHE }}$. Contrary to this, the onset of initial anodic dissolution is below the OER standard potential ( $\leq 1.23 \mathrm{~V}$ RHE). These observations lead to two conclusions: i) increasing the potential leads to a change in dissolution mechanism which is independent of the catalyst loading and activity, and ii) The early onset and start of severe dissolution rate at a fixed 
potential when exceeding 1.4 $\mathrm{V}_{\mathrm{RHE}}$ are independent of OER activity, thus it seems possible to control the dissolution reaction independently of the OER activity of iridium-based catalysts. ${ }^{[44,125]}$

In galvanostatic experiments (mimicking real operation of a PEM electrolyzer), dissolution shows an inverse relation to the oxide thickness. Cherevko et al. argue that this is an activity effect. Thicker oxides exhibit a lower overpotential for OER, thus a lower potential (at the same current density) which leads to less dissolution. This is another indication for independently tunable processes for OER and dissolution. Dependence of dissolution on the scan rate, potential limits, and pretreatment have been shown especially for potentiodynamic measurements. ${ }^{[44,95 a, 125]}$ In order to understand the Ir degradation mechanism better, a priority in stability studies should be the identification of the postulated Ir intermediates as mentioned in section 4.a.ii.

\section{Differential Electrochemical Mass-Spectrometry / On-Line Electrochemical Mass-Spectrometry (DEMS/OLEMS)}

Often, DEMS or OLEMS setups are used to evaluate the efficiency of electrocatalysts by quantifying the evolved oxygen ${ }^{[63 \mathrm{~b}, 126]}$ but the technique can be also used to elucidate the nature of postulated intermediate species and possible dissolution products. New setups provide improved time resolution without any loss in the measurement sensitivity. ${ }^{[127]}$ Experiments tracing the isotope of interest (e.g., oxygen, deuterium or iridium) can identify whether the catalyst itself is participating in the reaction. For example, this isotope approach has been shown in combination with DEMS/OLEMS and also Raman spectroscopy. [31a, 43a, 128] 

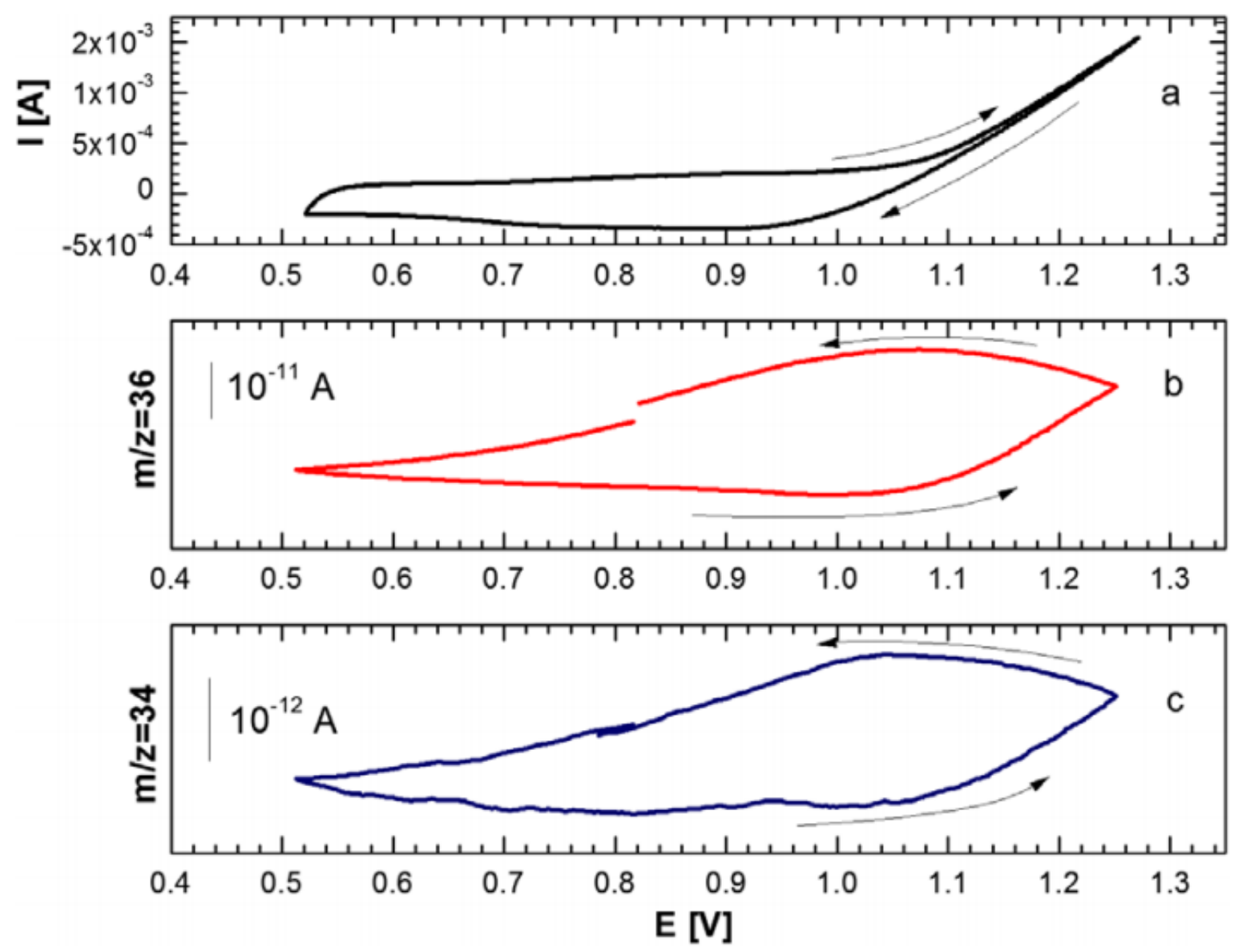

Fig. 19: DEMS signals of an $\mathrm{O}^{18}$ labelled, cycled RuNiOx electrode; a) $\mathrm{CV}$ b) $\mathrm{O}^{18}$-O ${ }^{18}$ mass signal c) $\mathrm{O}^{18}$-O $^{16}$ signal $^{[129]}$; reprinted with permission from Elsevier

Fig. 19 shows the DEMS measurement of an $\mathrm{O}^{18}$ labelled $\mathrm{RuNiO}_{\mathrm{x}}$ electrode. The top graph a) shows the $\mathrm{CV}$ measured during the DEMS test while b) and c) show the corresponding ion currents for $\mathrm{O}_{2}$ formed by two $\mathrm{O}^{18}$ atoms or $\mathrm{O}^{18}+\mathrm{O}^{16}$, respectively. With $\mathrm{O}^{18}$ being only available in the catalyst, lattice oxygen participation in the OER mechanism on this catalyst material can be assumed if after quantification more $\mathrm{O}^{18}$ evolved than would be available on the catalyst surface. A loss of faradaic efficiency of carbon supported OER catalysts above $1.5 \mathrm{~V}_{\mathrm{RHE}}$ could be attributed to accompanying carbon corrosion by an increase in $\mathrm{CO} 2$ mass signal $(\mathrm{m} / \mathrm{z}=44)$ during DEMS measurements. ${ }^{[74]}$

\section{Raman and Infrared-Spectroscopy}

Raman scattering and Fourier-transformed infrared spectroscopy (FTIR) have also been employed in insitu electrochemical studies because they provide mechanistic information and can elucidate the nature of the intermediates. Both techniques have proven to be powerful in observing surface species for different electrocatalytic processes. ${ }^{[130]}$ Reier et al., for instance, relate the diminishing Raman signal intensity of iridium dioxide in concurrence with emerging peaks of $\mathrm{TiO}_{2}$ from the titanium substrate to loss of $\mathrm{IrO}_{2}$ by forming a mixed phase of Ti-Ir-oxide. ${ }^{[81]}$ 


\section{iii. Full PEM-Cell in-situ Techniques}

The techniques mentioned in section 5.b.ii provide important insight into the mechanism and dissolution products of the OER, but are mainly limited to model systems in solution-based electrochemical cells and not actual PEM electrolyzers. Electrochemical techniques mentioned in section 5.b.i can be applied to full PEM cell tests by using the cathode as quasi-reference electrode or by employing a separate reference electrode and a number of methods have been developed to investigate the real catalyst state.

Brightman et al. report the use of a reference electrode similarly to a Luggin capillary allowing them to detect anode/cathode contributions separately. ${ }^{[131]}$ The two-phase flow of water and oxygen bubbles was investigated by several groups, including Selamet et al., by optical and neutron imaging in PEM electrolyzers. ${ }^{[132]}$ The main outcome of Selamet et al.'s studies is the need for sufficient water flow of at least $\xi>3$, where $\xi$ is the ratio of $\mathrm{H}_{2} \mathrm{O}$ mass flow in versus $\mathrm{H}_{2} \mathrm{O}$ removed in eqn. (6) with $\dot{m}_{\text {in }}=$ incoming, $\dot{m}_{c o n}=$ consumed and $\dot{m}_{e o}=\mathrm{H}_{2} \mathrm{O}$ lost to the cathode side by electro-osmotic drag.

$$
\xi=\frac{\dot{m}_{\text {in }}}{\dot{m}_{\text {con }}+\dot{m}_{e o}}(6)
$$

In other words, the supplied amount of water has to be much higher than the amount consumed. If $\xi \leq 3$, water starvation effects like uneven current distribution and slowed bubble flow, as well as membrane dehydration, start to occur. High currents promote slug over bubble flow and bigger bubbles tend to stick in the flow field pores or porous transport layer (PTL). Similar observations were also made by Tanaka et al. with X-Ray imaging of the bubble formation. ${ }^{[133]}$ Mat et al. found that the bubble generation was not linearly related to the current as a higher surface fraction will be blocked at higher currents and will therefore not be available to the gas evolution reaction. ${ }^{[134]}$ In order to tackle these bubble formation/transport problems, a flow field design similar to a cross-flow heat exchanger concept was developed by these authors. This completely suppressed slug flow in the investigated water flow range $\left(26-1137 \mathrm{~cm}^{3} \mathrm{~min}^{-1}\right)$ and thus could minimize current deviations caused by surface blockage. ${ }^{[135]}$

Studying dissolution at high current densities in PEM-electrolyzers, complementary to SFC-ICP-MS measurements discussed in section 5.b.ii., could provide additional insight with respect to static dissolution at high current densities $\left(100-2,000 \mathrm{~mA} \mathrm{~cm} \mathrm{~cm}^{-2}\right.$. To perform a similar test in single-cell electrolyzer tests, the hardware must be modified with a leak-proof sampling port at the anode outlet to connect an ICP-MS. Because of the increased volume, the dead time will increase drastically, and realtime observation of dissolution will not be possible. Since equilibration has to be achieved for each potential, a low sampling rate, e.g., extraction of samples every $30 \mathrm{~min}$, seems reasonable, but has to be confirmed experimentally.

iv. Synchrotron-based in-situ Techniques

Recent specialized experimental setups allow the selective in-situ investigation of catalyst properties using very high energy $(\sim \mathrm{GeV})$ radiation sources. In these studies, a full PEM- electrolyzer setup is not an ideal test apparatus because of the large number of components and the overall complexity involved. 
A reported PEM fuel cell setup for use in in-situ EXAFS may be applicable to PEM electrolysis if the necessary water film for operation can be kept sufficiently thin $(\leq 1 \mu \mathrm{m})$ to avoid total absorption of the beams. $^{[136]}$ Synchrotron-based in-situ variations of X-Ray Absorption Spectroscopy (XAS) such as Extended X-Ray Absorption Fine Structure (EXAFS) and X-Ray Absorption Near-Edge Spectroscopy (XANES) as well as X-Ray Photoelectron Spectroscopy (XPS) can help in identifying changes in the catalyst structure as well as surface species during and after catalysis. XAS is suitable to investigate illdefined and amorphous materials because it does not depend on the presence of long range order and as such is an ideal local probe for many of the OER catalysts whose active state(s) appear to be quite amorphous in structure.

\section{EXAFS and XANES}

A recent report on the catalytically active state of Co oxide for OER uses extensive synchrotron analysis to elucidate reversible structural changes during the oxygen evolution reaction. ${ }^{\text {[94a] }}$ Quasi-in-situ EXAFS and XANES together with pre-/post-catalysis XPS allowed Bergmann et al. to deduct a reversible amorphization of the catalyst surface upon reaching OER potentials $(\sim 1.62 \mathrm{~V}$ RHE $)$ that is accompanied by an increase in mean oxidation state and octahedrally coordinated di- $\mu$-oxo bridged motifs. ${ }^{[94 a]}$ The energy of the selected element edge in the XANES spectra can be used to calculate the mean oxidation states. ${ }^{[137]}$ For the cobalt oxide catalyst, Bergmann et al. have reported an oxidation state between $+2 /+3$ in the as-prepared state and up to $3+/ 4+$ with increasing potential (up to $1.62 \mathrm{~V}_{\mathrm{RHE}}$ ). Comparing simulations with the Fourier-transformed EXAFS spectra allows deduction of the local atomic structure of the investigated element.

Two other specialized techniques include AXAFS and $\Delta \mu$ XANES which are described in detail in a recent review. ${ }^{[137]}$ AXAFS or Atomic X-Ray Absorption Fine-Structure analyzes scattering of the outgoing photoelectron by the absorber (and emitter) atom and its localized valence electrons. AXAFS signals can be fitted to give information on the number of bonds, shift of electron binding energies. The signal shape and intensity also depend on metal-support interactions and thus give valuable information for stability investigations. AXAFS has not been widely applied due to its delicate analysis, but its ability in offering new insight in the topic of catalyst stability should not be underestimated.

$\Delta \mu$ XANES, on the other hand, adds surface sensitivity to XANES analysis. ${ }^{[138]}$ However, its application in OER is limited. The technique is limited to small particles/crystallites $\left(\leq 8 \mathrm{~nm}^{[138]}\right)$ and is based on the assumption that the particles are metallic and do not change in shape and crystallinity during catalysis. New theoretical models that extend $\Delta \mu$ XANES to oxidized particles would need to be developed in order to apply this technique to the OER.

\section{XPS}

X-Ray Photoelectron Spectroscopy has been widely applied in the studies of the (surface) composition and appearance of surface species in the pre- and post-analysis of electrocatalysts. Even though its interpretation is not facile at all, it is an important technique for in-depth characterization. ${ }^{\text {[23b, 50a, 59a] }}$ Possible changes in the catalyst by UHV conditions should always be taken into account when analyzing XPS data. Only in recent years, with the development of near-ambient pressure XPS (NAP-XPS) in 
operando XPS became possible. ${ }^{[139]}$ Typical test cells employ a catalyst coated membrane serving as the working electrode exposed to the XPS chamber with an electrolyte reservoir at the counter electrode. Water supply to the working electrode is established by permeation through the membrane between the electrodes due to the pressure gradient. ${ }^{[139]}$ Other setups measure the catalyst backside through a thin $\mathrm{Si}_{3} \mathrm{~N}_{4}$ window, requiring the catalyst layer to be extremely thin. ${ }^{[140]}$

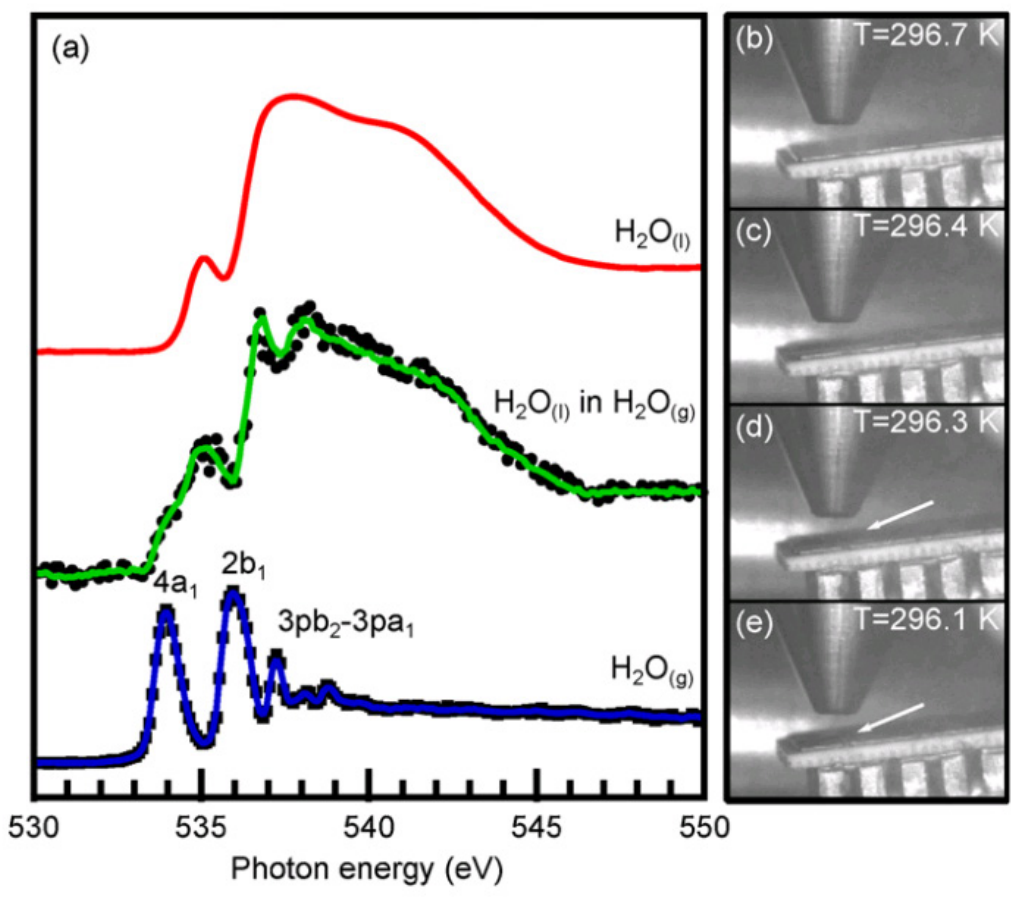

Fig. 20: a) in-operando NAP-XPS spectra of water between $\mathrm{Si}_{3} \mathrm{~N}_{4}$ windows and condensed on gold and b-e) photographic evidence of water droplet formation ${ }^{[139 b]}$; reprinted with permission from Elsevier

A small number of research groups have published NAP-XPS results for PEM electrolysis. ${ }^{[45,141]}$ XPS studies of OER require a fine balance between the applied pressure and liquid water film to result in adequate signal quality. It has been argued that low oxygen pressure limits the chemical potential of oxygen; thereby hindering the oxide layer growth. Inhibiting fast oxidation reaction allows analysis of the early onset of oxidation and corrosion reactions. A study by Arrigo et al. provided evidence for different oxide species on platinum during the electrolysis of water. ${ }^{[139 a]}$ Another study supports the theory of two distinct Ir surface oxides (dry, thin vs. "gel-like", thicker) depending on the applied potentials. ${ }^{[45]}$ Ogasawara and others observed the formation of $\mathrm{OH}$ species in the $\mathrm{O} 1 \mathrm{~s}$ spectrum of $\mathrm{IrO}_{2}$ upon

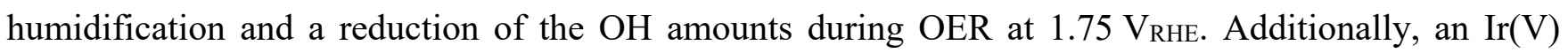
species was detected in the Ir $4 \mathrm{f}$ spectrum during OER that is confined to the catalyst surface as spectra collected with higher incident energies (probing deeper catalyst layers) do not show the $\operatorname{Ir}(\mathrm{V})$ state. ${ }^{[141]}$ The latter finding supports the corrosion mechanism suggested by Cherevko et al. ${ }^{[44]}$ Another finding was the increase of $\mu 2$-oxo-bridge motifs in active Ir catalysts. ${ }^{[142]}$ Stabilization of these motifs should help to maintain an active catalyst.

v. Importance of in-situ Techniques 
In-situ techniques are vital in providing insight into the OER catalyst degradation mechanism(s). In order to understand corrosion, the in-situ ICP-MS techniques in conjunction with DEMS or NAP-XPS are stateof-the-art and provide unprecedented insight into reaction mechanism by correlating reaction products or intermediates with the electrochemical potential. These insights allow building of new catalyst protocols that can be used to either exacerbate dissolution in an ALT in order to understand their degradation mechanisms or minimize it for real applications. AXAFS, XPS and other related techniques can be used to monitor changes in the active state as well as catalyst support interactions and deduce reaction intermediates.

\section{A Comprehensive New Generalized Test Protocol of OER Catalyst Stability}

In this section, we derive a new comprehensive degradation and stability test protocol that should make stability data more standardized and comparable between laboratories and catalysts. The electrochemical stability test protocols are generally designed differently for full electrolyzer cell tests than for idealized model tests, such as RDE or stationary flat-plate measurements in three-electrode setups. Ideally, the same type of electrochemical stability test protocol could be used for both full electrolyzer cells and idealized classical electrochemical cells. The protocol proposed by McCrory et al. is used as a starting point and is shown in Fig. 21. ${ }^{[2]}$ Measuring the elemental composition on the pristine electrode by XPS is an excellent method but not available to every lab. Ex-situ characterization by more commonly available methods such as ICP-OES, XRF and EDX are also possible (see 5.a). Based on our current state of understanding of OER catalyst degradation, especially based on insight from transient dissolution, we suggest the test protocol illustrated in Fig. 22. In order to remove the influence of massive transient dissolution by potential cycling on the initial catalyst activity, it is suggested to begin with an activity measurement. This is done by two quasi-stationary $\left(5 \mathrm{mV} \mathrm{s}^{-1}\right)$ potential cycles between $1.23 \mathrm{~V}$ RHE to a potential where a current density of $20 \mathrm{~mA} \mathrm{~cm}^{-2}$ is reached. Next, surface area and redox features are assessed by $\mathrm{CV}$ in suitable potential limits for the investigated catalyst and EIS, followed by measuring the catalytic activity with quasi-stationary scans and chronopotentiometry steps. Subsequently, initial steady-state stability can be measured in a galvanostatic measurement at $20 \mathrm{~mA} \mathrm{~cm}$. The test is concluded with a second set of surface analysis and activity test to monitor changes after the stability run. The protocol should be conducted at $80{ }^{\circ} \mathrm{C}$ and with $1600 \mathrm{rpm}$ in $0.05 \mathrm{M} \mathrm{H}_{2} \mathrm{SO}_{4}$ if done in an RDE setup. For PEM-cell tests a flow ratio of $\xi>3$ should be maintained. 


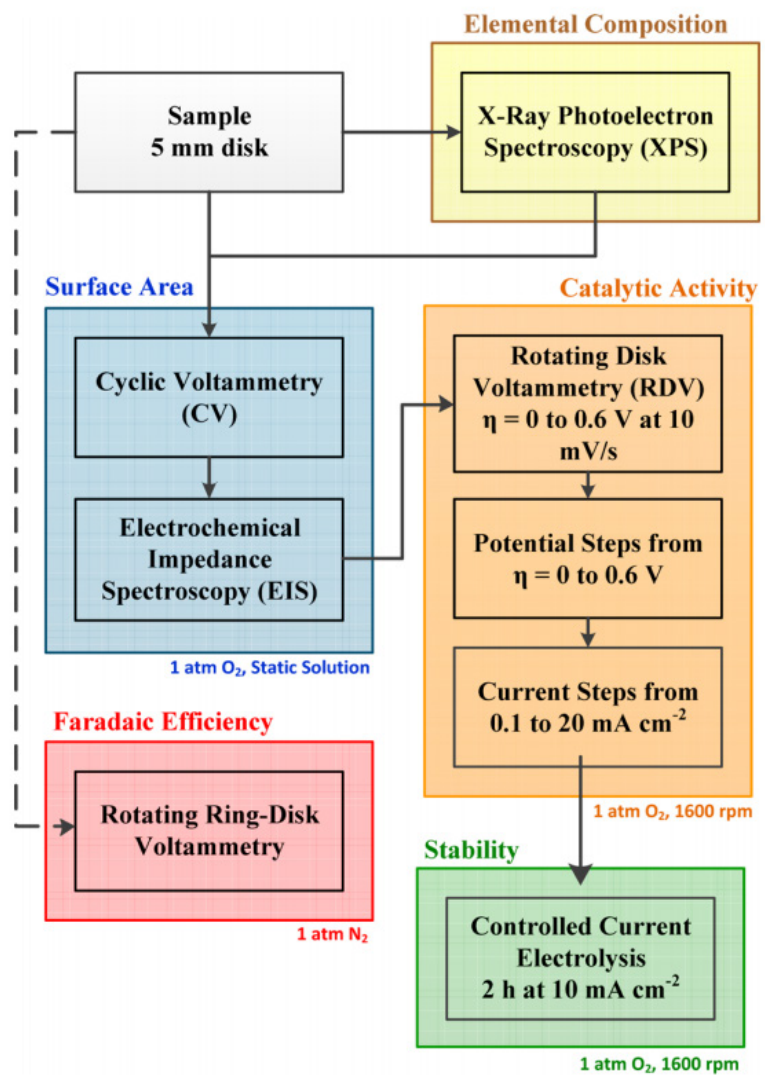

Fig. 21: Proposed protocol by McCrory et al. ${ }^{[22]}$; reprinted with permission from ACS

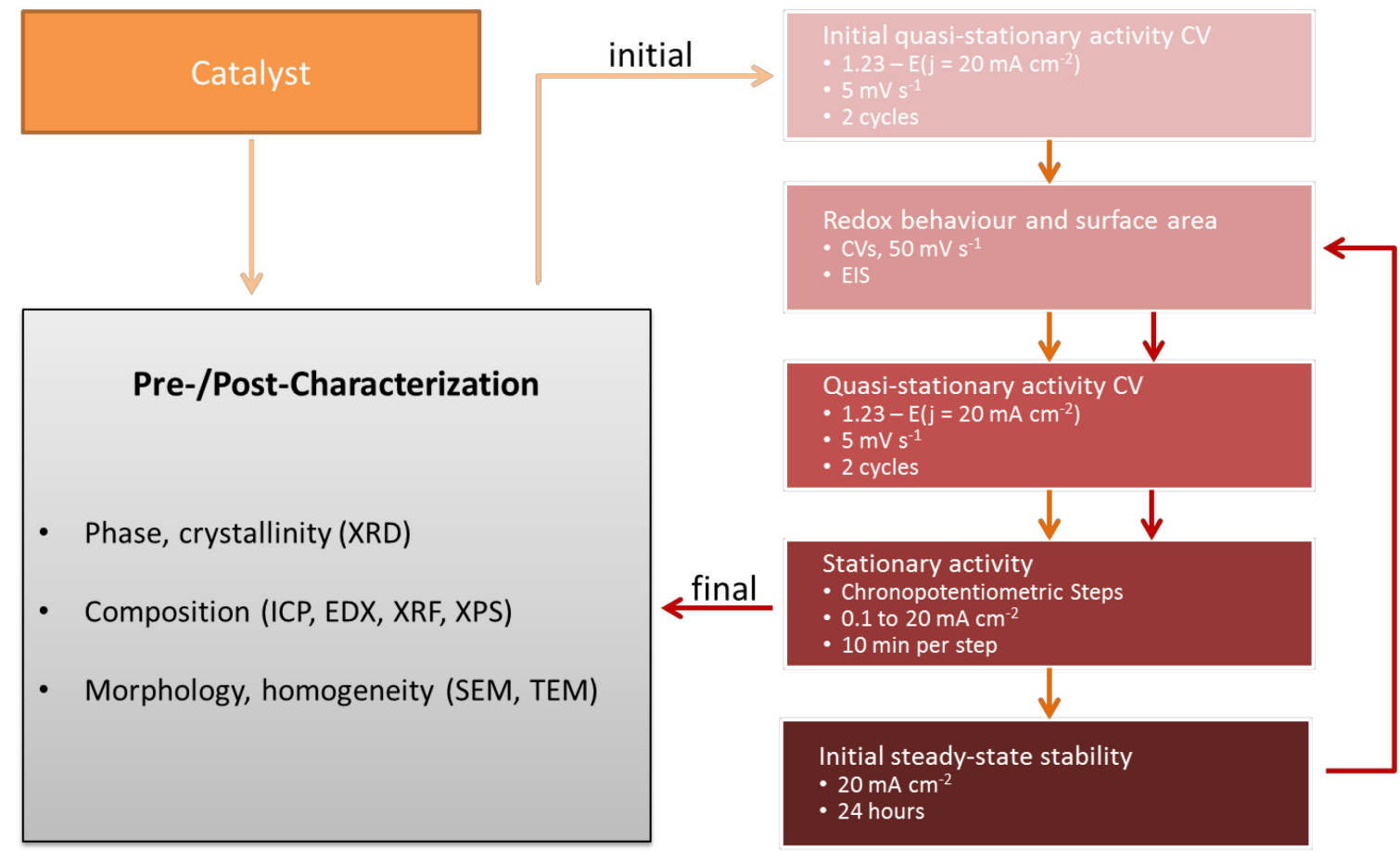

Fig. 22: Proposed model-catalyst protocol, $\mathrm{T}=80^{\circ} \mathrm{C}, 0.05 \mathrm{M} \mathrm{H}_{2} \mathrm{SO}_{4}, 1600 \mathrm{rpm}$ in $\mathrm{RDE}, \xi>3$ in PEM-cell; based on the protocol proposed by McCrory et. al ${ }^{[22]}$ 
Our protocol can now be adapted for full PEM cell tests. Activity is probed by polarization curves while a stability test consisting of one of the two galvanostatic tests proposed in Table 4 is added. For the first set of test protocols, the intent is to pre-screen the catalysts and keep the comparability to already published results at $1 \mathrm{~A} \mathrm{~cm}^{-2}$. The second set of tests ensures that promising catalysts are suitable for long-term performance and more detailed studies at the DOE target of $2 \mathrm{~A} \mathrm{~cm}^{-2}$.

Table 4: Proposed catalyst galvanostatic stability evaluation parameters

\begin{tabular}{|c|c|c|c|c|}
\hline Nature of Test & Mode & $\begin{array}{l}\text { Temperature / } \\
{ }^{\circ} \mathrm{C}\end{array}$ & $\begin{array}{l}\text { Current Density / } \\
\text { mA cm-2 }\end{array}$ & Time / hours \\
\hline Pre-Screening & Galvanostatic & 80 & 1000 & 24 \\
\hline Full Study & Galvanostatic & 80 & 2000 & 100 \\
\hline
\end{tabular}

The stability test runtime must be commensurate to typical commercial electrolyzer stack performance lifetimes. A lifetime of 20,000-50,000 hours has been proposed as necessary for the state-of-the-art PEM electrolyzer stacks by Smolinka et al. and Ayers et al. ${ }^{[13 c, 143]}$ These numbers emphasize the need for an accelerated lifetime test (ALT) that can be performed in a much shorter amount of time while still being representative of the catalyst degradation. The benefits of repetitive CV cycling are shown in Fig. 16 and well known from PEM fuel cell catalyst testing reports. ${ }^{[144]}$ Increased dissolution during transient operation, as shown by SFC-ICP-MS, makes extensive cycling numbering in the thousands of cycles at $500 \mathrm{mV} \mathrm{s}^{-1}$ a plausible technique to provide degradation data similar to prolonged static operation. Alternatively, it has also been shown that a combined duty-cycle protocol, consisting of constant operation in consecutive, potentiostatic steps followed by transient operation in slow OER-CVs and multiple repetitions of the two test modes serves as an ALT. ${ }^{[37]}$ These two methods can be combined into one by the use of square wave voltammetry. Assuming a CV cycling protocol, the extent of catalyst dissolution (in $\mathrm{ng} \mathrm{s}^{-1}$ ) can be precisely defined. The amount of dissolved iridium during galvanostatic operation and the corresponding cycle number for dissolving the same amount of iridium during transient operation ( $\left.0.05-1.4 \mathrm{~V}_{\mathrm{RHE}} ; 500 \mathrm{mV} \mathrm{s}^{-1}\right)$ was calculated based on the numbers presented by Cherevko et al. ${ }^{[44]}$ The results are presented in Fig. 23 for different electrolyzer runtimes. The calculations are presented in the supporting information. Clearly, the advantage of an ALT is shown since in less than 24 hours of potential cycling the iridium dissolution of 5,000 hours of galvanostatic operation can be met. The experimental runtime can be decreased substantially by using the suggested ALT. However, simulating plant runtimes of 20,000 or 50,000 hours will still take a lot of time and should be reserved for specific cases close to commercialization. 


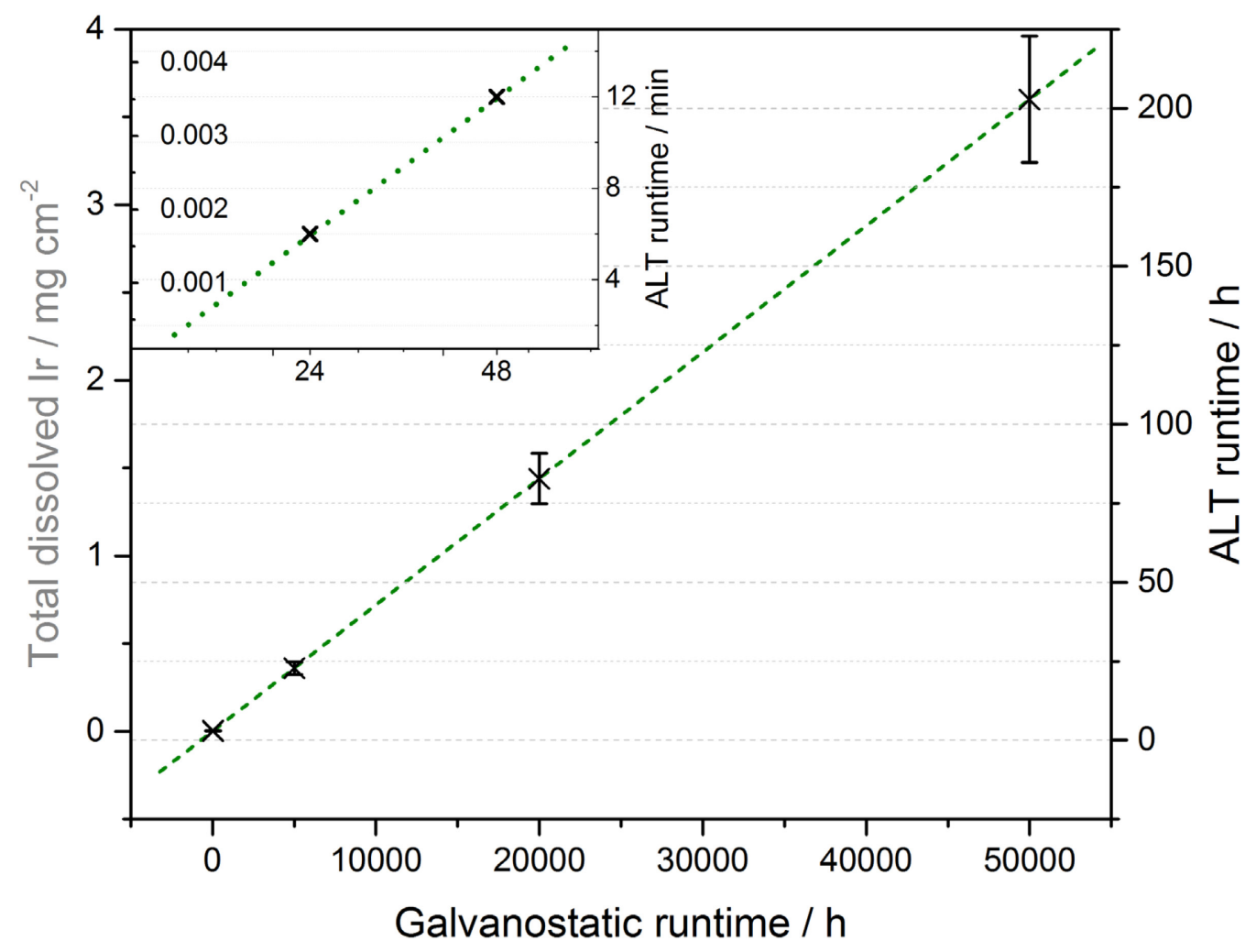

Fig. 23: Comparative runtimes of galvanostatic and potentiodynamic operation based on reaching similar dissolution levels. Dissolution values are extrapolated from measurements by Cherevko et al. at room temperature in $\mathrm{O.1}_{\mathbf{1}} \mathrm{M} \mathrm{H}_{2} \mathrm{SO}_{4}$. Inset shows an enlarged section for galvanostatic runtimes of 24 and $48 \mathrm{~h}$.

Similar to the suggested protocol in Fig. 22, the ALT (shown in Fig. 24) should start with a polarization curve to measure initial activity before damaging the catalyst any further. Surface area and redox features are measured with CVs and EIS before the accelerated testing is conducted. Based on the calculations above, cycling between 0.04 and $1.4 \mathrm{~V}_{\mathrm{RHE}}$ at $500 \mathrm{mV} \mathrm{s}^{-1}$ for 15,000 cycles is suggested. Alternatively, square-wave cycling in the same potential limits with a $3 \mathrm{~s}$ hold period per potential step is suggested for 14,000 cycles (where one cycle has a period of $6 \mathrm{~s}$ ). The latter has been shown to exhibit the most pronounced dissolution rate for the thermally oxidized $\mathrm{IrO}_{2}$ films by the same authors. ${ }^{[95 \mathrm{a}]}$ Because of missing data points, a similar calibration plot as for CV data in Fig. 23 could not be compiled. Thus, the actual extent of dissolution by square-wave cycling is yet to be determined. The protocol is completed with a second set of surface area characterization, followed by a polarization curve. The potential limits of the ALT cycling are based on findings of Cherevko et al. ${ }^{[4]}$ Maximized dissolution for these two limiting potentials is shown by the authors. This ALT is suitable for testing full PEM electrolyzer cells as well as model systems in classical electrochemical three-electrode cells. 

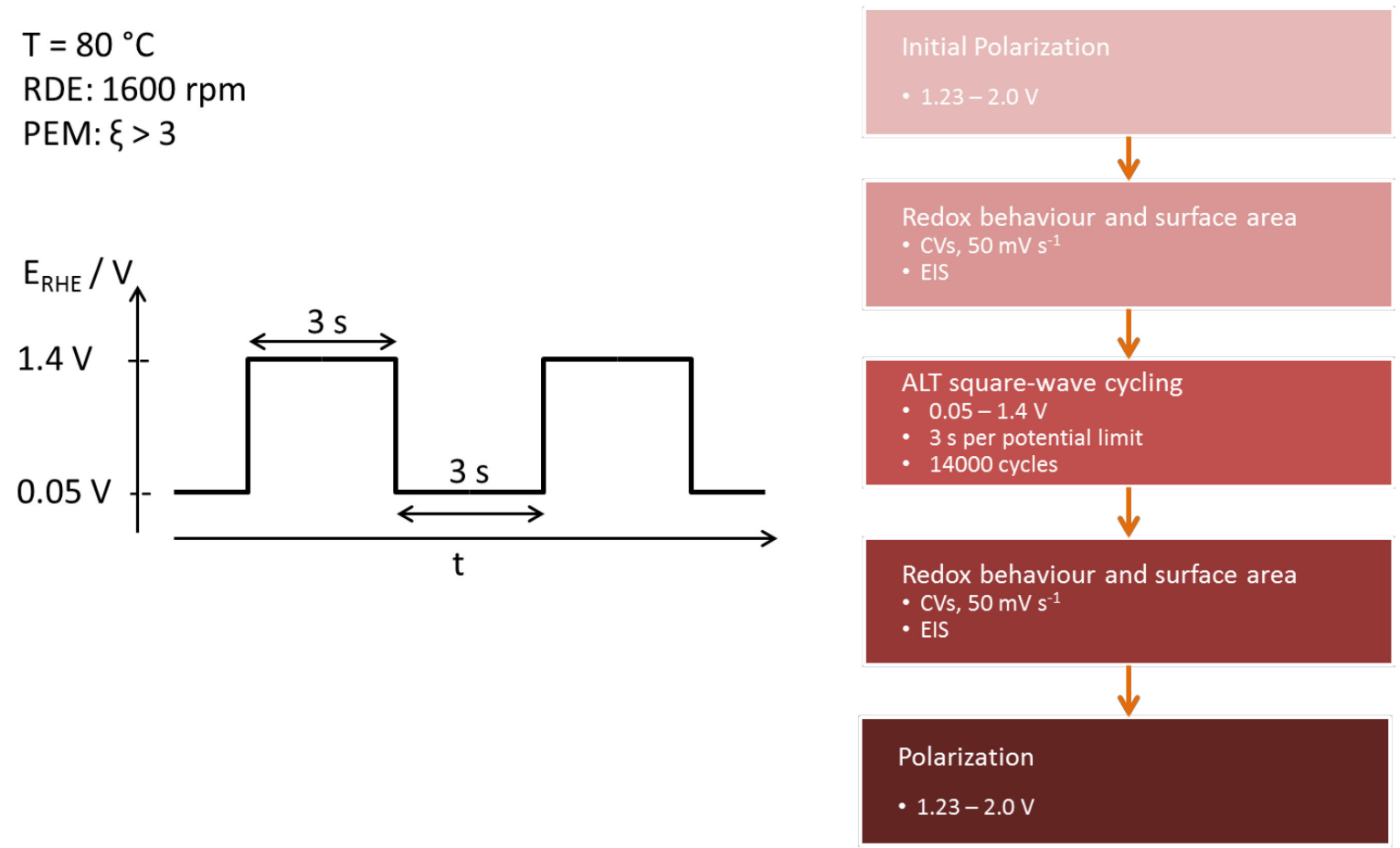

Fig. 24: Proposed ALT protocol for accelerated stability testing, designed for both - three-electrode and single cell electrolyzer setups; ALT square-wave cycling is explained in the left part.

Further research focused on static dissolution during operation at higher current densities $\left(1-2 \mathrm{~A} \mathrm{~cm}^{-2}\right)$ as suggested in section 5.b. is necessary to provide insight on the actual dissolution. Irrespective of the results, the observed relation of higher dissolution during transient operation than in static operation should hold true. Therefore, the suggested ALT cycling should provide the expected enhanced dissolution, even though the absolute numbers might change. For oxides containing no or low contents of iridium the dissolution behavior may change and the ALT in itself should not necessarily be considered as sufficient test of stability. Combined with pre- and post-ALT characterization or in-situ analysis other influences on degradation such as particle sintering or detachment can be identified and investigated further. Furthermore, addition of controlled amounts of impurities or changing the temperature these influences can be studied as well. In full PEM-cell tests monitoring the fluorine release rate (FRR) of Nafion-based cells can give additional information on the membrane degradation. ${ }^{[145]}$ F-release from the membrane may also attack Ti-based supports as mentioned earlier.

In order to support understanding and enhance comparability of results, OER activities and stability should be reported in standardized values. We suggest normalizing the current to the total active metal mass or molar loading of active material in the catalyst. Until a true active area measurement can be established, this seems to be the most realistic and convenient methods allowing comparison of OER results in the literature and between different laboratories. Electrode potentials should be reported as iRcorrected voltage against RHE which allows consistent and easy comparison of results. The latter is an often overlooked source of errors. We propose to report activity at $1.5 \mathrm{~V}_{\mathrm{RHE}}(270 \mathrm{mV}$ overpotential $)$ and at $10 \mathrm{~A} \mathrm{~g}^{-1}$, as suggested earlier by Fabbri et al. ${ }^{[13 \mathrm{a}]}$ The former potential, which corresponds to the DOE 
goals $^{[13 \mathrm{c}]}$, is well above the OER onset of promising catalysts, and furthermore currents are moderate, ruling out any mass transport/bubble blockage problems masking the actual activity. For full cell PEM electrolyzer tests the activity should be additionally reported at $2 \mathrm{~A} \mathrm{~cm}^{-2}$ to highlight possible shortcomings with respect to the DOE goal of reaching this current density at 1.5 VRHE. Because of the apparent differences in three-electrode setups and full PEM cells, the latter is not suitable for model catalyst measurements done in an RDE or similar setups. Tests should be conducted in $0.05 \mathrm{M} \mathrm{H}_{2} \mathrm{SO}_{4}$ at $80{ }^{\circ} \mathrm{C}$ or, if not possible, at room temperature (mainly in RDE or for ease of operation). The former corresponds to the operating temperature of commercial PEM water electrolyzers. Stability should be reported by three figures of merit: i) the change in activity after a preliminary stability run $(\Delta \mathrm{j}$ at $\eta=270$ $\mathrm{mV})$ ii) the potential degradation during galvanostatic operation $\left(\Delta \eta / \mathrm{mV} \mathrm{h}^{-1}\right)$, and iii) the runtime of either galvanostatic operation or ALT cycling ( $\mathrm{t} / \mathrm{h}$ or $\#$ of cycles until catalyst failure). If possible a dissolution value (even if obtained ex-situ) should be given. We define initial signs of catalyst instability as a $50 \%$ increase in overpotential during galvanostatic operation or by the complete disappearance of redox features in the ALT cycling. If the FRR is measured, the DOE end-of-life (EOL) criteria for $10 \%$ total fluoride loss can be applied to full PEM-cell tests using Nafion membranes. ${ }^{[145]}$

A detailed discussion of possible sources of errors (random and systematic) is beyond the scope of this paper. However, statistical significance of the data based on an appropriate number of measurements and samples, is vital to ensure repeatability of results obtained in a given laboratory. For further confidence, reproducibility tests (i.e., performing similar measurements but in a different laboratory) and testing of protocols between a number of labs should be performed. Industry associations such as the US Fuel Cell Council have found this approach important for standardization and commercialization of the technology.

\section{Conclusions}

a. Suggested Physical and Electrochemical Characterization Protocol

A literature review was conducted to survey the most common test conditions used to evaluate catalyst stability in single-cell electrolyzer test stations. It was found that a 24-hour test with a cell temperature of $80{ }^{\circ} \mathrm{C}$, a current density of $1-2 \mathrm{~A} \mathrm{~cm}^{-2}$ while operating in galvanostatic mode were the most common parameters used. The choice of these parameters were rationalized based on mimicking commercial electrolyzer conditions while respecting the material (i.e., membrane dehydration) and test station limits. As such, these exact parameters were listed as the suggested pre-screening protocol for catalyst stability. Fig. 25 summarizes possible influences on catalyst stability discussed in the previous sections. Two main categories (dark red) govern the catalyst stability (blue) pictured on top. Material stability covers properties affecting stability independent of test conditions distinguished between supported and bulk materials whereas operational stability is made up of processes affecting catalyst stability during an electrochemical test. Below these subcategories (dark red) the phenomena affecting the corresponding categories are listed in purple. 


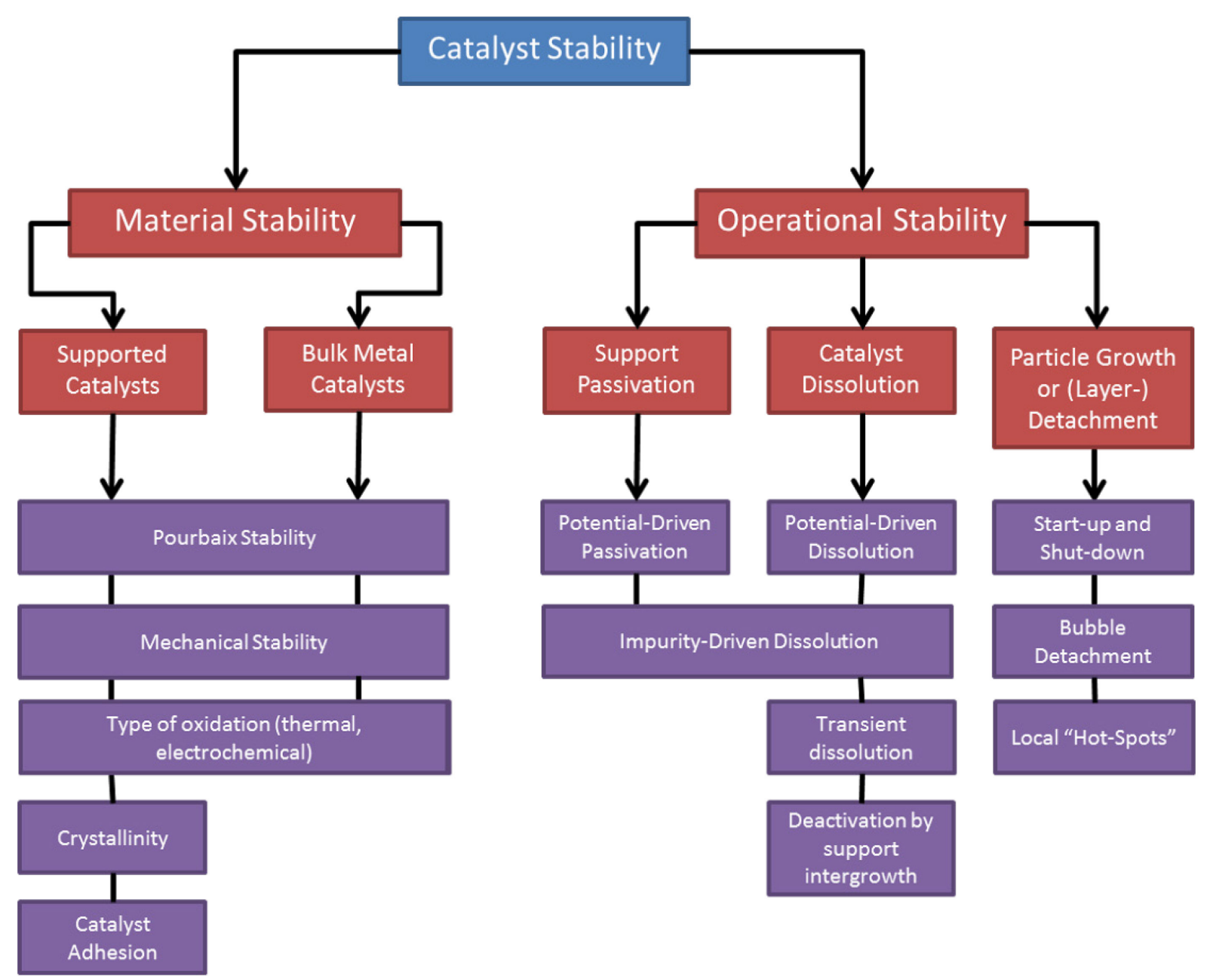

Fig. 25: Influences on catalyst stability as discussed in the previous sections; arrows indicate sublevels; lines connect equal levels

Commercial stack requirements for runtime are within the 20,000-50,000 hour range. A repetitive CV protocol was designed to mimic similar PEM electrolyzer degradation effects observed by in-situ ICPMS measurement. This protocol should be representative of commercial lifetimes while significantly reducing the test duration. Together with the previously developed pre-screening protocol, a more extensive ALT test protocol as shown previously in Fig. 24 is suggested as a stability benchmark for OER catalysts in PEM electrolysis. The suggested protocol is based on stability data for iridium oxide which is the most common catalyst or catalyst base material for acidic PEM electrolyzers to date.

Physical characterization is a crucial part of understanding catalyst stability but specific characterization tools might not be available to every lab. While research focusing on elucidating the corrosion mechanism is dependent on the techniques introduced in section 5.b., a general physical characterization based on techniques available to most labs is suggested.

A thorough identification of catalysts should be done by at least investigating phase and crystallinity (XRD), composition (ICP, EDX, XRF or XPS) and homogeneity (SEM/TEM). One of the technologies mentioned for each property should be available to most labs or at least at every institute and thus allow 
a comparative characterization of catalysts. Pre- and post-characterization is an initial insight to catalyst degradation, and will build the knowledge-base (if reported) for all new electrolyzer catalyst materials. Fundamental understanding of the degradation reaction mechanism may be possible by combining these insights with in-situ investigations in the future. Standardized figures of merit for reporting catalyst activity and stability are suggested.

b. Scope and Application

The goal of this review was to highlight the importance and the limited current state of understanding of OER catalyst stability. We also addressed the lack of standardization for both performing and reporting catalyst stability analysis today, which makes it difficult to compare results generated from different laboratories in a meaningful way. The extensive ALT protocol coupled with the suggested physical characterization techniques is an attempt to provide a standard method, similar to the standard figures of merit that exist for the ORR. The implications of this work include advancing fundamental insight and understanding of the OER and its degradation mechanisms while providing guidance on conducting experiments efficiently without being too financially or resource demanding. Achieving OER catalyst stability measurement standards moves us towards improved information exchange, more reliable results, and overall growth in the field of water electrolysis. 


\section{Associated Content}

Supporting Information available: This material is available free of charge via the Internet at [insert link here]

\section{Conflict of Interest Disclosure}

The authors declare no competing financial interest.

\section{Acknowledgements}

Financial support by the German Research Foundation (DFG) through grant STR 596/3-1 under the Priority Program 1613 "Regeneratively formed fuels by water splitting" is gratefully acknowledged. This publication has been developed as a result of a mobility stay at UBC funded by the Erasmus Mundus Programme of the European Commission under the Transatlantic Partnership for Excellence in Engineering - TEE Project. The UBC authors gratefully acknowledge support from the Natural Sciences and Engineering Research Council of Canada (NSERC).

Keywords: oxygen evolution reaction $(\mathrm{OER}) \cdot$ electrolyzer $\bullet$ iridium $\bullet$ ruthenium $\bullet$ catalyst dissolution $\bullet$ proton exchange membrane $(P E M) \cdot$ accelerated life testing $(A L T)$

\section{References}

[1] B. R. Singh, O. Singh, in Fossil Fuel and the Environment (Ed.: S. Khan), InTech, 2012, p. 316.

[2] R. K. Pachauri, L. A. Meyer, (Eds.: R. K. Pachauri, L. A. Meyer), IPCC, Geneva, Switzerland, 2014, p. 151.

M. Khalid, A V. Savkin V. G. Agelidis, in 2015 IEEE Conference on Control Applications (CCA), 2015, pp. $739-743$.

T. Kousksou, P. Bruel, A. Jamil, T. El Rhafiki, Y. Zeraouli, Solar Energy Materials and Solar Cells 2014, 120, 59-80.

U. S. DOE, in Lower and Higher Heating Values of Hydrogen and Other Fuels, Vol. 2016, Hydrogen Analysis Resource Center.

U. S. DOE, in History of H2 Fact Sheet, Vol. 2016.

K. Zeng, D. Zhang, Progress in Energy and Combustion Science 2010, 36, 307-326.

J. Ivy, in Summary of electrolytic hydrogen production: milestone completion report, Revision ed., National Renewable Energy Laboratory (U.S.), Golden, CO, 2004, p. 27.

[9] a) M. Carmo, D. L. Fritz, J. Merge, D. Stolten, International Journal of Hydrogen Energy 2013, 38, 4901-4934; b) A. Manabe, M. Kashiwase, T. Hashimoto T. Hayashida, A. Kato, K. Hirao, I. Shimomura, I. Nagashima, Electrochimica Acta 2013, 100, 249-256; c) K. Mette, A. Bergmann, J. P. Tessonnier, M. Havecker, L. D. Yao, T. Ressler, R. Schlogl, P. Strasser, M. Behrens, Chemcatchem 2012, 4, 851-862.

[10] A. Ursua, L. M. Gandia, P. Sanchis, Proceedings of the IEEE 2012, 100, 410-426.

[12] T. Smolinka, M. Günther, J. Garche, in NOW-Studie: Stand und Entwicklungspotenzial der Wasserelektrolyse zur Herstellung von Wasserstoff aus regenerativen Energien, Revision 1 ed., Fraunhofer ISE, 2011, p. 53.

[13] a) E. Fabbri, A. Habereder, K. Waltar, R. Kotz, T. J. Schmidt, Catalysis Science \& Technology 2014, 4, 3800-3821; b) I. Katsounaros, S. Cherevko, A. R. Zeradjanin, K. J. J. Mayrhofer, Angewandte Chemie-International Edition 2014, 53, 102-121; c) K. E. Ayers, C. Capuano, E. B. Anderson, ECS Transactions 2012, 41, 15-22; d) M. Chandesris, V. Medeau, N. Guillet, S. Chelghoum, D. Thoby, F. Fouda-Onana, International Journal of Hydrogen Energy 2015, 40, 1353-1366.

[14] a) V. A. Alves, L. A. Dasilva, J. F. C. Boodts, S. Trasatti, Electrochimica Acta 1994, 39, 1585-1589; b) S. H. Chang, J. G. Connell, N. Danilovic, R. Subbaraman, K. C. Chang, V. R. Stamenkovic, N. M. Markovic, Faraday Discussions 2014, 176, 125-133; c) L. M. Da Silva, D. V. Franco, L. A. De Faria, J. F. C. Boodts, Electrochimica Acta 2004, 49, 3977-3988; d) H. Dau, C. Limberg, T. Reier, M. Risch, S. Roggan, P. Strasser, Chemcatchem 2010, 2, 724-761.

[15] J. Rossmeisl, P. Ferrin, G. A. Tritsaris, A. U. Nilekar, S. Koh, S. E. Bae, S. R. Brankovic, P. Strasser, M. Mavrikakis, Energy \& Environmental Science 2012, 5, 8335-8342.

[16] R. Hutchings, K. Muller, Kotz, S. Stucki, Journal of Materials Science 1984, 19, 3987-3994.

[17] L. Bertuccioli, A. Chan, D. Hart, F. Lehner, B. Madden, E. Standen, in Study on development of water electrolysis in the EU, Final Report ed. (Ed.: L. Bertuccioli), Fuel Cell and Hydrogen Joint Undertaking, Switzerland, 2014, p. 160

P. C. K. Vesborg, T. F. Jaramillo, Rsc Advances 2012, 2, 7933-7947.

K. E. Ayers, J. N. Renner, N. Danilovic, J. X. Wang, Y. Zhang, R. Maric, H. Yu, Catalysis Today 2016, 262, $121-132$.

a) M. H. Miles, E. A. Klaus, B. P. Gunn, J. R. Locker, W. E. Serafin, S. Srinivasan, Electrochimica Acta 1978, 23, 521-526; b) T. Reier, H. N. Nong, D. Teschner, R. Schlögl, P. Strasser, Advanced Energy Materials 2016, 1601275.

[21] a) A. J. Atanacio, Y. Ikuma, Journal of the American Ceramic Society 2016, 99, 1512-1519; b) C. Comninellis, G. P. Vercesi, Journal of Applied Electrochemistry 1991, 21, 136-142; c) C. Das, P. Roy, M. Yang, H. Jha, P. Schmuki, Nanoscale 2011, 3, 3094-3096; d) A. Hagemeyer, Z. Hogan, M. Schlichter, B. Smaka, G. Streukens, H. Turner, A. Volpe, H. Weinberg, K. Yaccato, Applied Catalysis a-General 2007, 317, 139-148; e) W. Hu, S. L. Chen, Q. H. Xia, International Journal of Hydrogen Energy 2014, 39, 6967-6976.

[22] C. C. L. McCrory, S. H. Jung, J. C. Peters, T. F. Jaramillo, Journal of the American Chemical Society 2013, 135, 16977-16987.

[23] a) R. S. Chen, A. Korotcov, Y. S. Huang, D. S. Tsai, Nanotechnology 2006, 17, R67-R87; b) H. N. Nong, L. Gan, E. Willinger, D. Teschner, P. Strasser, Chemical Science 2014, 5, 2955-2963; c) H. S. Oh, H. N. Nong, T. Reier, M. Gliech, P. Strasser, Chemical Science 2015, 6, $3321-3328$.

[24] G. Kopp, J. L. Lean, Geophysical Research Letters 2011, 38. 
S. Kocha, Y. Garsany, D. Myers, in Testing Oxygen Reduction Reaction Activity with the Rotating Disc Electrode Technique, NREL, DOE, 2013. U. S. DOE, in Fuel Cell Technologies Office Multi-Year Research, Development, and Demonstration Plan (Ed.: U. S. DOE), U.S. Department of Energy, 2015.

a) N. J. Bjerrum, in Periodic Report Summary - WELTEMP (Water Electrolysis at Elevated Temperatures), EU FP7 Programme, Denmark, 2011, p. 4; b) M. S. Thomassen, in Periodic Report Summary - NEXPEL (Next-generation PEM electrolyser for sustainable hydrogen production), EU FP7 Programme, Norway, 2012.

M. S. Thomassen, in Periodic Report Summary 2 - NOVEL (Novel materials and system designs for low cost, efficient and durable PEM electrolysers), EU FP7 Programme, 2016 W. G. Colella, B. D. James, J. M. Moton, G. Saur, T. Ramsden, in Electrolytic Hydrogen Production Workshop, Strategic Analysis Inc., NREL, Golden, CO, 2014.

[30] H. Xu, Giner Inc., Newton, MA, 2014.

a) S. Fierro, T. Nagel, H. Baltruschat, C. Comninellis, Electrochemistry Communications 2007, 9, 1969-1974; b) S. Trasatti, Electrochimica Acta 1984, $29,1503-1512$.

S. Trasatti, O. A. Petrii, Pure and Applied Chemistry 1991, 63, 711-734

S. Watzele, A. S. Bandarenka, Electroanalysis 2016, 28, 2394-2399.

[34] V. K. Puthiyapura, S. Pasupathi, S. Basu, X. Wu, H. N. Su, N. Varagunapandiyan, B. Pollet, K. Scott, International Journal of Hydrogen Energy 2013, 38, 8605-8616.

[35] a) J. Ahn, R. Holze, Journal of Applied Electrochemistry 1992, 22, 1167-1174; b) J. Chattopadhyay, R. Srivastava, P. K. Srivastava, Korean Journal of Chemical Engineering 2013, 30, 1571-1577; c) J. L. Corona-Guinto, L. Cardeno-Garcia, D. C. Martinez-Casillas, J. M. Sandoval-Pineda, P. TamayoMeza, R. Silva-Casarin, R. G. Gonzalez-Huerta, International Journal of Hydrogen Energy 2013, 38, 12667-12673; d) J. C. Cruz, V. Baglio, S. Siracusano, R. Ornelas, L. Ortiz-Frade, L. G. Arriaga, V. Antonucci, A. S. Arico, Journal of Nanoparticle Research 2011, 13, 1639-1646; e) J. C. Cruz, S. Rivas, D. Beltran, Y. Meas, R. Ornelas, G. Osorio-Monreal, L. Ortiz-Frade, J. Ledesma-Garcia, L. G. Arriaga, International Journal of Hydrogen Energy 2012, 37, 13522-13528; f) K. S. Kadakia, P. H. Jampani, O. I. Velikokhatnyi, M. K. Datta, S. K. Park, D. H. Hong, S. J. Chung, P. N. Kumta, Journal of Power Sources 2014, 269, 855-865; g) S. J. Kim, T. Sakai, H. Oda, Y. Okuyama, Y. Mizutani, J. I. Hamagami, M. Matsuka, T. Ishihara, H. Matsumoto, Journal of Solid State Electrochemistry 2012, 16, 3587-3592; h) G. F. Li, H. M. Yu, W. Song, X. Y. Wang, Y. K. Li, Z. G. Shao, B. L. Yi, International Journal of Hydrogen Energy 2012, 37, 16786-16794; i) G. F. Li, H. M. Yu, X. Y. Wang, S. C. Sun, Y. K. Li, Z. G. Shao, B. L. Yi, Physical Chemistry Chemical Physics 2013, 15, 2858-2866; j) J. Y. Lim, G. Rahman, S. Y. Chae, K. Y. Lee, C. S. Kim, O. S. Joo, International Journal of Energy Research 2014, 38, 875-883; k) G. Y. Liu, J. Y. Xu, J. M. Jiang, B. S. Peng, X. D. Wang, International Journal of Hydrogen Energy 2014, 39, 1914-1923; I) V. V. Panic, B. Z. Nikolic, Journal of the Serbian Chemical Society 2008, 73, 1083-1112; m) S. Siracusano, V. Baglio, A. Stassi, R. Ornelas, V. Antonucci, A. S. Arico, International Journal of Hydrogen Energy 2011, 36, 7822-7831; n) E. Slavcheva, I. Radev, S. Bliznakov, G. Topalov, P. Andreev, E. Budevski, Electrochimica Acta 2007, 52, 3889-3894; o) S. Song, H. Zhang, X. Ma, Z. Shao, R. T. Baker, B. Yi, International Journal of Hydrogen Energy 2008, 33, 4955-4961; p) H. N. Su, V. Linkov, B. J. Bladergroen, International Journal of Hydrogen Energy 2013, 38, 9601-9608; q) C. C. Sung, C. Y. Liu, International Journal of Hydrogen Energy 2013, 38, 10063-10067; r) X. Y. Wang, Z. G. Shao, G. F. Li, L. S. Zhang, Y. Zhao, W. T. Lu, B. L. Yi, International Journal of Hydrogen Energy 2013, 38, 9057-9064; s) G. Q. Wei, Y. X. Wang, C. D. Huang, Q. J. Gao, Z. T. Wang, L. Xu, International Journal of Hydrogen Energy 2010, 35, 3951-3957; t) H. B. Xu, Y. H. Lu, C. H. Li, J. Z. Hu, Journal of Applied Electrochemistry 2010, $40,719-727$.

[36] M. Thomassen, L. Colmenares, in First International Workshop - Durability and Degradation Issues in PEM Electrolysis Cells and its Components, Fraunhofer ISE, SINTEF, Freiburg, 2013.

[37] H. N. Nong, H. S. Oh, T. Reier, E. Willinger, M. G. Willinger, V. Petkov, D. Teschner, P. Strasser, Angewandte Chemie-International Edition 2015, 54, 2975-2979.

[38] a) G. N. Martelli, R. Ornelas, G. Faita, Electrochimica Acta 1994, 39, 1551-1558; b) T. Binninger, R. Mohamed, K. Waltar, E. Fabbri, P. Levecque, R. Kotz, T. J. Schmidt, Scientific Reports 2015, 5, 7.

[39] T. Reier, D. Teschner, T. Lunkenbein, A. Bergmann, S. Selve, R. Kraehnert, R. Schlogl, P. Strasser, Journal of the Electrochemical Society 2014, 161, F876-F882.

[40] R. Kotz, S. Stucki, D. Scherson, D. M. Kolb, Journal of Electroanalytical Chemistry 1984, 172, 211-219.

[41] M. Pourbaix, Atlas of Electrochemical Equilibria in Aqueous Solutions, Pergamon Press, Brussels, 1966.

[42] S. Cherevko, A. R. Zeradjanin, A. A. Topalov, N. Kulyk, I. Katsounaros, K. J. J. Mayrhofer, Chemcatchem 2014, 6, 2219-2223.

[43] a) J. Willsau, O. Wolter, J. Heitbaum, Journal of Electroanalytical Chemistry 1985, 195, 299-306; b) M. Wohlfahrt-Mehrens, J. Heitbaum, Journal of Electroanalytical Chemistry 1987, 237, 251-260.

[44] S. Cherevko, S. Geiger, O. Kasian, A. Mingers, K. J. J. Mayrhofer, Journal of Electroanalytical Chemistry 2016.

[45] V. Pfeifer, T. E. Jones, J. J. V. Velez, C. Massue, M. T. Greiner, R. Arrigo, D. Teschner, F. Girgsdies, M. Scherzer, J. Allan, M. Hashagen, G. Weinberg, S. Piccinin, M. Havecker, A. Knop-Gericke, R. Schlogl, Physical Chemistry Chemical Physics 2016, 18, $2292-2296$.

[46] A. R. Zeradjanin, A. A. Topalov, Q. Van Overmeere, S. Cherevko, X. X. Chen, E. Ventosa, W. Schuhmann, K. J. J. Mayrhofer, Rsc Advances 2014, 4, 9579-9587.

[47] a) M. Oezaslan, F. Hasche, P. Strasser, Chemistry of Materials 2011, 23, 2159-2165; b) X. Tuaev, J. P. Paraknowitsch, R. Illgen, A. Thomas, P. Strasser, Physical Chemistry Chemical Physics 2012, 14, 6444-6447; c) Z. Liu, S. Koh, C. Yu, P. Strasser, Journal of the Electrochemical Society 2007, 154, B1192-B1199.

[48] a) G. Lodi, E. Sivieri, A. Debattisti, S. Trasatti, Journal of Applied Electrochemistry 1978, 8, 135-143; b) Y. Takasu, S. Onoue, K. Kameyama, Y. Murakami, K. Yahikozawa, Electrochimica Acta 1994, 39, 1993-1997.

[49] C. Angelinetta, S. Trasatti, L. D. Atanasoska, R. T. Atanasoski, Journal of Electroanalytical Chemistry 1986, 214, 535-546.

[50] a) B. Johnson, F. Girgsdies, G. Weinberg, D. Rosenthal, A. Knop-Gericke, R. Schlogl, T. Reier, P. Strasser, Journal of Physical Chemistry C 2013, 117, 25443-25450; b) N. Ozer, M. D. Rubin, C. M. Lampert, Solar Energy Materials and Solar Cells 1996, 40, 285-296.

[51] W. Hume-Rothery, G. W. Mabbott, K. M. C. Evans, Philosophical Transactions of the Royal Society of London A: Mathematical, Physical and Engineering Sciences 1934, 233, 1-97.

[52] M. Gliech, A. Bergmann, C. Spöri, P. Strasser, Journal of Energy Chemistry 2016, 25, 278-281.

[53] D. Santos, A. Lopes, M. J. Pacheco, A. Gomes, L. Ciríaco, Journal of the Electrochemical Society 2014, 161, H564-H572

[54] a) K. Kameyama, K. Tsukada, K. Yahikozawa, Y. Takasu, Journal of the Electrochemical Society 1994, 141, 643-647; b) L. E. Owe, M. Tsypkin, K. S. Wallwork, R. G. Haverkamp, S. Sunde, Electrochimica Acta 2012, 70, 158-164; c) I. C. Man, Theoretical study of Electro-catalysts for oxygen evolution, Technical University of Denmark (DTU), 2011.

[55] R. Forgie, G. Bugosh, K. C. Neyerlin, Z. C. Liu, P. Strasser, Electrochemical and Solid State Letters 2010, 13, D36-D39.

[56] a) T. Audichon, S. Morisset, T. W. Napporn, K. B. Kokoh, C. Comminges, C. Morais, Chemelectrochem 2015, 2, 1128-1137; b) J. Y. Kim, J. Choi, H. Y. Kim, E. Hwang, H. J. Kim, S. H. Ahn, S. K. Kim, Applied Surface Science 2015, 359, 227-235; c) T. Reier, M. Oezaslan, P. Strasser, Acs Catalysis 2012, 2, 1765-1772; d) M. Vukovic, D. Marijan, D. Cukman, P. Pervan, M. Milun, Journal of Materials Science 1999, 34, 869-874.

[57] a) C. P. De Pauli, S. Trasatti, Journal of Electroanalytical Chemistry 2002, 538, 145-151; b) J. Y. Xu, G. Y. Liu, J. L. Li, X. D. Wang, Electrochimica Acta 2012, 59, 105-112; c) X. Wang, F. Y. Deng, Z. Z. Tang, B. Wu, D. Tang, W. Lin, Physical Chemistry Chemical Physics 2013, 15, 3977-3984.

[58] X. Wang, Q. Q. Yin, Z. Z. Tang, X. H. Liu, D. Tang, W. Lin, Journal of the European Ceramic Society 2013, 33, 3045-3052.

[59] a) S. Ardizzone, C. L. Bianchi, G. Cappelletti, M. Ionita, A. Minguzzi, S. Rondinini, A. Vertova, Journal of Electroanalytical Chemistry 2006, 589, 160166; b) L. Massot, P. Palau, A. Savall, P. Taxil, Journal of New Materials for Electrochemical Systems 2007, 10, $123-128$.

[60] K. Kadakia, M. K. Datta, O. I. Velikokhatnyi, P. Jampani, S. K. Park, P. Saha, J. A. Poston, A. Manivannan, P. N. Kumta, International Journal of Hydrogen Energy 2012, 37, 3001-3013.

[61] K. Kadakia, M. K. Datta, O. I. Velikokhatnyi, P. H. Jampani, P. N. Kumta, International Journal of Hydrogen Energy $2014,39,664-674$. 
[62]

a) M. Huynh, D. K. Bediako, D. G. Nocera, Journal of the American Chemical Society 2014, 136, 6002-6010; b) R. Frydendal, E. A. Paoli, I. Chorkendorff, J. Rossmeisl, I. E. L. Stephens, Advanced Energy Materials 2015, 5, 9.

a) E. Ortel, T. Reier, P. Strasser, R. Kraehnert, Chemistry of Materials 2011, 23, 3201-3209; b) M. Bernicke, E. Ortel, T. Reier, A. Bergmann, J. F. de Araujo, P. Strasser, R. Kraehnert, Chemsuschem 2015, 8, 1908-1915.

L. A. Kibler, A. Cuesta, M. Kleinert, D. M. Kolb, Journal of Electroanalytical Chemistry 2000, 484, 73-82.

a) S. H. Chang, N. Danilovic, K. C. Chang, R. Subbaraman, A. P. Paulikas, D. D. Fong, M. J. Highland, P. M. Baldo, V. R. Stamenkovic, J. W. Freeland J. A. Eastman, N. M. Markovic, Nature Communications 2014, 5; b) E. Özer, C. Spöri, T. Reier, P. Strasser, Chemcatchem 2016, DOI: 10.1002/cctc. 201600423.

T. Reier, Z. Pawolek, S. Cherevko, M. Bruns, T. Jones, D. Teschner, S. Selve, A. Bergmann, H. N. Nong, R. Schlögl, K. J. J. Mayrhofer, P. Strasser, Journal of the American Chemical Society 2015, 137, 13031-13040.

a) R. Yang, P. Strasser, M. F. Toney, The Journal of Physical Chemistry C 2011, 115, 9074-9080; b) M. Heggen, M. Oezaslan, L. Houben, P. Strasser, The Journal of Physical Chemistry C 2012, 116, 19073-19083.

a) N. B. Halck, V. Petrykin, P. Krtil, J. Rossmeisl, Physical Chemistry Chemical Physics 2014, 16, 13682-13688; b) K. Macounova, J. Jirkovsky, M. V. Makarova, J. Franc, P. Krtil, Journal of Solid State Electrochemistry 2009, 13, 959-965; c) V. Petrykin, Z. Bastl, J. Franc, K. Macounova, M. Makarova, S. Mukerjee, N. Ramaswamy, I. Spirovova, P. Krtil, Journal of Physical Chemistry C 2009, 113, 21657-21666.

a) M. K. Debe, S. M. Hendricks, G. D. Vernstrom, M. Meyers, M. Brostrom, M. Stephens, Q. Chan, J. Willey, M. Hamden, C. K. Mittelsteadt, C. B. Capuano, K. E. Ayers, E. B. Anderson, Journal of the Electrochemical Society 2012, 159, K165-K176; b) L. Krzysztof, in PEM Electrolysis for Hydrogen Production (Eds.: D. G. Bessarabov, H. Wang, H. Li, N. Zhao), CRC Press, 2015, pp. 87-117.

O. Diaz-Morales, S. Raaijman, R. Kortlever, P. J. Kooyman, T. Wezendonk, J. Gascon, W. T. Fu, M. T. M. Koper, Nature Communications 2016, 7, 12363.

A. G. Pshenichnikov, Y. G. Chirkov, V. I. Rostokin, Russian Journal of Electrochemistry 2002, 38, 213-219.

H. Y. Lee, C. Barber, A. R. Minerick, Electrophoresis 2014, 35, 1782-1789.

a) K. C. Neyerlin, G. Bugosh, R. Forgie, Z. Liu, P. Strasser, Journal of the Electrochemical Society 2009, 156, B363-B369; b) P. Strasser, Journal of Combinatorial Chemistry 2008, 10, 216-224.

H.-S. Oh, H. N. Nong, D. Teschner, T. Reier, A. Bergmann, M. Gliech, J. Ferreira de Araújo, E. Willinger, R. Schloegl, P. Strasser, Journal of the American Chemical Society 2016.

a) K.-S. Lee, I.-S. Park, Y.-H. Cho, D.-S. Jung, N. Jung, H.-Y. Park, Y.-E. Sung, Journal of Catalysis 2008, 258, 143-152; b) J. Xu, Q. Li, M. K. Hansen, E. Christensen, A. L. Tomás García, G. Liu, X. Wang, N. J. Bjerrum, International Journal of Hydrogen Energy 2012, 37, $18629-18640$.

Y. X. Liu, H. Masumoto, T. Goto, Materials Transactions 2004, 45, 3023-3027.

K. F. Chow, T. M. Carducci, R. W. Murray, Journal of the American Chemical Society 2014, 136, 3385-3387.

a) T. J. Toops, M. P. Brady, F.-Y. Zhang, H. M. Meyer lii, K. Ayers, A. Roemer, L. Dalton, Journal of Power Sources 2014, 272, 954-960; b) M. P. Gurrola, J. Gutierrez, S. Rivas, M. Guerra-Balcazar, J. Ledesma-Garcia, L. G. Arriaga, International Journal of Hydrogen Energy 2014, 39, 16763-16770; c) L. T. Yan, K. Huang, Y. G. Chen, Y. C. Xing, Ecs Electrochemistry Letters 2014, 3, F27-F29.

H.-S. Oh, H. N. Nong, P. Strasser, Advanced Functional Materials 2015, 25, 1074-1081.

G. Liu, J. Xu, Y. Wang, X. Wang, Journal of Materials Chemistry A 2015, 3, 20791-20800.

T. Reier, I. Weidinger, P. Hildebrandt, R. Kraehnert, P. Strasser, ECS Transactions 2013, 58, 39-51.

M. D. Earle, Physical Review 1942, 61, 56-62.

S. Siracusano, V. Baglio, C. D'Urso, V. Antonucci, A. S. Aricò, Electrochimica Acta 2009, 54, 6292-6299.

A. Kumar, V. K. Ramani, ECS Transactions 2013, 58, 1823-1834.

a) I. Cerri, T. Nagami, J. Davies, C. Mormiche, A. Vecoven, B. Hayden, International Journal of Hydrogen Energy 2013, 38, 640-645; b) M. De Koninck, P. Manseau, B. Marsan, Journal of Electroanalytical Chemistry 2007, 611, 67-79.

L. Lu, M. L. Guo, S. Thornley, X. P. Han, J. H. Hu, M. J. Thwaites, G. S. Shao, Solar Energy Materials and Solar Cells 2016, 149, 310-319.

R. Steinitz, R. Resnick, Journal of Applied Physics 1966, 37, 3463-3471.

J. Polonsky, I. M. Petrushina, E. Christensen, K. Bouzek, C. B. Prag, J. E. T. Andersen, N. J. Bjerrum, International Journal of Hydrogen Energy 2012 37, 2173-2181.

Y. Liu, T. G. Kelly, J. G. Chen, W. E. Mustain, Acs Catalysis 2013, 3, 1184-1194.

L. Yu, Y. Liu, F. Yang, J. Evans, J. A. Rodriguez, P. Liu, The Journal of Physical Chemistry C 2015, 119, 16614-16622.

X. Y. Shi, W. Zhang, C. Zhang, W. T. Zheng, H. Chen, J. G. Qi, Journal of Microscopy 2016, 262, 203-215.

P. N. Plessow, M. Bajdich, J. Greene, A. Vojvodic, F. Abild-Pedersen, The Journal of Physical Chemistry C 2016, 120, 10351-10360.

a) G. Lodi, A. Debattisti, G. Bordin, C. Deasmundis, A. Benedetti, Journal of Electroanalytical Chemistry 1990, 277, 139-150; b) L. Ouattara, S. Fierro, O. Frey, M. Koudelka, C. Comninellis, Journal of Applied Electrochemistry 2009, 39, 1361-1367; c) I. A. Lervik, M. Tsypkin, L. E. Owe, S. Sunde, Journal of Electroanalytical Chemistry 2010, 645, 135-142; d) Z. B. Bao, H. Murakami, Y. Yamabe-Mitarai, Applied Surface Science 2011, 258, $1514-1518$.

a) A. Bergmann, E. Martinez-Moreno, D. Teschner, P. Chernev, M. Gliech, J. F. de Araujo, T. Reier, H. Dau, P. Strasser, Nature Communications 2015, 6; b) R. L. Doyle, I. J. Godwin, M. P. Brandon, M. E. G. Lyons, Physical Chemistry Chemical Physics 2013, 15, 13737-13783; c) L. D. Burke, E. J. M. Osullivan, Journal of Electroanalytical Chemistry 1981, 117, 155-160.

a) S. Cherevko, T. Reier, A. R. Zeradjanin, Z. Pawolek, P. Strasser, K. J. J. Mayrhofer, Electrochemistry Communications 2014, 48, 81-85; b) M. Vukovic, Journal of Applied Electrochemistry 1987, 17, 737-745.

N. Danilovic, R. Subbaraman, K. C. Chang, S. H. Chang, Y. J. J. Kang, J. Snyder, A. P. Paulikas, D. Strmcnik, Y. T. Kim, D. Myers, V. R. Stamenkovic, N. M. Markovic, Journal of Physical Chemistry Letters 2014, 5, 2474-2478.

J. Lim, S. Yang, C. Kim, C. W. Roh, Y. Kwon, Y. T. Kim, H. Lee, Chemical Communications 2016, 52, 5641-5644.

a) G. P. Vercesi, J. Y. Salamin, C. Comninellis, Electrochimica Acta 1991, 36, 991-998; b) J. Q. Zhu, X. Wang, Z. H. Yi, Z. Z. Tang, B. Wu, D. Tang, W. Lin, Journal of Physical Chemistry C 2012, 116, 25832-25839.

Y. B. He, A. Stierle, W. X. Li, A. Farkas, N. Kasper, H. Over, Journal of Physical Chemistry C 2008, 112, 11946-11953

L. E. Owe, I. A. Lervik, M. Tsypkin, M. V. Syre, S. Sunde, Journal of the Electrochemical Society 2010, 157, B1719-B1725.

D. Bernsmeier, E. Ortel, J. Polte, B. Eckhardt, S. Nowag, R. Haag, R. Kraehnert, Journal of Materials Chemistry A 2014, 2, 13075-13082

H. Su, B. J. Bladergroen, V. Linkov, S. Pasupathi, S. Ji, International Journal of Hydrogen Energy 2011, 36, 15081-15088.

N. J. C. Ingle, A. Sode, I. Martens, E. Gyenge, D. P. Wilkinson, D. Bizzotto, Langmuir 2014, 30, 1871-1879.

M. Bernt, H. A. Gasteiger, Journal of the Electrochemical Society 2016, 163, F3179-F3189.

a) C. H. Cui, L. Gan, M. Heggen, S. Rudi, P. Strasser, Nature Materials 2013, 12, 765-771; b) L. Gan, C. H. Cui, M. Heggen, F. Dionigi, S. Rudi, P. Strasser, Science 2014, 346, 1502-1506.

a) S. Stucki, G. G. Scherer, S. Schlagowski, E. Fischer, Journal of Applied Electrochemistry 1998, 28, 1041-1049; b) S. A. Grigoriev, K. A. Dzhus, D. G. Bessarabov, P. Millet, International Journal of Hydrogen Energy 2014, 39, 20440-20446.

F. Fouda-Onana, M. Chandesris, V. Médeau, S. Chelghoum, D. Thoby, N. Guillet, International Journal of Hydrogen Energy 2016.

P. Lettenmeier, R. Wang, R. Abouatallah, S. Helmly, T. Morawietz, R. Hiesgen, S. Kolb, F. Burggraf, J. Kallo, A. S. Gago, K. A. Friedrich, Electrochimica Acta 2016, 210, 502-511.

R. Lin, F. Xiong, W. C. Tang, L. Técher, J. M. Zhang, J. X. Ma, Journal of Power Sources 2014, 260, $150-158$.

G. Li, H. Yu, X. Wang, S. Sun, Y. Li, Z. Shao, B. Yi, Physical Chemistry Chemical Physics 2013, 15, 2858-2866.

S. Rudi, X. Tuaev, P. Strasser, Electrocatalysis 2012, 3, 265-273.

a) E. Z. Kurmaev, A. Moewes, O. G. Bureev, I. A. Nekrasov, V. M. Cherkashenko, M. A. Korotin, D. L. Ederer, Journal of Alloys and Compounds 2002, 347, 213-218; b) M. Gorlin, M. Gliech, J. F. de Araujo, S. Dresp, A. Bergmann, P. Strasser, Catalysis Today 2016, $262,65-73$. 
[113] V. Natarajan, S. Basu, International Journal of Hydrogen Energy 2015, 40, 16702-16713.

[114] L. Ma, S. Sui, Y. Zhai, Journal of Power Sources 2008, 177, 470-477.

[115] B. D. Cullity, S. R. Stock, Elements of X-Ray Diffraction: Pearson New International Edition, 3 ed., Pearson Education Limited, Edinburgh Gate, Harlow, Essex CM20 2JE, 2014

[116] P. J. Ferreira, G. J. la O', Y. Shao-Horn, D. Morgan, R. Makharia, S. Kocha, H. A. Gasteiger, Journal of the Electrochemical Society 2005, 152, A2256A2271.

[117] K. A. Stoerzinger, L. Qiao, M. D. Biegalski, Y. Shao-Horn, Journal of Physical Chemistry Letters 2014, 5, 1636-1641.

[118] J. van der Merwe, K. Uren, G. van Schoor, D. Bessarabov, International Journal of Hydrogen Energy 2014, 39, 14212-14221.

[119] a) I. Dedigama, P. Angeli, K. Ayers, J. B. Robinson, P. R. Shearing, D. Tsaoulidis, D. J. L. Brett, International Journal of Hydrogen Energy 2014, 39 4468-4482; b) S. Sun, Y. Xiao, D. Liang, Z. Shao, H. Yu, M. Hou, B. Yi, Rsc Advances 2015, 5, 14506-14513.

[120] R. Frydendal, E. A. Paoli, B. P. Knudsen, B. Wickman, P. Malacrida, I. E. L. Stephens, I. Chorkendorff, Chemelectrochem 2014, 1, $2075-2081$.

[121] a) L. E. Owe, M. Tsypkin, S. Sunde, Electrochimica Acta 2011, 58, 231-237; b) M. Wehrens-Dijksma, P. H. L. Notten, Electrochimica Acta 2006, 51, 3609-3621; c) G. T. Cheek, W. E. O'Grady, Journal of Electroanalytical Chemistry 1997, 421, 173-177.

[122] a) M. Chatenet, Y. Soldo-Olivier, E. Chainet, R. Faure, Electrochimica Acta 2007, 53, 369-376; b) Y. H. Chu, C. C. Hu, K. H. Chang, Electrochimica Acta 2012, 61, 124-131.

[123] F.-B. Li, A. Robert Hillman, S. D. Lubetkin, D. J. Roberts, Journal of Electroanalytical Chemistry 1992, 335, 345-362.

[124] a) S. O. Klemm, A. A. Topalov, C. A. Laska, K. J. J. Mayrhofer, Electrochemistry Communications 2011, 13, 1533-1535; b) P. Jovanovic, A. Pavlisic, V. S. Selih, M. Sala, N. Hodnik, M. Bele, S. Hocevar, M. Gaberscek, Chemcatchem 2014, 6, 449-453.

S. Cherevko, S. Geiger, O. Kasian, A. Mingers, K. J. J. Mayrhofer, Journal of Electroanalytical Chemistry 2016, 773, 69-78

[126] M. V. Martinez-Huerta, N. Tsiouvaras, G. Garcia, M. A. Pena, E. Pastor, J. L. Rodriguez, J. L. G. Fierro, Catalysts 2013, 3, 811-838.

[127] a) D. B. Trimarco, T. Pedersen, O. Hansen, I. Chorkendorff, P. C. K. Vesborg, Review of Scientific Instruments 2015, 86; b) J.-P. Grote, A. R. Zeradjanin, S. Cherevko, K. J. J. Mayrhofer, Review of Scientific Instruments 2014, 85, 104101.

O. Diaz-Morales, F. Calle-Vallejo, C. de Munck, M. T. M. Koper, Chemical Science 2013, 4, 2334-2343.

K. Macounova, M. Makarova, P. Krtil, Electrochemistry Communications 2009, 11, 1865-1868.

[130] a) S. R. Brankovic, J. X. Wang, Y. Zhu, R. Sabatini, J. McBreen, R. R. Adzic, Journal of Electroanalytical Chemistry 2002, 524, 231-241; b) N. S. Marinkovic, J. X. Wang, H. Zajonz, R. R. Adzic, Journal of Electroanalytical Chemistry 2001, 500, 388-394; c) R. Nakamura, T. Tanaka, Y. Nakato, The Journal of Physical Chemistry B 2005, 109, 8920-8927.

[131] E. Brightman, J. Dodwell, N. van Dijk, G. Hinds, Electrochemistry Communications 2015, 52, 1-4

[132] O. F. Selamet, U. Pasaogullari, D. Spernjak, D. S. Hussey, D. L. Jacobson, M. D. Mat, International Journal of Hydrogen Energy 2013, 38, 5823-5835.

[133] Y. Tanaka, K. Kikuchi, Y. Saihara, Z. Ogumi, Electrochimica Acta 2005, 50, 5229-5236.

[134] M. D. Mat, K. Aldas, International Journal of Hydrogen Energy 2005, 30, 411-420.

[135] P. Argyropoulos, K. Scott, W. M. Taama, Electrochimica Acta 1999, 44, 3575-3584

[136] K. M. Caldwell, S. Kaserer, C. Roth, D. E. Ramaker, Chemelectrochem 2015, 2, 1502-1509.

[137] D. E. Ramaker, D. C. Koningsberger, Physical Chemistry Chemical Physics 2010, 12, 5514-5534.

[138] C. Brieger, J. Melke, N. van der Bosch, U. Reinholz, H. Riesemeier, A. Guilherme Buzanich, M. K. Kayarkatte, I. Derr, A. Schökel, C. Roth, Journal of Catalysis 2016, 339, 57-67.

[139] a) R. Arrigo, M. Havecker, M. E. Schuster, C. Ranjan, E. Stotz, A. Knop-Gericke, R. Schlogl, Angewandte Chemie-International Edition 2013, 52, 1166011664; b) S. Kaya, H. Ogasawara, L.-A. Näslund, J.-O. Forsell, H. S. Casalongue, D. J. Miller, A. Nilsson, Catalysis Today 2013, $205,101-105$.

[140] J. J. Velasco-Vélez, V. Pfeifer, M. Hävecker, R. Wang, A. Centeno, A. Zurutuza, G. Algara-Siller, E. Stotz, K. Skorupska, D. Teschner, P. Kube, P. J. J. Velasco-Vélez, V. Pfeifer, M. Hävecker, R. Wang, A. Centeno, A. Zurutuza, G. Algara-Siller, E. Stotz, K. Skorur
Braeuninger-Weimer, S. Hofmann, R. Schlögl, A. Knop-Gericke, Review of Scientific Instruments 2016, 87, 053121.

[141] a) H. G. S. Casalongue, M. L. Ng, S. Kaya, D. Friebel, H. Ogasawara, A. Nilsson, Angewandte Chemie-International Edition 2014, 53, 7169-7172; b) H. Ogasawara, S. Kaya, A. Nilsson, Topics in Catalysis 2016, 59, 439-447.

[142] V. Pfeifer, T. Jones, S. Wrabetz, C. Massue, J.-J. Velesco-Velez, R. Arrigo, M. Scherzer, S. Piccinin, M. Haevecker, A. Knop-Gericke, R. Schlogl, Chemical Science 2016.

[143] T. Smolinka, in International Symposium on Water Electrolysis and Hydrogen as Part of the Future Renewable Energy System, Copenhagen, Denmark 2012.

[144] F. Hasche, M. Oezaslan, P. Strasser, Chemcatchem 2011, 3, 1805-1813.

[145] M. Hamdan, in PEM Electrolyzer Incorporating an Advanced Low-Cost Membrane, U.S. DOE, Washington, DC, 2013. 
Entry for the Table of Contents (Please choose one layout)

Layout 1:

\section{REVIEW}

This review addresses the challenges, their scientific basis, as well as recent progress and the road ahead with respect to fundamental understanding of the stability and degradation of OER catalysts operating in acidic environments. We highlight the importance of identifying universal figures of merit for stability and develop a comprehensive accelerated life test (ALT) that would yield comparable performance data across labs and catalyst types.

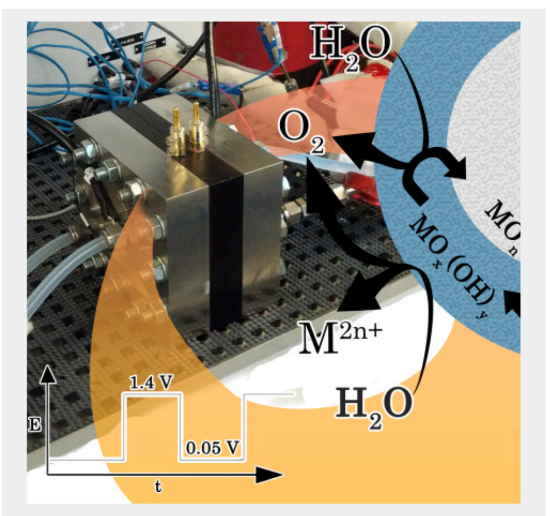

Camillo Spöria, Jason Tai Hong Kwan ${ }^{b}$, Arman Bonakdarpour ${ }^{b}$, David $P$. Wilkinson $^{\star b}$ and Peter Strasser ${ }^{\star a, c}$

Page No. - Page No.

The Stability Challenges of Oxygen Evolving Electrocatalysts: Towards a Common Fundamental Understanding and Mitigation of Catalyst Degradation 